\title{
Forming Working Selves: Flexibility and Generational Identity Formation in the Public Library
}

\author{
by
}

Kritee Ahmed

A thesis submitted to the Faculty of Graduate and Postdoctoral Affairs in partial fulfillment of the requirements for the degree of

Master of Arts

in

Political Economy

Carleton University

Ottawa, Ontario

(C) 2012, Kritee Ahmed 
Library and Archives

Canada

Published Heritage

Branch

395 Wellington Street

Ottawa ON K1A ON4

Canada
Bibliothèque et

Archives Canada

Direction du

Patrimoine de l'édition

395 , rue Wellington

Ottawa ON K1A ON4

Canada
Your file Votre référence

ISBN: 978-0-494-93535-4

Our file Notre référence

ISBN: $978-0-494-93535-4$
NOTICE:

The author has granted a nonexclusive license allowing Library and Archives Canada to reproduce, publish, archive, preserve, conserve, communicate to the public by telecommunication or on the Internet, loan, distrbute and sell theses worldwide, for commercial or noncommercial purposes, in microform, paper, electronic and/or any other formats.

The author retains copyright ownership and moral rights in this thesis. Neither the thesis nor substantial extracts from it may be printed or otherwise reproduced without the author's permission.
AVIS:

L'auteur a accordé une licence non exclusive permettant à la Bibliothèque et Archives Canada de reproduire, publier, archiver, sauvegarder, conserver, transmettre au public par télécommunication ou par l'Internet, prêter, distribuer et vendre des thèses partout dans le monde, à des fins commerciales ou autres, sur support microforme, papier, électronique et/ou autres formats.

L'auteur conserve la propriété du droit d'auteur et des droits moraux qui protege cette thèse. $\mathrm{Ni}$ la thèse ni des extraits substantiels de celle-ci ne doivent être imprimés ou autrement reproduits sans son autorisation.
In compliance with the Canadian Privacy Act some supporting forms may have been removed from this thesis.

While these forms may be included in the document page count, their removal does not represent any loss of content from the thesis.
Conformément à la loi canadienne sur la protection de la vie privée, quelques formulaires secondaires ont été enlevés de cette thèse.

Bien que ces formulaires aient inclus dans la pagination, il n'y aura aucun contenu manquant. 


\begin{abstract}
Using a lens that is heavily influenced by poststructuralism, this study renders visible techniques used to shape and form capacities within individuals at Toronto Public Library through workplace changes associated with technology, organizational culture and workplace roles among other things. It further reveals that generational differences between workers joining the organization before a merger of library systems into Toronto Public Library and those joining after this amalgamation are limited. Though the study cannot be entirely conclusive in its findings due to its incomplete nature, it is still observed that Toronto Public Library is a highly complex organizational entity, which may account for the broad emergent identities encountered. Thus, this research project provides vital groundwork in the pursuit of future studies of library work, library work identities, and the study of Toronto Public Library.
\end{abstract}




\section{Acknowledgements}

An acknowledgement section is difficult to fashion as there are always so many people to thank for their support and assistance in the success of this research project. To that end, I want to apologize in advance, in case I missed mentioning someone here.

Firstly, I am grateful to my participants. Thank you so much for your contribution. Moreover, in directly facilitating this project I am particularly indebted to Phyllis Malette and Toronto Public Library management and staff as well as Maureen O'Reilly and the Toronto Public Library Workers Union, CUPE Local 4948. Without any of your support, there would be no project.

At Carleton, my supervisor Dr. Wallace Clement has been a source of strength for me, providing calm, focused direction that I so crucially required and my committee member, Dr. Hugh Armstrong, also provided vital advice regarding this project. As well, Donna Coghill at the Institute of Political Economy has been an indispensable guide throughout my MA journey. Moreover, my colleagues at the Institute deserve to be mentioned as they imparted their scholastic and academic wisdom upon me as I moved through the research process. To them, I can only hope I offered something similar.

Finally, I must acknowledge my parents, Sanjeeda Ahmed and Mahiuddin Ahmed, without whom I would lack the priceless support, care labour and roofing needed to nourish the budding young scholar within me. If they had not put up with me, who knows how or when this project would have been completed... 


\section{Table of Contents}

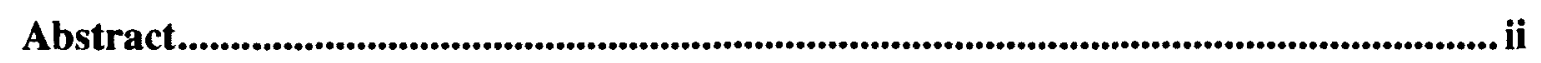

Acknowledgements ................................................................................................................................ iii

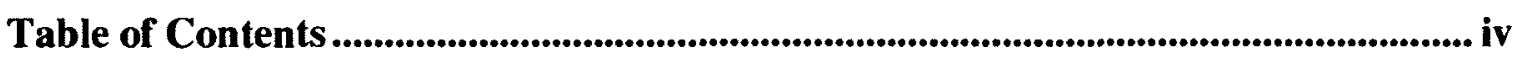

List of Tables ............................................................................................................................................ vii

List of Appendices............................................................................................................................... viii

1 Chapter: Introduction .......................................................................................................... 1

1.1 Research Problem.................................................................................................

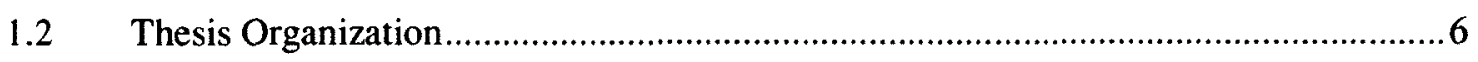

2 Chapter: Theoretical Framework …………...................................................................... 8

$2.1 \quad$ Theoretical Context ................................................................................................

$2.2 \quad$ Questions of Identity and Subjectivity ……......................................................13

2.3 Identity Work and Identity Regulation ......................................................................17

2.4 Governmentality, Identity and the Transformation of Individuals ..............................18

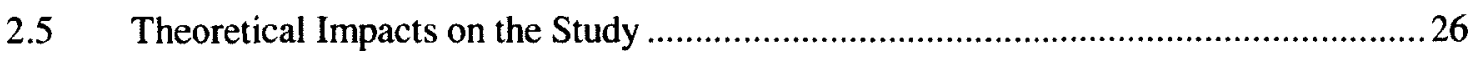

3 Chapter: Research Process and Design ........................................................................ 31

3.1 Methodological Context ..................................................................................... 31

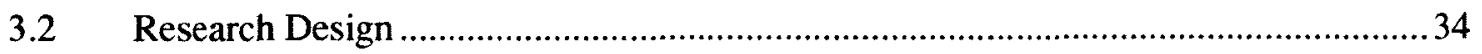

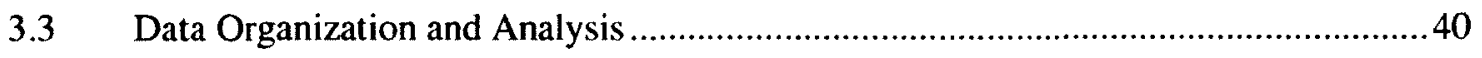

3.4 The Limitations of Methods and Researcher Reflexivity .............................................42

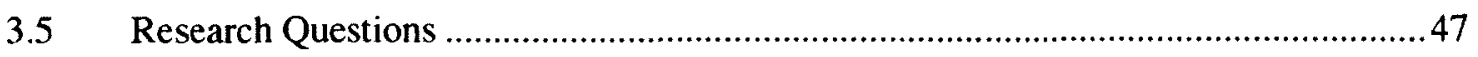

4 Chapter: Literature Review.................................................................................4 48

$4.1 \quad$ Surveying the Context ......................................................................................48

4.2 The Study of Library Work and the Formation of Working Selves .............................52

4.2.1 Studies in Library Work …..........................................................................52 
5 Chapter: Techniques that Shape Identity................................................................65

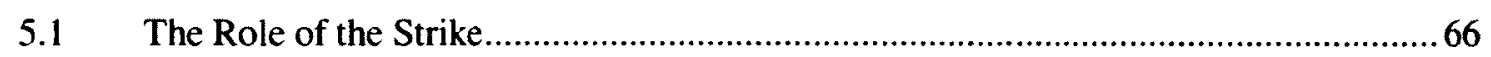

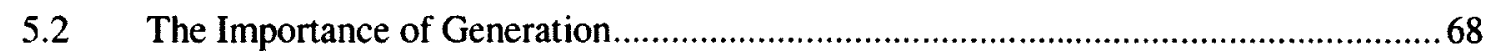

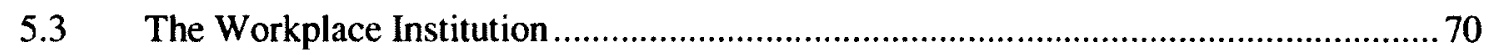

$5.4 \quad$ Organizational Culture and its (Dis)contents ........................................................ 76

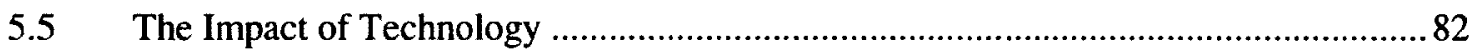

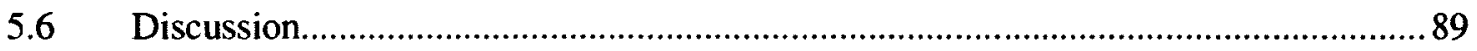

6 Chapter: Forming Working Selves ................................................................................ 93

6.1 The Redundant and Docile Self ........................................................................ 94

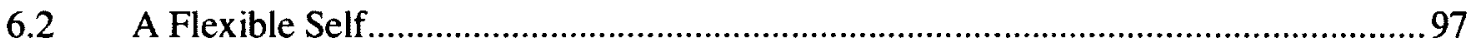

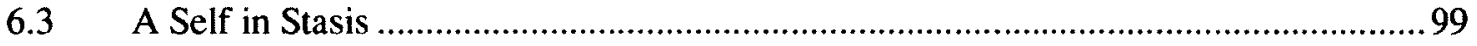

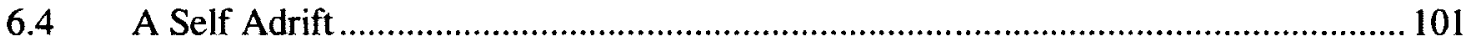

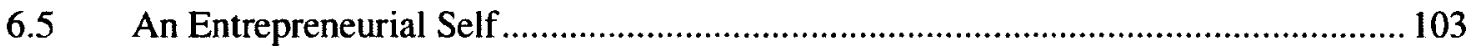

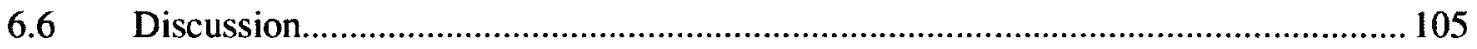

7 Chapter: Research Implications......................................................................................... 107

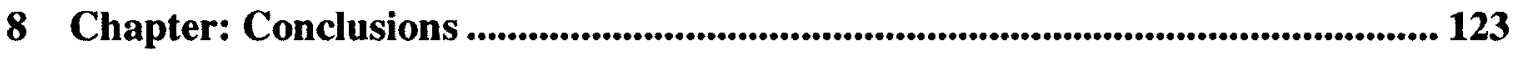

8.1 Limitations, Lessons Learned and Looking Forward .......................................... 123

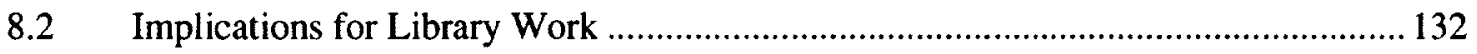

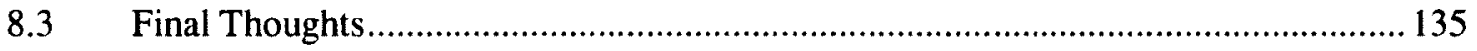

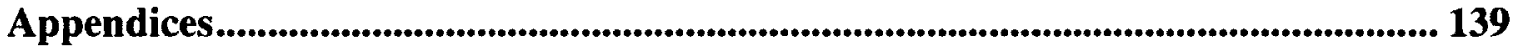

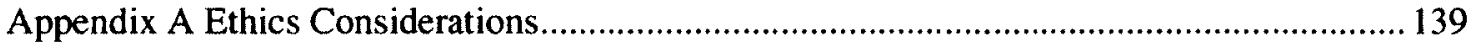

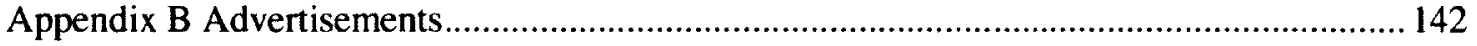

B.1 Text of Advertisement sent in first @ $@$ TPL .......................................................... 142

B.2 Text of Advertisement that was to be sent through Union ................................... 142 


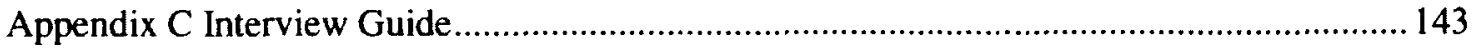

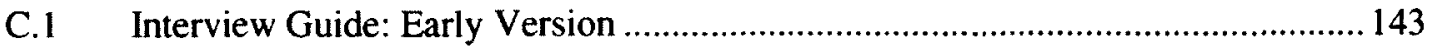

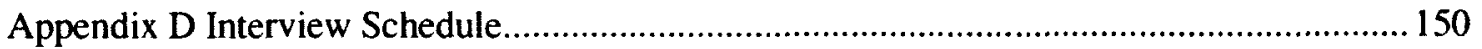

Bibliography .......................................................................................................................................... 151 


\section{List of Tables}

Table 1: Categories for Analysis - organizing interview common themes................ 41 


\section{List of Appendices}

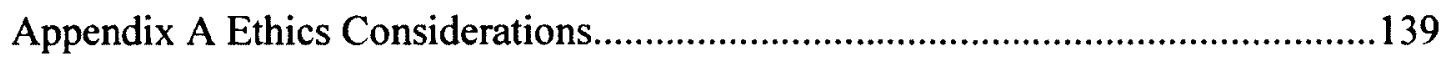

Appendix B Advertisements........................................... 142

B.1 Text of Advertisement send in first @TPL.............................142

B.1 Text of Advertisement that was to be sent through Union...............142

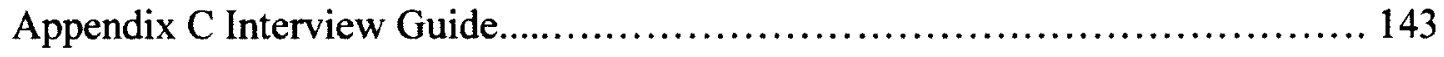

C.1 Interview Guide: Early Version..................................... 151

Appendix D Interview Schedule........................................... 150 


\section{Chapter: Introduction}

When I began this project associated with Toronto Public Library, little did I realize that events would unfold in the way that they have. Toronto Public Library funding was at the forefront of Toronto City Hall budget debates. A passionate discussion for and against cuts to the library budget were raised by concerned citizens, pundits and city councillors alike. Alongside this, as my project progressed, discussions about a new labour contract emerged as library workers, important partners in facilitating my project, were no longer under contract as of January $1^{\text {st }}, 2012$.

When Toronto Public Library Workers Union (TPLWU) went on strike in mid to late March, this initially left my project in the balance. However, it is here, I started to notice the particular salience of this research. Not only was I writing about a group of workers in an organization of which I was formerly a member, but their claims as workers mediated through their Union became clearer to me. In a Toronto Star article, it was noted that " $[u]$ nder the collective agreement that expired on Dec. 31, no permanent library worker could be laid off in the event of outsourcing or technological changes" (Dale, 2012). Moreover, the same piece noted "[m]any of the workers who picketed City Hall on Monday said they are unhappy with what they said is an ongoing shift toward part-time work" (Dale, 2012). Similar concerns drove an interest in this project in that I was interested in the impact of technological change and organizational reform in the public library and their impact on workers, but I was largely unaware of their importance in negotiations for a contract for Toronto Public Library Workers Union (TPLWU) members. Thus circumstances unrelated to the research process enabled the public library to become a hot topic. 
While the discussion of the public library may have become "a hot topic," my own interest in studying library work stems from my personal experience working at Toronto Public Library. I worked in this public library system on two separate occasions: once as a high school student and a young person heading towards further education, and once after completing my bachelor's degree, right before I started graduate school and eventually this MA-level project. In drawing on my own experiences as an insider working regularly at Toronto Public Library and noticing changes in simple tasks at work and reflecting upon them later as an outsider (after receiving theoretical training at the MA-level), I began to think about why and how the public library is an important site to study labour.

What I have learned is that library work is facing particularly significant changes in the way tasks are conducted and completed and is facing challenges related to the broader organization, structure of work, as well as service delivery. The public library also sits at the epicentre of significant changes namely technological (Walton, 2007)both in the changes happening in the workplace in relation to workplace routines and tasks, and the pressures which impact the very existential nature of the library (see for example the rise of technologies such as the iPod, Kindle, Kobo, etc.), as well as the shifting needs of users and staff (O'Brien and Hayden, 2007, p. 222). This does not mean that historically there have not been technological changes or pressures present within the organization of library work, but rather there are important new technological developments that are changing workplace practices. These include such things as self- 
checkout ${ }^{1}$ and self-check-in technologies implemented in some branches of Toronto Public Library. I will explore these particular examples a bit more in depth in this study. Moreover, the public library is a public organization that provides services in and to diverse communities. As a great equalizer, the public library provides access to literature, literary services and language and training programs among other things to the public (Toronto Public Library, 2012a; Brooklyn Public Library, 2012). This is significant because staff are required to administer and operate these programs, and doing so requires libraries to be operated by staff during flexible hours that are not always fixed to the "standard" 9 to 5 Monday to Friday work week. For these reasons, we must look to the public library as a site of study and observation to elucidate larger transformations in the labour process. Through an exploration of these changes, we can start to observe their impact on the very people who help deliver them to fellow citizens. These changes might also yield an understanding of how the government and regulation of public service workers occurs and consequently, they may reveal how these changes impact one's attachment to work, one's perception of one's place at work and one's place in a capitalist society that has emphasized greater flexibility and mutability in and around work.

\subsection{Research Problem}

Workplace practices in public libraries have been significantly impacted through flexibilization in the workplace. This is not a new phenomenon, but it is important to highlight nonetheless. For example, flexible work in libraries have been observed in countries such as Ireland (O'Brien and Hayden, 2007) and the U.K. (Goulding and

\footnotetext{
${ }^{1}$ The automated checkout machine is alternately referred to as "express checkout," "self-checkout," and "RFID." RFID refers to the broader technology that is used to check material in and out of the library.
} 
Kerslake, 1996a; 1996b; Kerslake and Goulding 1997). Such flexibility may have appeared in the form of technological innovation that has altered the way in which staff conduct work in the name of greater productivity and efficiency. This is not to suggest that public libraries have been completely flexibilized, but rather highlights that flexible work practices have impacted the way in which one goes about working. I will discuss the impact of "flexibility" in public organizations more thoroughly in the literature review.

Questions about workplace identities and subjectivities inevitably led me to examine the techniques and processes that are involved in forming workplace identities in the public library and public organizations and the types of identities and subjectivities that are promoted and elicited through workplace practices. These practices may be part and parcel of processes that aim to create leaner, more efficient and more productive workplaces. Exploring the impact of changing work practices may enable a deeper appreciation of the techniques involved in eliciting certain types of behaviours and subjectivities of individuals who are associated with them. Dean's (1995) study of Australian administrative practices towards the unemployed provides a strong example of how client-case manager relationships and the processes involved in the receipt of benefits can come to shape job-ready citizens. This helps demonstrate the relationship between practices and their impact in eliciting certain types of behaviours, identities and subjectivities within individuals.

To this end, the study of library work identities permits an examination of how changes in workplace practices can also come to shape certain types of workers in particular ways - their impact on workers. Furthermore, the study of identity, then, may 
have further consequences in understanding the constitution of the type or types of workers that are needed in order for there to be a successful valorization of capital and/or the exploitation of labour (cf. Foucault, 1995, pp. 25-6; cf. Lemke, 2002, p. 58 who also draws from Foucault, 1995). Finally, in examining changing practices, we may be able to investigate if newer means of conducting the same tasks and procedures have had differential impacts in shaping identities of workers who have spent different lengths of time working in the public library. This impels an exploration into how the generational entry of a worker into the library system may mediate the impacts of changing workplace practices in the formation of selves and capacities to be fostered within individuals.

Toronto Public Library, then, permits an ideal site to study identity, subjectivity and generation at work, as the organization is an amalgamation of several library systems that may have had different organizational tasks, routines and cultures. In 1998, library systems that existed within the various municipalities in the former Metropolitan Toronto were merged into the Toronto Public Library. Consequently, the study of this unified library system allows interesting complexities to be surveyed, particularly in relation to workers who had worked in other library systems within Metropolitan Toronto and workers who had joined the organization after amalgamation. This elicits certain questions: Did these workers have different perceptions of their identity because of their diverse backgrounds and relationships with the organization? Is it possible that in being acculturated to one library organization conflicts with what Toronto Public Library may be promoting and are the experiences of workers, who have joined the organization before the amalgamation, impacted differently than newer workers with these changing labour and organizational practices? 
Combining these aforementioned insights have helped shape two important research questions which drive this project:

What practices aid in the constitution of workplace identities in the public library and what subjectivities emerge as a result of these practices?

How, and to what end, does one's generation mediate these practices into identities?

In answering these questions, it will become possible to discover what practices and processes within the public library come to shape or alter behaviours of workers and promote certain ways of being at work. Furthermore, it will help to establish how and if generation impacts how one interprets practices that promote certain actions or dispositions in the public library.

Workplace identities, and the formation of a working self then are particularly important to understand in a climate where public workers face the discursive attacks of being part of a "cozy" public sector form of work. Concurrently, the work that people do at work are shifting and changing, and these changes almost certainly have an impact in how workers perceive themselves at work and in a broader societal context. Some of these changes have been briefly alluded to above (Walton, 2007; O'Brien and Hayden, 2007, p. 222). Through this project, I hope to resolve the research questions above in understanding library workers and their concerns, and through their narratives, I aim to understand what the impact of organizational change has on the very people who enable public service organizations to function for the use of citizens.

\subsection{Thesis Organization}

The subsequent chapter will explore the theoretical lens through which this research project will operate. The theoretical ideas presented here are highly influenced by a poststructural perspective. While my work uses aspects of this lens, it in no means 
tries to form an ideal poststructural framework to examine questions of identity and subjectivity. Instead, drawing heavily from Foucault, I use his theoretical insights as tools to help understand the logic that pervades identity formation in library work. The theory chapter is then followed by an introduction of the methods employed and includes some broad research questions that guide the broader project. This is followed by the literature review, which aims to locate the research project in the broader literature, by surveying the context of the research and surveying work on library studies and identity. I aim to underscore how my research draws from others, uses some research as markers and further develops others. Here, I seek to position myself within broader discussions associated with the study of library work, and identity formation.

This is followed by two chapters which constitute the observation and analysis of the project. The first chapter examines the broader techniques through which one observes a generational lens, events, images, cultures and technology that impact identity. This is followed by a more in depth look at the types of identities and subjectivities which appear to be fostered and revealed in the library workplace.

The final two chapters of this research project compose the discussion of the findings from the research as well as the conclusions. The discussion is composed of an examination of implications of the findings and the conclusion highlights the limitations of the research, the lessons learned from those limitations and how they may be used for subsequent work. It also finally examines the implications project findings have on library work before giving way to some final thoughts.

The next chapter will theoretically ground this research project. 


\section{Chapter: Theoretical Framework}

In exploring questions of identity and the formation of a working self, it is critical to examine the material techniques and practices which impact, form and shape the way we think, the way we act and the way we exist. These techniques in themselves may lead us to see how practices to which we are subjected from a variety of sources discursively, through institutions, through our relations with others and with the things we do and the way we perform - "compose" the shaping of working selves; this may have consequences in other aspects of our lives. Consequently, this research is premised on the idea that practices are at the very heart of shaping who we are as individuals at work. Workplace practices allow us to look at critical points of contact, where certain actions or procedures are required to form a certain type of individual.

To this end, this chapter will set the theoretical basis from which to understand the practices that enable and impact individuals to shape and form themselves and their identities at work. In particular, it will discuss the need to examine practices at workplaces as the basis for the formation of working selves and constructing identity. First, this chapter will set the context of the theoretical framework to be used in this paper. This will be helpful in theoretically positioning this project. Then it will proceed to a discussion on identity and subjectivity - two related and complementary concepts. This is followed with a brief exploration of two other concepts - identity work and identity regulation. Afterwards, the chapter shifts into a discussion on government, governmentality and "technologies," before concluding with an examination of the implications of these theoretical concepts in this research project. 


\subsection{Theoretical Context}

Before beginning a discussion on theoretical identity formation and self, it is necessary to develop an understanding of power in this project. Power is a means through which we can understand the way in which individuals can come to be who they are in relation to discourse, environment and practices. Yet, the way in which we understand the operation of power will also shape the way we come to see things shifting, moving and changing. Foucault (1980a) notes that:

[i]f power were never anything but repressive, if it never did anything but to say no, do you really think one would be brought to obey it? What makes power hold good, what makes it accepted, is simply the fact that it doesn't only weigh on us as a force that says no, but that it traverses and produces things, it induces pleasure, forms knowledge, produces discourse. It needs to be considered as a productive network which runs through the whole social body, much more than as a negative instance whose function is repression (p. 119).

When examining questions of power, there has been some emphasis placed on who has power over whom. Power has also been something which has been recognized as having a negative connotation, that somehow the exercise of power is "bad" and that its function is to limit the action of people, by persuasively managing their ability to act. However, Foucault's (1980a) description of power brings to focus an impact of power that transgresses a much more limited understanding of power as "power over others." Moreover, Foucault (1980b) states that:

[p]ower represses nature, the instincts, a class, individuals. Though one finds this definition of power as repression endlessly repeated in present day discourse, it is not that discourse which invented it [...]. [...] In any case, it has become almost automatic in the parlance of the times to define power as an organ of repression. So should not the analysis of power be first and foremost analysis of the mechanisms of repression? (p. 90). 
Foucault (1980b) consequently draws our attention to the processes and techniques through which power can be seen. In another sense, one is not considering institutional power - the notion that power is derived from the state or capital, etc. (Knights and Vurdubakis, 1994, p. 175) and as a result imposes certain ways of acting on its subjects and nor does it seek to explore questions of who or what has power over whom. Instead this project's discussion of power includes an analysis of the practices and means which enable power to become "operable" and that consequently shape the way individuals come to act (Knights and Vurdubakis, 1994, pp. 174-5). In other words, examining context specific practices and techniques makes visible the means and methods through which power is made operable (Knights and Vurdubakis, 1994, p. 174). To this end, when one focuses their analysis on institutions as sources of power, one loses sight of the fact that it is in looking at practices, we can see how the dominance of such institutions and agents of power such as the state, capital or their constituent actors come into being and become, in themselves, institutionalized (Knights and Vurdubakis 1994, pp. 174-5). Thus, the operation of power appears to be everywhere all the time (Knights and Vurdubakis, 1994, p. 176; Foucault, 1980c, p. 141).

This notion of power is not without criticism, as Poulantzas (1978) has argued that if power is everywhere, all the time, then how can there ever be any resistance to it (p. 149)? Knights and Vurdubakis (1994) draw out this question further by stating “[...] if, as Foucault claims, resistance takes place so to speak 'within' power, then resistance can offer no escape" (pp. 176-7). Ultimately, these are suggestive of a type of relationship where resistance should be observed in opposition to power. Moreover, it is suggestive of a relationship where acts of resistance manifest themselves outside of the 
power which it opposes, yet when Foucault describes power, he generally refers to relations of power (my emphasis, Knights and Vurdubakis, 1994, pp. 176-7), ${ }^{2}$ denoting that " $[\ldots]$ there are no relations of power without resistances; the latter are all the more real and effective because they are formed right at the point where relations of power are exercised" (Foucault, 1980c, p. 142). The effect of this is that if resistance is to be found within power relationships (Sakolsky, 1992, p. 243), then they are a part of the mechanism of the power logic which they oppose. Thus, resistance permits one to carve space for political action within a certain power relationship. Knights and Vurdubakis

(1994) illustrate this relationship in an analogy in the following passage:

[...] for example, once the 'attitudes', skills and 'needs' of organizational members are identified/constituted as resistant or less than flexible with respect to the introduction, use and development of new technology, consultants have created not only a point of entry but also a 'problem' that their 'packages' are designed to resolve. Their intervention for purposes of transforming employee behaviour through programmes of technology assessment, training, awareness-raising and so on is rendered not only legitimate but also necessary by this exercise of power. In short, consultants readily constitute certain forms of conduct as 'resistance to technology' as this gives them some purchase on its reform by identifying a space in which expertise can be brought to bear in the exercise of power. Resistance consequently plays the role of continuously provoking extension, revisions and refinements of those same practices which it confronts (p.180).

Thus, the practice of resistance allows those who are able to make change to have the power to reform by having their attention drawn to certain practices or actions.

Resistance, then, operates within a power relationship but it also acts to modify this relationship actively. Moreover, this highlights how one becomes part of the process of

\footnotetext{
${ }^{2}$ I am drawing from Knights and Vurdubakis (1994) and their interpretation of Foucault's use of relations of power (p. 176-7).
} 
negotiating space through acting in a relationship. Finally, the analogy also serves to highlight how resistance is productive within a power relationship.

Conceptualizing power in this way has crucial implications for the study of labour because it notably shifts attention away from contending at its simplest that labour relations are only inherently exploitative, oppressive and repressive. Instead, being informed by a poststructural lens helps to guide an analysis of identity formation in four ways. Firstly, this conception of power suggests that power relations can always be changing depending on the context or the situation. This would indicate that the circumstances within which one exists is bound by this relationship; things are mutable and so are power relations. Secondly, this conception of power allows one to ask what practices render power to become operable and thus affect how one acts. The critical aspect here is in the use of practices in the workplace. Thirdly, if power is everywhere all the time, how individuals act and behave is part of a response (whether this is in resistance, in compliance or in any other manner) to that power relationship. Finally, resistance can be a basis for one to create political space in relations at work. Such motivation to act may then stem from one's attachment or identification with such work.

By introducing poststructuralism in the theoretical context of this chapter, I do not aim to take a position that refutes a Marxist approach. Rather an approach that is influenced by poststructuralism will be more useful to understand questions of identity. This is partly because the interest I have in this project does not aim to seek a particular specified outcome, nor is it seeking a particular form of change or advocating for it; I aim to make questions of identity become more visible, particularly in how they allow individuals to become part of their own subjugation or how they allow one to negotiate 
space because of how they identify with their place of work. Thus, my interest is coloured by how one's own experience of workplace change and workplace culture affect how individuals' identify, and are shaped by their work - how does one's attachment to work consequently mediate one's ability to be transformed by the work one does, and changing work practices? Before further delving into a theoretical discussion that will be used to help us understand work identities in the public library, I must again caution that I do not mean to use Foucault's oeuvre to establish a pure and accurate portrayal of a Foucauldian analysis. Instead, I am using his theoretical insights as a toolbox to illuminate an understanding of public service work identities.

The rest of this chapter will develop a discussion on the theoretical lens to be employed in this research project.

\subsection{Questions of Identity and Subjectivity}

At its simplest, identity contributes to the ongoing exploration of the question "who am I?" It is concerned with, on a more intimate level, questions associated with what one identifies and the means which allow one to identify with something. The question of identity and its relationship with work is critical in that it focuses one's attention on if and how living under a particular economic system emphasizes a need for a certain type of person. It also explores more generally how one should become in order to be governed in aspects of everyday life. To this end, how one's identity is shaped and to what one's identity evolves is of great importance. The formation of identities become a crucial means through which to conceive who we are, why we are the way we are, and for what purpose we are who we are. Lewis' (2007) asserts, “[...] identity shaping has to be seen for what it is - a work process, the transformation of people issuing from the 
same capitalist need as the transformation of other production inputs" (p. 402). Though Foucault (1995) and Lemke (2002) who in part draws from Foucault (1995), have noted that before one can be exploited and used by the needs of capitalist production, one must be trained, educated, disciplined and constituted as a productive individual (Foucault, 1995, pp. 25-6; Lemke, 2002, p. 58). Thus, as has been mentioned before, there is an important connection between the transformation of worker identities and the needs of the workplace and society at large.

Du Gay (1996) describes the relationship of identity to broader questions of governance but specifically notes that the constitution of identity comes through discursive practices. He argues that:

$[\ldots]$ the identity of the 'worker' has been differentially constituted in the changing practices of governing economic life. 'Workers' and 'managers' have been 'made up' in different ways - discursively re-imagined and reconceptualized - at different times through their positioning in a variety of discourses of work reform" (du Gay, 1996, p. 55).

Identities are further said to be shaped by discourses near and afar, which need to be justified not only to ourselves, but also to others to develop a particular narrative (Kuhn, 2006, p. 1340). Identities, then, can be associated with two meanings, one associated with "[...] institutional, normative and discourse practices $[\ldots]$ " and the other, with how individuals identify and align themselves with their environment and practices (Billett, 2006, p. 7). Thus, identity, at least in part, can be recognized through the interweaving of different experiences to create a greater coherence in thought and sensation (Alvesson and Willmott, 2002, p. 625). Moreover, subjectification and self-identities are always involved in a "[...] perpetual tension between power and resistance or subjectivity and identity" (Jermier, Knights and Nord, 1994, p. 8). 
Subjectivity, while not precisely the same as identity, is inherently associated with it as both subjectivity and identity express attributes and characteristics associated with ways of being. Crucially, subjectivity can be understood as " $[\ldots]$ the way in which individuals understand their lives, their relations and their work" (Knights and McCabe, 2003, p. 1588). This makes it valuable in a study of identity because it enables an exploration into the experiences and personal knowledge that are used to develop one's own understanding of how things function in one's own surrounding.

Subjectivity also requires a further discussion of what constitutes a subject. It is here that Foucault (1980b) provides an interesting answer:

Let us not, therefore, ask why certain people want to dominate, what they seek, what is their overall strategy. Let us ask, instead, how things work at the level of on-going subjugation, at the level of those continuous and uninterrupted processes which subject our bodies, govern our gestures, dictate our behaviours etc. In other words, rather than ask ourselves how the sovereign appears to us in his lofty isolation, we should try to discover how it is that subjects are gradually, progressively, really and materially constituted through a multiplicity of organisms, forces, energies, materials, desires, thoughts etc. We should try to grasp subjection in its material instance as a constitution of subjects (p. 97).

Thus, Foucault (1980b) acknowledges that relationships associated with questions of rule enable the transformation and constitution of persons into subjects. He specifically describes the way in which various processes come to shape individuals. The concern here is not so much with how certain groups or persons aim to impose a certain identity over others, but to investigate the techniques that are involved in subjecting an individual to techniques that foster certain ways of being. While Foucault discusses the outward impacts of practices on shaping a subject, Billett (2006) discusses "subjectivities" and how one's subjectivity is composed of certain aspects of identity that do not always become immediately clear to individuals: 
[...] individuals' subjectivities comprise a set of conceptions, procedures beliefs and values and dispositions that are, in part, non-conscious (yet quickly become conscious when something we experience doesn't fit) and, in part, conscious. Therefore, individual subjectivities and the allied concepts of sense of self and identity are essential to understanding engagement in work and learning (p. 6).

Furthermore, Billett (2006) describes an important relationship between questions of identity, subjectivity and learning - that the impacts of techniques that foster change within an individual, and the sets of conceptions and values that are present within a person that may or may not always be conscious, are together aspects of human learning. Individuals, consequently, are always involved in processes of learning that guide and shape the way we process knowledge and information and how we come to act in our day to day lives. The material and discursive practices that are ongoing in one's environment are in some way, techniques used to teach individuals how to act. How that teaching manifests itself is discussed further on.

Questions of identity and subjectivity are intricately tied to our own understandings of self and how we view the world, particularly when consciously positioning ourselves in the flow of particular practices or processes which govern our environment and ourselves. Examining identity and subjectivity follow an exploration of self particularly in mutable surroundings. Moreover, it should be noted that identity itself may never be as stable or fixed as one might expect it to be as individuals are constantly re(forming) or repairing " $[\ldots]$ the constructions that are productive of a precarious sense of coherence and distinctiveness" (Alvesson and Willmott, 2002, p. 626). This notion of constantly working on one's identity leads into a discussion on identity work. 


\subsection{Identity Work and Identity Regulation}

Two related areas of the study of identity are expressed through the concepts of identity work and identity regulation (Alvesson and Willmott, 2002). Identity work is a process which individuals undertake in transforming, maintaining or strengthening an understanding of self and in particular, "[...] specific events, encounters, transitions and surprises, as well as more constant strains, serve to heighten awareness of the constructed quality of self-identity and compel more concentrated identity work" (Sveningsson and Alvesson, 2003, p. 1165). Moreover, identity work research has explored individuals and their attempts to fashion a coherent sense of self, in relation to "[...] scripts, roles, and subject positions encountered in both work and non-work activity" (Kuhn, 2006, p. 1341). Thus, the relationship between working on one's own self is tied to not only events but to positionality, the performance of roles and the various discursive techniques that are deployed throughout various aspects of life. Identity work, then, refers to a project of ongoing transformation highlighting the inherently complex processes involved in shaping oneself; the formation of working self then is an ongoing project, which is mediated by ongoing interactions.

Identity regulation, on the other hand, is associated with discursive techniques associated with scripts, roles and subjectivity in a person's relationship with social structures (Kuhn, 2006, p. 1340). Through workplace practices such as training, and through techniques such as induction, organizations can come to inculcate workers (Alvesson and Willmott, 2002, p. 625). Thus, when workers are particularly attached to an organization's perceived identity or corporate identity, identity regulation will impact identity work (Alvesson and Willmott, 2002, p. 625). In other words, identity regulation 
explores the way in which an organization, through various means, comes to shape the identity of its staff indirectly through managerial discourses or perhaps more directly through specific techniques and practices that promote certain ways of being and acting.

This association of identity regulation with corporate identity then has relevance to an attachment to a corporate or organizational culture. Organizational cultures can be a set of norms which can be used to alter individual behaviour (Rouillard and Giroux, 2005, p. 332). Through norms and practices, then, identities can come to be modulated and regulated for processes of organizational control of workers. Thus:

[...] mechanisms and practices of control - rewards, leadership, division of labour, hierarchies, management accounting, etc - do not work 'outside' the individual's quest(s) for self-definition(s), coherence(s) and meaning(s). Instead, they interact, and indeed are fused, with what we term the 'identity work' of organizational members (Alvesson and Willmott, 2002, pp. 621-2).

These mechanisms and practices of control, then, can come to be seen as other examples of identity regulation. Like Alvesson and Willmott (2002), then, it is fair to suggest that identity work, itself, is a critical means through which control and the regulation of workers is practiced and achieved, particularly through workplace practices.

Identity work and identity regulation may then be seen as particular techniques or practices through which individuals come to be shaped or worked on. They aim to transform individuals and allow individuals to work on and transform themselves. These, then, appear related to practices that are used to govern individuals.

\subsection{Governmentality, Identity and the Transformation of Individuals}

Exploring workplace practices and changing workplace practices will allow us to see what is required of workers, as they adapt to new routines and tasks. As previously 
mentioned, to look for practices which can be crucial to understand how formations of a working self come to be, I am inspired by Mitchell Dean's (1995) study on Australian administrative practices towards the unemployed, where client-case manager relationships as well as the processes associated with receipt of benefits can come to shape job-ready citizens. His examination of Australian social security practices demonstrates how they "[...] seek to define the proper and legitimate orientation and conduct of those who claim support" and "[...] engage 'clients' in their own government by demanding their complicity in these practices of self-shaping, self-cultivation and selfpresentation" (Dean, 1995, p. 567). One may further wish to recall identity work noted above, which entails transforming, maintaining or strengthening an understanding of self (Sveningsson and Alvesson, 2003, p. 1165) as something that can be related to these practices of government in an individual's self-transformation.

In keeping with a discussion of governmentality studies, this project seeks to avoid discussing who rules and from what emanates this power of rule and thus is focused more so on the relations of ruling - the practices and techniques that are used to govern (Dean 2010, pp. 39-40). Moreover, as Dean (2010) notes himself, “[a]n analytics of government brackets out such questions not merely because they are stable, tiresome, unproductive and repetitive. It does so because it wants to understand how different locales are constituted as authoritative and powerful, how different domains are constituted as governable and administrable" (pp. 39-40). These are some elements which I am interested in exploring in relation to identity.

It is here that a discussion of government becomes critical. Government, can thus be understood as "the conduct of conduct," which describes " $[\ldots]$ a form of activity 
aiming to shape, guide or affect the conduct of some person or persons" and "[g]overnment as an activity could concern the relation between self and self, private interpersonal relations involving some form of control or guidance, relations within social institutions and communities and, finally, relations concerned with the exercise of political sovereignty" (Gordon, 1996, pp. 2-3). Moreover, governmentality can be described as the series of techniques and practices through which individuals can come to assume a set of beliefs and values to engage in self-regulation (Winiecki, 2006). Thus the importance of governmentality studies helps us to reframe the discussion on work to one that is constituted in relation to the regulation and attempts at formation of selves.

Furthermore, Inda (2005) directs our attention towards the relation of subjects to governmental power and the implications this has on the study of identity and subjectivity:

To focus on the subjects of government is thus, on one level, to direct attention to how governmental practices and programs seek to cultivate particular types of individual and collective identity as well as forms of agency and subjectivity. It is to emphasize how government is intimately involved in making modern subjects - whether it be as workers, citizens, consumers, students, or the like. The importance of such subject-making is that through it - that is, through attaching individuals to particular identities, through getting them to experience themselves as specific kinds of human beings with certain kinds of capacities and qualities government is able to mold human conduct in such a way as to bring about individual and collective wellbeing. On another level, to focus on the subjects of government is to deal with how particular agents cultivate 'their own' selves and identities (Inda, 2005, p. 10).

The passage above particularly resonates because the means through which subjects are formed through governmental power are the things which I am, at least in part, interested in investigating. Governmental practices, thus, play a role in shaping certain subjects and promoting certain tendencies within them. Inda's (2005) use of language here is careful 
to suggest that governmental practices play a role in nurturing, promoting or encouraging certain subject positions or identities. To this, one should note Dean (2010) who provides a clear caution that the identities that are promoted by governmental practices "[...] should not be confused with a real subject, $[. .].[\ldots]$ a subject that is the endpoint of a terminal of these practices and constituted through them" (original emphasis, p. 43). This serves as a warning in highlighting that practices that affect the promotion of certain identities do not lead to the formation of a final or fixed identity. This is important to consider as I use the terms "subject" and "subjectivity" throughout this paper. I will discuss the implications of this a bit more thoroughly in the "Theoretical Impacts" section below.

Rose (1996) notes Colin Gordon who suggests that Foucault deploys the concept of governmentality in two ways:

First, to draw attention to a dimension of our experience - not itself specifically modern - constituted by all those ways of reflecting and acting that have aimed to shape, guide, manage or regulate the conduct of persons - not only other persons but also oneself - in the light of certain principles or goals. [... And secondly] [g]overnmentality both extends the concerns of rules to the ordering of the multitudinous affairs of a territory and its population in order to ensure its wellbeing, and simultaneously establishes divisions between the proper spheres of action of different types of authority" (original emphasis, pp. 41-2).

In this project, the focus here lays not so much in the definition of the latter, but rather in the former - in drawing our attention to the human experience in the way that individuals come to be regulated, guided, managed and/or shaped for particular ends. It is also worth considering Winiecki's (2006) position, which skillfully articulates the power of governmentality in relation to organizations by suggesting that it "[...] 'spreads' across many individuals at once and acts to inculcate [an] organisation's values into subjects' so 
they manage themselves according to its principles" (p. 13). Thus, governmentality is important to consider in relation to (re)constructions of self because it highlights the means through which individuals and workers can become who they are to fit particular modes of rationalities. One's work identity is inextricably tied to the techniques and practices, whether implicitly or explicitly, deployed in the workplace.

To further conceptualize those "practices" it is worth considering Burkitt's (2002) use and definition of the term "technology." Drawing from Dewey, Bourdieu, Mauss and Foucault, Burkitt (2002) states that:

[...] technology is a form of practical action accompanied by practical reason, which aims to instil in the body certain habitual actions-either moral virtues (that is, right ways of acting in a situation) or technical skills - and, later, to give people the reflexive powers to reason about their virtues or skills, providing them with the capacity to refine, modify or change them. In other words, technology is a means through which humans produce not only products and works, but also themselves as human selves in both their reflexive and non-reflexive aspects. It is through various technologies that humans develop the habits, capacities, skills, identity, and knowledge that mark them out as individual members of a social and cultural group (p. 224).

The practical aspects of technology, in that they facilitate action and in themselves activate within individuals a sense to act in certain ways, give individuals a sense of who they are, what their capacities are to be, and what their potential might be. Technology shapes the body and its uses. Moreover, whether in a theoretical or technical sense, technologies affect the way in which one performs tasks, and at the same time, shape those actors whom they affect; they fulfil an educative purpose within an individual by training their minds and their bodies. Thus, technology gives a practical understanding of the impact of practices on human selves and force one to recognize the very tools that come to shape how and what we should become. 
The practical aspects of technologies and their influence in shaping individual behaviour and identity are then key to an understanding of self - physically and socially. To this end, it is worth considering Foucault's (1988) typology of technologies or techniques: technologies of production, technologies of sign systems, technologies of power and finally, technologies of the self:

[...] we must understand that there are four major types of these 'technologies,' each a matrix of practical reason: (1) technologies of production, which permit us to produce, transform, or manipulate things; (2) technologies of sign systems, which permit us to use signs, meanings, symbols, or signification; (3) technologies of power, which determine the conduct of individuals and submit them to certain ends or domination, an objectivizing of the subject; (4) technologies of the self, which permit individuals to effect by their own means or with the help of others a certair number of operations on their own bodies and souls, thoughts, conduct, and way of being, so as to transform themselves in order to attain a certain state of happiness, purity, wisdom, perfection, or immortality (p. $18)$.

Most relevant to the purpose of this research project are technologies of power and technologies of the self. One technology of power to consider is disciplinary power: "[d]isciplinary powers are concerned with the creation of obedient bodies and are fixed through the discursive practices which constitute them" (Thornborrow and Brown, 2009, p. 358). As in the theoretical context described above, this form of power is not merely negative or repressive, but is also productive and "[...] produces domains of objects and rituals of truth" (Foucault, 1995, p. 194). One of the methods used to "discipline" individuals, is through normalization, which "[...] imposes homogeneity; but it individualizes by making it possible to measure gaps, to determine levels, to fix specialities and to render the differences useful by fitting them one to another" (Foucault, 1995, p. 184). Normalization, thus operates through a calculated method. One integral 
aspect of normalization requires a form of surveillance or gaze, which can be used to help shape one's self. In becoming visible, the effect of power on individuals is rendered operable, and being constantly visible, one is placed under disciplinary techniques (Foucault, 1995, p. 187). Discipline also allows individuals to become self-regulating and self-disciplining (Thornborrow and Brown, 2009, p. 358). Discipline, as a technology of power, then, allows an individual to train oneself appropriately, perhaps through technologies of the self, through a self-transformation.

Technologies of the self are pertinent to examine in relation to practices because, as a tool, they can help us identify those practices that are used to change, shift, or develop oneself by oneself. In other words, technologies of the self are the processes that allow us to transform who we are, to shape ourselves to a certain end; they permit selfregulation. Conceptualizing them in relation to techniques of change or practices can allow us to examine certain sites of study in new ways. They permit an exploration of those practices that enable individuals to make self-corrective transformations.

Foucault (1993) notes:

[one] has to take into account the points where the techniques of the self are integrated into structures of coercion and domination. The contact point, where the individuals are driven by others is tied to the way they conduct themselves, is what we can call, I think, government. Governing people, in the broad meaning of the word, governing people is not a way to force people to do what the governor wants; it is always a versatile equilibrium, with complementarity and conflicts between techniques which assure coercion and processes through which the self is constructed or modified by [oneself] (pp. 203-4). 
What Foucault (1993) suggests here is critical as it firstly notes how technologies of domination or power are related to technologies of the self. ${ }^{3}$ Asdal (2008) and Burchell (1996) who in part draws from Foucault (1993), have both highlighted that technologies of the self and technologies of power interact with each other and the point where they do so is government (Asdal, 2008, p. 23; Burchell, 1996, p. 20). The way in which one acts and behaves is ultimately tied to a conception of self and relates to how one governs oneself. These techniques of the self affect one's identity in how one comes to shape oneself. Thus, techniques of the self are a vital concept to consider within the context of this proposed project, for it might unearth those contact points where one comes to shape one's identity. Burchell (1996) also notes that techniques of the self might be important to study because they might ultimately lead to an understanding of "[...] how freedom can be practised" (original emphasis, p. 21). These ultimately give rise to a realization of how individuals may come to act in society and furthermore indicate the constrained nature under which one may practice freedom.

Technologies or techniques of the self are important in relation to the idea of identity formation. Burkitt (2002) forces one to consider that technologies of the self are ultimately:

[...] forms of production as well as means of domination. They produce human selves with various dispositions and capacities that are formed in the matrixes of practical reason: that is, modes of activity that are supported and mediated by artifacts (as in the case of tool use for example) and social institutions, which aim to transform the world by the

\footnotetext{
${ }^{3}$ I take Foucault's (1993) discussion of technologies or techniques of domination to refer to technologies of power. Technologies of power, as noted above, determine the conduct of individuals and submit them to domination (Foucault, 1988, p. 18). Moreover, Asdal (2008) states "[...] government is to be understood as a point of contact where techniques of the self interact with techniques of domination or power" (p. 23). Hence, one can see how technologies of domination or technologies of power refer to the same thing.
} 
production of new works as much as they aim to reproduce the existing world (original emphasis, p. 235).

By examining these practices, then, we can see how these modes of activity "reproduce the existing world" and more specifically, within individuals. In this manner, they have an educative practice, in training the minds and bodies of individuals for particular ends. Burkitt (2002) notes that "[...] the technical education of individuals in any culture involves training in techniques of the body, and this can go for any type of technical education, be it in techniques of production, of art, of sport, or in learning the correct moral predispositions" (p. 223). Thus, technologies of the self facilitate a formation of identity and self, particularly in relation to the technical skills required for an individual before being useful for the valourization of capital and/or exploitation of a worker (cf. Foucault, 1995, pp. 25-6; Lemke, 2002, p. 58 who also draws from Foucault, 1995). Through them, in shaping working selves, it can become possible to forge the (re)construction of the right type of individual (un)successfully for the benefit of greater questions of productivity and efficiency through individual work subjects. In other words, technologies of the self, particularly in working in tandem with technologies of power, can be connected to more than just measures of control in that they function to help shape a worker-subject in relation to what is needed in an organization and/or economy.

\subsection{Theoretical Impacts on the Study}

While a broader discussion of the public library and its place within governmentality studies is possible, the focus of this project's use of governmentality is in its exploration of the formation of identities. In discussing regimes of practices, Dean 
(2010) notes that an attention to the formation of identities " $[\ldots]$ is concerned with the forms of individual and collective identity through which governing operates and which specific practices and programmes of government try to form" (p. 43). In this regard, studying identity involves questions such as what characteristics and capacities are required of those who rule, and those who are governed (Dean, 2010, p. 43)? Dean (2010), as I have noted above, also argues that one should not consider the formation of identities as being tied to notions of subjectivity or subject position or how certain practices necessarily lead to the formation of certain end forms of identity or identity outcomes, but rather how regimes of government try and promote certain qualities and/or capacities in individuals (pp. 43-4). Moreover, Dean's (2010) focus here is to underscore that "[r] egimes of government do not determine forms of subjectivity" (original emphasis, p. 43).

Thus, in this project when I refer to subjectivity or subject position, I am not referring to the necessarily fixed outcomes of identities, but rather am discussing how certain identities or subjectivities are promoted. In other words, I am discussing how practices push certain subjectivities to develop, not that these subjectivities are necessarily the final outcome of a set of practices. In a sense, a discussion about subjectivity is more to do with a "snapshot" in how one perceives of an identity at a particular place or point in time. This is where the concepts of identity work and identity regulation make much sense in relation to the study of identity, subjectivity and governmentality. These concepts underscore how individuals work on themselves through practices to develop a sense of self. Identity work is something which is ongoing as individuals are constantly engaged in (re)forming their identities and when events, 
transitions, or experiences, among other things occur, they allow individuals to become more aware of their identity and this then fuels individuals to further work on the self, or engage in identity work (Willmott and Alvesson, 2002, p. 626). The key part here is that identity work is ongoing and is not fixed. Examining identities or subjectivities that form as a result of a collection of practices then describe identities that are promoted perhaps towards an end, but are not the end point of a set of practices. There is also likely no guarantee that any particular techniques will lead necessarily to any particular identities.

Thus, in relation to this project, one might ask, how is it that certain persons are made into library workers or are constituted as being employees of Toronto Public Library and how do individuals make sense of these practices that transform them into library workers? Along these lines, it is then worth asking what capacities or qualities are promoted or fostered of these workers in their work environment and what the implications of these might be in relation to broader questions of public service work.

Further questions arise in emphasizing the role that many factors play in shaping the identity of workers at work, particularly, when workers are faced with change. One might ask: what contextual factors modulate, alter or shape one's identity? For example, one's subjection to power may be mitigated or filtered through characteristics such as class, gender, or race (Sakolsky, 1992, p. 236). These classifying criteria are also characteristics of identity in themselves as they help answer questions such as "who am I?" and may also play a role in filtering one's attachment and identification with one's place of work. However, I do not engage with class, gender or race in this project. These are not within the scope of this project, but do present themselves as crucial identity lenses to explore in future research. 
Instead, my focus in this research project is to look at the impact of generation in examining how questions of identity come to be realized. This is of significance theoretically because it examines not so much age, but to some degree, the role of one's accumulated knowledge within a particular institution during different periods of its organization. This is theoretically significant because as a control factor, it may be something which mediates and which is mediated by what has been noted above: organizational culture, work on the self, and regulation and control at work. Thus, looking through the lens of generation adds another layer of complexity to this research project.

Ultimately, this research project is concerned with identity formation, particularly in relation to changes in workplace practices. Coupling these thoughts with what has been developed in this chapter, it is useful to think about the following questions in relation to this research project:

- How do workers see themselves in relation to the work they do?

- How do they develop a sense of self through discursive techniques, that is to say, through the way in which they understand themselves through language?

- In what way does one's attachment to an organization revolve around the organization's culture or the meaning they attach to their work or place of work? Is there a disciplinary impact?

- How does one's experience come to speak about the type of person that is required at work? Are there broader implications in relation to this?

- How do workplace practices help individuals transform themselves? 
The next chapter will map out how I went about resolving the questions above through conducting this research. 


\section{Chapter: Research Process and Design}

\subsection{Methodological Context}

There are essentially two methods that will be employed in this proposed research project: narratives and naturalistic observation. Narratives are an important aspect of this research. To recognize the formation of identities, and some of the character values of library workers, interviews and responses to interview questions were used to construct narratives. As Archer (2007) states, "[t]he subjective powers of reflexivity mediate the role that objective structural or cultural powers play in influencing social action and are thus indispensible to explaining social outcomes" (original emphasis, p. 5). This suggests that the reflexive role of narratives can help to establish how one's environmental factors can come to shape action. Similarly, drawing on the work of others, Collinson (2005) notes that "[...] self-identity is a reflexively organized endeavour designed to sustain coherent biographical narratives in the search for ontological security" (p. 533). Thus, the power of narrative becomes a central feature of this research to address questions related to who we are and who we want to be and the tensions and contradictions that form as a result of trying to become that which is needed in the workplace. Through a narrative-approach it can become possible to gauge how a worker's identity forms in relation to work.

The ability to develop a narrative provides an opportunity to affirm that the manner in which one leads one's life "[...] as being worth telling and thus worth living. Being narratable implies value and attributes reality" (Frank, 2002, p. 111). Narratives, in a sense, may also appear in the form of stories. Storytelling, then provides a practical means through which order can be fashioned out of experience (Moen, 2006, p. 56). 
Stories “[ $[.$.$] enter new interpretative frames, where it might assume meanings not$ intended by the persons involved in the original event" (Moen, 2006, p. 62). This statement has important implications. Stories allow the researcher to link a participant's experiences through different theoretical and analytical lenses; the implications for narrative analysis and the study of identity and self are thus linked through the study of these experiences and narratives help to identify the key role that discursive practices play in the interview process. Crucially, Kuhn's (2006) study recognizes the importance of discourse as critical to identity work and identity regulation and subsequently states that " $[\ldots]$ identities are considered discursive constructions realized and negotiated in interaction, and the interview is one relevant forum for this" (p. 1344). The narratives associated with the experiences of work then reveal much about the ability of discourse to help construct identities and simultaneously the interview itself provides a venue for selfidentity and identity formation to congeal and cohere. The interview itself, it should be noted, does provide a space where identity work can be actively practiced by a participant.

Thus, one must recognize that stories may be taken out of context from the meaning which a participant intended. It is very much a likelihood that the research process is actively shaped by the researcher, and consequently aspects from interviews may have been unintentionally ignored or silenced (Neysmith, Bezanson and O'Connell, 2005, p. 19). This is where researcher reflexivity (Ballamingie and Johnson, 2011) is important in that it may prepare one for such challenges, though it is perhaps a fairer argument that one may be unable to entirely avoid all the pitfalls of research associated with narrative analysis all the time. 
While the narrative-driven structure is meant to elucidate what the participant feels as pertinent practices which come to shape their behaviours and identities, the interview process might appear similar to that of a job performance appraisal. In these work evaluations, one is given the opportunity to reflect upon one's performance and work ethic in front of a supervisor or manager. Similarly, "feedback" at performance appraisals can be described as a means of managerial control and the individualized worker's controlling (Swan and Fox, 2009, p. S153) and performing of self-identity (Adkins and Lury, 1999, pp. 601-3). The performance evaluation is an important similar practice to discuss as "[f]eedback not only makes available all aspects of the self for management, it does so in terms that are set by the individual [themselves]..." (Adkins and Lury, 1999, p. 603). Feedback anchors the rationality behind utilizing the narrative technique as a means from which to discover workers' identities. It is ultimately the person who performs and is affected by labour practices who can reveal the impacts on the self. While allowing participants to perform their own identity is critical, it is important to maintain an impartial position as a researcher and acknowledge that the research process itself is not a performance appraisal - the power dynamics are not the same.

However, narratives themselves are not the only means through which information was collected. This project included naturalistic observation to gather information in how library workers work in their public work environment for the purposes of refining questions for interviews and developing an understanding of what type of labour practices might come to affect identity. I was not interested in being exhaustive with this technique, as I was only interested in observation to refine interview 
questions as empirically observing what work is done is different from imagining abstractly what work is done. This technique allowed me to be more grounded in preparing questions for the interviews.

\subsection{Research Design}

In trying to understand how various techniques and practices that encourage and promote certain capacities within individuals impact the shaping of working people's identity, this project aimed to interview 10 participants. In selecting participants to interview, a technique of strategic selection was employed. I also made a conscious decision to exclude potential participants who I recalled having worked with in the past or those who knew of me from my past association with them. This included former coworkers who have been my past supervisors. While I could not be certain who to include and who to exclude perfectly, I went on a case by case basis and made the decision of who I could interview and who I could not. This was important because I wanted participants to be freer in expressing themselves, not having to worry about my relationship with others, nor did I want those who had past supervisory experience with me to feel conflicted in what to say during the interview that might put them in an awkward position.

Initially, I had constructed two generational groups of participants, those ranging in age from 18 to 31 and another from 32 and up. The logic behind the categorization was based on an interpretation of workers and their possible work history connection to Toronto Public Library. Age was thus made implicit in an understanding of when people started working at Toronto Public Library. It was thus assumed that if one was employed before 1998, then it could be assumed that one has likely been employed with a 
predecessor Toronto-area library system and is likely above the age of 32 . If one was 18 in 1998, then in 2011, one would be 31 and this helped shape the age range. However, I soon realized that my age range was fixed by age, and time itself was not fixed. Thus, in 2012 , these age ranges needed to be adjusted.

Accordingly, 5 participants were to be selected from an age range of 18-32 and another 5 were to be selected from an age range of 33 and up. The age range was selected based on a reinterpretation of workers and their possible work history connection to Toronto Public Library. If one was employed before 1998, then it could be assumed that one had likely been employed with predecessor library systems and is likely 33 or older. If the worker was 18 in 1998 - the time of amalgamation - then in 2012 they would likely be 32 years of age. If aged less than 33 , it would be likely that the worker would not have had the experience of working in a predecessor system or was hired during the time of amalgamation.

Eventually, I found that the method for constructing generations was too complex. Using age as a key indicator of a person's generational affiliation was problematic, as age is always changing, whereas dates are fixed. To this end, I abandoned using age as an indicator and a categorical tool. I instead decided that using 1998 as an event that could more or less aid to delineate generations of people would be most effective for this research project. Regardless, this was the original intent of using age as an indicator in dividing groups of persons into two generations around the critical event of amalgamation. In this way, I was more easily able to put workers into two different categories to be able to code and compare people's experiences of those who were hired before amalgamation in a predecessor system forming the first generation of workers and 
those who were hired after amalgamation, thus forming the second generation. The idea here was that those who were hired before the year of amalgamation would have different experiences than those who were hired after that date. This was a comparative technique to help understand generational differences in this project. Age, which may be a relevant factor in these, did not come to play a factor in the study.

However, I should note that I was unable to find all 10 of the participants that I needed for the project. Instead, I was only able to find 5 qualifying participants, 3 of whom were of the first generation, and 2 of whom were from the second. This presented a significant challenge to this project and I discuss this further in the limitations section of this chapter.

Before, engaging in the interviews, I engaged in naturalistic observation at public libraries in Toronto. Through observing library staff working, I found it useful to help sharpen the questions I planned on asking during interviews. These helped establish the usefulness of preformed questions through observing staff and patrons perform tasks and conduct their seemingly regular routines. I spent anywhere from part of a day, to a whole day - up to 8 hours observing. This was also an important aspect of the research to help crystallize and understand visually how labour practices can come to shape notions of selfhood. It was not necessary to be too exhaustive in this part of the research because I only wanted to develop an idea of the tendencies, practices and the contact points where identity and behaviour might come to be shaped. My aim here was not to record people's activity to augment the research as a whole, but to observe the activity to help me (re)formulate interview questions. I found this to be a fruitful exercise. 
To find participants for this project, I prepared an advertisement that was looked over by management at Toronto Public Library. Through a dialogical process, the original advertisement was modified slightly, and placed in an electronic newsletter called @ TPL, which I was told was received by all staff. I have given a sample of the text that was put into the first newsletter (see Appendix B, B.1). An ad was sent in three electronic newsletters. The newsletter was emailed to staff and was in a .pdf format. Potential participants were asked to contact me, and I responded to them and screened them for their appropriateness to the criteria as mentioned above. However, not all the participants I was looking for were solicited through @TPL. In realizing that more participants were needed for this interview process, I eventually contacted the Toronto Public Library Workers Union (TPLWU) to help me solicit more participants. It was my understanding that the union was able to send out an email on my behalf to stewards and union executives, attach my ad to the Union President's President's Message and forward my ad through the organization's mailing list. Members who had signed on to the organization's website mailing list would be able receive this email. With each of the means provided to me by the unions, I asked to have sent a slightly modified version of the ad that appeared in the first issue of @TPL which had my ad placed in it (See Appendix B, B.2). The ad that was to be sent through the Union was more specific in the types of participants I was seeking out and provided a deadline to contact me. Through these direct electronic means, I hoped that I would be able to reach out to more participants. I was also hoping that those who received the ad would share information about my desire to find more participants to other members within the organization. 
I subsequently met with the potential participants based on their preferences, at a place of their choosing for an interview. In a few cases, this meant initially meeting somewhere, and finding another place to engage in the interview. The preference of the participant in selecting an environment to be interviewed was important because I wanted them to feel comfortable in a place of their choosing when responding to questions. Ultimately, though, I found that participants were very open to be interviewed in a variety of venues and participants were open to suggestions of places to be interviewed as well. It should be noted that participants were asked to sign a consent form.

The purpose of the interview phase was to engage library workers about their perception and conception of self. Classifying questions such as age range, gender, identification of a cultural/racial/ethnic group, years of service and position and tasks related to and required of the position were taken into consideration, but were not necessarily deemed important for the study. Subsequent questions were constructed with the key concepts of flexibility, technologization, identity and the Foucauldian theoretical concept of technologies of the self in mind. Questions and themes associated with questions, however developed throughout the research process. The questions asked remained open-ended and were segmented into broader topics pertaining to mobility, responsibilities, technology and responsibilities, resistance, relationship with the public and self-reflection. The semi-structured method was useful in that it allowed for a more flowing interview process, giving me, the researcher, greater freedom in seeking to develop interesting points which may blossom from discussion. I developed an Interview Guide, which guided my approach to interviews (see Appendix C). I later revised this guide as I engaged in my interviews. I found that each interview helped shape the type of 
questions I might ask for the next interview. Not all questions were asked from the interview guide. I also aimed to make sure that participants knew when I proposed to finish my research project, how I would allow them to access a final copy of my research project, and how and when I planned to archive and destroy the data (electronic recording and transcriptions). While this was not always noted at the end of an interview as I had expected to do in my Interview Guide, I made sure these were things that were discussed when meeting the participant for the interview. The process for meeting a participant and conducting an interview, after all, is not a perfect process, and one must be willing to adapt to different situations as they present themselves.

Originally, I had allocated between approximately 30 to 60 minutes for an interview, but quickly, I began to notice that interviews started to take longer than I had anticipated. The interviews ranged from approximately 45 minutes to 90 minutes. This meant that interviews were far richer in the data they provided for the project, and for subsequent research in the field of library work. The interviews were recorded, and along with the recordings, I took some hand written notes of the interview. With the electronic recordings, I transcribed the discussion. As much as possible, I attempted to keep as close to the actual wording in the interview to replicate as much of the narrative which participants provided. I tried to mitigate the "uhhhhs," "ahhhs," and "hmms" as much as possible, however, at times, I found myself typing them out in the transcription, generally because I thought they augmented or were relevant to the transcription. I realize that I may have missed certain words here and there in the transcription process as well. However, I recognize in doing so, I may be actively creating reality in my research 
(Thornborrow and Brown, 2006, p. 362). ${ }^{4}$ While I have attempted to be careful in the transcription process, errors and missed words are always possible, though I believe I have kept, at the very least, close to the meaning conveyed by participants in the interview.

In transcribing, I listened closely to each of the recordings, often finding myself running the recording at half or two-thirds speed in order to capture the language being used in the interview. Once a transcription draft was completed, I listened and followed along the transcription with the recording playing in the background, looking to correct mistakes in the transcription I may have made. Throughout the process I looked to omit reference points in the interview that might allow participants to be identified.

Maintaining the anonymity of my participants was critical for me throughout this entire research process and for this reason, omitting these reference points or indicators was necessary.

\subsection{Data Organization and Analysis}

As I was proofreading the interviews and simultaneously listening to the audio, I also took notes indicating key ideas or points that I thought were relevant for this project. Using those notes, I was able to isolate common themes, which I used to build a table (see below for an example of a similar table used: Figure 1). Each theme was related to a category. Originally, these themes were very broad, but slowly, as I began to complete the table, the themes and categories became narrower and more focused. While I had

\footnotetext{
${ }^{4}$ Here, Thornborrow and Brown (2006) are drawing from Ragin and Flyvbjerg in their argument and are discussing the interview process. I however aim to highlight that the transcription process may also do the same. The language used by Thornborrow and Brown (2006) particularly resonated with me, and consequently needed to be noted here but in a different context.
} 
more categories than I could count, as I began to fill in the table, some of the categories did not appear useful, some were collapsed into others and others still came to be relevant later on, even if initially they were deemed irrelevant and were thus unused. In the table, I indicated my participants into a grouping of generation. I then began to note things I had noted from transcriptions and entered these into what I perceived to be the appropriate box. This helped categorize my notes thematically and by broad topic as well. After this was completed, I finished writing a draft of my theory chapter. Thus, to a large extent the theory and analysis aspect of this project have been engaged in a proverbial dialogue; each was constantly informing the other.

\begin{tabular}{l|l|l|l|l|l|l}
\hline \multicolumn{5}{|c}{ Categories for Analysis } \\
\hline ID/Generation & Category 1 & Category 2 & Category 3 & Category 4 & Category 5 & Category 6 \\
\hline $\mathbf{P} / 1$ & & & & & & \\
$\mathbf{R} / 2$ & & & & & & \\
$\mathbf{S} / 2$ & & & & & & \\
$\mathbf{T} / 2$ & & & & & \\
\hline
\end{tabular}

Table 1: Categories for Analysis - organizing interview common themes.

After finishing with a draft of the theory chapter, I went through the transcriptions again, highlighting important areas that were both related to the themes I had already extracted; these themes now were much more theoretically informed. It is important to note that the text of transcriptions themselves are open to interpretation of readers. Moen (2006) rightly notes that " $[\ldots]$ narratives fixed in a text $[\ldots]$ " are open to interpretation to those who read and hear about it and thus as an "open text" leave open the possibility to engage with the text by interpreting it in various ways (p. 62).

It was at this point, I had decided it was necessary to write out descriptions of each category, drawing on literature or theory as required. This method was inspired by Thornborrow and Brown (2006), who as part of their research on aspirational identities of 
British Parachute Regiment soldiers, constructed a generalized account of the composition of a paratrooper after developing categories of activities and interests of these paratroopers (pp. 361-362). The result of this "[...] allowed [them] to think again and in more detail about how the codes [or categories] related to each other and what important information they revealed" (Thornborrow and Brown, 2006, p. 362). I did something similar with the categories which I originally deemed relevant by elaborating on each of the categories and developing and drawing out their descriptions. This served three purposes. One purpose, which was deliberate, was to expound a theoretically informed and more detail-specific description of each category. The second purpose, which was also intentional, was aimed to enable me to collapse and simplify my data, if and when I came to see overlaps between themes or ideas. This promoted an aim to be concise and furthermore acknowledged that while categorizations are constructions and thus in themselves not easily delineated, they still have a useful purpose to play to help advance the research process. The third purpose, which was not initially intentional, allowed me to develop notes on what was to be written in the analysis chapters that would consequently be theoretically informed.

\subsection{The Limitations of Methods and Researcher Reflexivity}

Difficulties can very easily appear in using the narrative approach. Neysmith, Bezanson and O'Connell (2005), as I have noted above, indicate that ' $[\ldots]$ certain dimensions of [those interviewed] will have been ignored for various reasons: we may not have heard them; we may have effectively silenced them because our attention was elsewhere; or participants may have chosen not to share them with us. Thus, these stories 
have been shaped by us as authors" (p. 19). In this sense, one must remember that the research one does is of one's own voice despite the fact that one is collaborating with the stories which participants express. These experiences are then filtered through the theoretical, social, research and methodological filters which the researcher employs. Moreover, the way in which a researcher delivers these stories can shift the focus or reattenuate the attention that the participant seeks to emphasize. Somers (1994) also mentions that in engaging in research, one may actually come to look for certain fixed, pre-defined categories (such as age, sex, gender, race/ethnicity categories) to look for something specific and consequently ignore more mutable identities that might develop and be tied to "changing power relations" (Somers, 1994, pp. 610-1). As I am looking through a lens of generation, I am also engaging in this research with one eye fixed towards those notions of identity associated with generation. The result of this may be that I have overlooked other important things that may have emerged in the research project, yet remain invisible to me because of my focus. It is, I think, a fair assessment to state that this is unavoidable. Researchers might be looking for certain things in their work, and this might be revealed in the way data will be deconstructed and analyzed.

These things might be mitigated when examining what Ballamingie and Johnson (2011) refer to in terms of researcher reflexivity. While they refer to different forms of research vulnerabilities (such as power relations between the researcher and those who are part of the research) (Ballamingie and Johnson, 2011, p. 14), what is important to note is that reflexivity can become an important tool to mitigate challenges in the research process by forcing one to look upon that which has happened, that which could happen, and that which should happen. Employing such a tactic prepared me to be 
adaptable in the research process in preparing for potential risks and developing alternatives to deal with them. One of the means I engaged in reflexivity was in writing things down, whether by hand, or typed on the computer. I found these to be fruitful exercises, as I could never be sure when exactly I would develop an idea or conjure forth an important issue to worry or reflect upon in relation to this research project. In writing these things down, I sometimes found that these thoughts became useful for writing and also permitted me to recognize what challenges may come forth, thus being better able to resolve them.

However, no matter how much one writes, there is still a challenge in seeking out the number of participants needed for the research study. Not being able to secure 10 participants was another significant challenge. Having only 5 out of the 10 participants needed reduced the viability of the project. After all, the greater the number of participants, the richer the detail from which it would be possible to develop a clear case and argument. Moreover, of my 5 participants, only three of them were from the first generation, and 2 were from the second. This has meant that finding commonalities between the two groups was more difficult as there were fewer sources from which to juxtapose data and experiences. It also likely reduces my ability to replicate the findings from this research in future.

It should also be noted that conducting interviews is likely not as effective as ethnographic work in this project as it would enable me to observe and analyze Toronto Public Library much more holistically and visually. An ethnographic method would enable me to explore the contact points of domination and the practices that can lead to 
shifts in individual workers identities. However, due to the limited scope of this MA

project, the sole use of interviews help foster exploratory research into this area.

Sennett (2006) describes the impact ethnography can have in studying identity:

[...] life histories are seldom shapely. In ethnography, we are indeed less concerned with how coherent are the stories people tell us than with the effort of our subjects to make their experience cohere. This is not a oneshot effort. Frequently a subject will retell and reorganize an event, sometimes taking apart the seemingly logical story into disconnected bits, in order to see what lies beneath the surface. In technical lingo, this is 'narrative agency,' the narrator actively engaging and interpreting experience (p. 188).

Nonetheless, I would argue that engaging in interviews has allowed me to do the same.

They have enabled me to see how individuals may attempt to fashion a coherent worklife history. Perhaps the relative depth with which this project can engage with people's ability to fashion coherent identities is limited, but it still permitted me to explore how participants have actively engaged with and interpret their experiences at work.

There were also aspects of this research that both helped reveal certain things about the research, and at the same time, helped conceal or blur others. For example, Toronto Public Library provided a very interesting and salient place to study labour identities in public organizations. It was revealing in that it allowed me to explore ongoing changes within the organization that may impact individual workplace identities. However, this site of study is also highly complex as it was formed out of a merger of different library systems that had their own organizational cultures and procedures that may continue to linger within the larger organization. There is also variation among jobs and between individual branches. Not all branches, for example, have self-service checkouts or check-ins. This has meant that the impact of changes throughout the organization will not be uniform and the impacts of identities could potentially be greatly 
varied, particularly if those who were not interviewed did not experience things in the way that the project participants did. Thus, while the organization itself is a revealing place of study because there is so much variation and complexity to the organization, learning about workplace identities may be limited in what they reveal.

Moreover, as I had noted, the organization was undergoing a labour dispute during part of the research process. On the one hand, the strike allowed me to observe some common themes amongst participants. However, concurrently, the strike may have blurred generational differences. It may have also directed away the attention of some participants. As this was a fairly recent event, this appears to be unsurprising.

I also realize that in formulating questions and this research project, I went ahead with my own image of the public library and the work associated with it. This has meant that my focus was in some cases on certain types of technologies, such as the express or self-checkout or self-check-ins. The result of this may have been revealing, in that I was focused during interviews and could ask pointed questions, but at the same time, my own investment in the image of the library may have been so significant that it initially did not allow me to examine positions and tasks that were somewhat more removed from these technologies. My own orientation in this project, I have learned, can conceal other interesting aspects to things which the interviews unearthed. Unfortunately, not all these other interesting topics may have found themselves to be relevant for this research project, and it is possible that my own interests concealed my ability to develop these other findings further.

While there are significant limitations to this project, I have still been able to come to some limited conclusions about questions of labour and discursive practices and 
the emergent forms of subject positions and selves that came to appear in my research. The implications of these conclusions may have consequences for future research in this area of study and I will suggest means through which a more thorough study can be detailed. Before proceeding further, the next section will provide a map and will detail the research questions which guide this project.

\subsection{Research Questions}

In highlighting the processes that were used to procure and manage the information that has been highlighted, I can now turn to the research questions this project aims to examine. This includes the following:

- How and to what end does generation come to mediate the promotion and formation of certain identities within the library workplace?

- What are the broader implications for study of identity formation and the formation of a working self in the public library?

In attempting to answer these questions, the next chapter will locate the research in the broader literature. This will then be followed by the observation and analysis chapters of the research. The first of these chapters is composed of the techniques and practices that may play a strong role in shaping and educating workers. It will also develop the concept of generation further and it will note how an important event may disrupt the findings that I sought in this research project. Then, the impact of workplace practices may have in shaping or promoting certain types of selves will be highlighted. The final two chapters will then discuss the implications and conclusions of the research not only in what they make visible, but what they may allow for in future research.

The next chapter will proceed to the literature review. 


\section{Chapter: Literature Review}

This chapter is meant to help locate the research project in relation to the broader literature on organizations, library work and identity formation. It will begin by situating the study of the public library and library work within broader relevant literature within the study of work and organizations. Then it will survey research on library work and public libraries. This will help differentiate what has already been done in the field with what I aim to explore in this project. Then the chapter will go on to juxtapose the intent of the research project with other works in organizational studies and identity work. In doing so, this chapter will help establish what gaps exist in the study of library workers and the formation of their work identities. Ultimately, this chapter aims to underscore alternate ways of approaching and investigating the implications of technological developments, organizational cultures and relationships with others in order to observe what practices promote the formation of certain identities and how, if and to what degree generation mediates these.

\subsection{Surveying the Context}

Studs Terkel (2007) states that "[work] is about a search, too, for daily meaning as well as daily bread, for recognition as well as cash, for astonishment rather than torpor; in short, for a sort of life rather than a Monday through Friday sort of dying” (p. 301). Underpinning this meaning of work, which is more than simply paid employment, is the dynamic relationship between workers and their employers, and the social, economic, psychological and political links between them (Kalleberg, 2009, p. 12). Thus, Terkel (2007) and Kalleberg (2009) recognize that the value and meaning of work is not simply about a paycheque, but is rather immersed in personal meaning and broader questions of 
organizational operation and the influences that guide the techniques that govern and manage workers.

Flexibility has come to be a critical term used to refer to not only the structure of organizations but in the way they should be - that is to say, organizations are looked at as needing to be responsive and flexible. Regini (2000) has interpreted a definition of organizational flexibility from Piore and Sabel, to refer to an ability to differentially combine the use of machines and labour in adapting to fluctuating market conditions ( $p$. 15). This language of flexibility filters into the way in which workers should come to act within labour markets. Further drawing from this broad definition above from Piore and Sabel, Regini (2000) describes labour flexibility as " [...] the ability to combine different components of the employment relation $[\ldots]$ " such as wages, skills, job security and work times (among other things), diversely (p. 15). While there are other types of flexibility, one should also note functional flexibility, which refers to a firm's ability to allocate the labour force from within an organization without having to access the external labour market (Michie and Sheehan-Quinn, 2001, p. 289).

Sennett (1999) also describes the concept of "flexible capitalism" under which "[w]orkers are asked to behave nimbly, to be open to change on short notice, to take risks continually, to become ever less dependent on regulations and formal procedures" (Sennett, 1999, p. 9). Flexible capitalism thus requires a certain type of worker-subject who can thrive under a regime of flexibility. For workers, flexibility can:

[...] arouse anxiety: people do not know what risks pay off, what paths to pursue. To take the curse off the phrase 'capitalist system' there developed in the past many circumlocutions, such as the 'free enterprise' or 'private enterprise' system. Flexibility is used today as another way to lift the curse of oppression from capitalism. In attacking rigid bureaucracy 
and emphasizing risk, it is claimed, flexibility gives people more freedom to shape their lives (Sennett, 1999, pp. 9-10).

Here, Sennett (1999) draws attention to the personal consequences of work-how capital, through work creates an emotional response in an individual. These requirements of nimbleness, quick change and risk-taking then begin to affect one personally. The seemingly freeing nature of flexible capitalism might appear in one's outward relation to the labour market, in one's ability to move flexibly from job to job or a varied work schedule, but it concurrently creates personal unfreedoms in non-market and non-work aspects of life.

Here, it is worth noting that public organizations have mimicked private sector firms in the pursuit of newer efficiencies, performance, and greater productivity (Balfour and Grubbs, 2000, pp. 575-6). Nowhere is this clearer, than in Osborne and Gaebler's (1992) Reinventing Government, which openly advocates for public organizations to become more market-oriented, entrepreneurial and flexible. The public sector's drive to accept private sector organizational change is well recognized in the concept of New Public Management, a movement to reform the bureaucratic style system to a leaner, efficient and results-oriented government that is less involved in service-delivery (Lowe, 2001, p. 5); it has come to play a significant role in the public sector. Five critical characteristics of New Public Management include:

[...] (a) social progress through economically defined productivity; (b) application of sophisticated technologies to improve productivity; (c) a labor force disciplined in accordance with the productivity ideal; (d) management as the key player in achieving greater productivity; and (e) managerial flexibility or the "right to manage"" (Politt, cited in Balfour and Grubbs, 2000, p. 576). ${ }^{5}$

\footnotetext{
${ }^{5}$ I must note here that I derived this cited passage from Balfour and Grubbs, 2000, p. 576 and not from Politt's original source.
} 
Of particular note is the discussion underscored by the second characteristic, the application of sophisticated technologies. As has been mentioned above, the effect of technology as a tool to replace labour is not a threat to be easily dismissed since as Regini (2000) has noted drawing from Piore and Sabel, the use of machines can be used for the purposes of organizational flexibility (p. 15) - something that will be featured in this project. Technology, it has been argued, has expedited organizational change and public service has been improved (Lowe, 2001, p.19).

Technical innovation as a replacement for labour, however, is not a new phenomenon. Braverman (1998) has noted that "[a] necessary consequence of management and technology is a reduction in the demand for labor" (p. 163). Regardless, Aronowitz and DiFazio (2010) note that "[...] the technological revolution of our time should be understood as leading a vast change in the way we work, how we address social issues, and the ways we spend our 'free' time" (p. xii). Knowing this, it is important to realize the impact that technology has on work. Thus, technology as a replacement of labour has a significant impact, particularly in considering questions of flexibility in public organizations.

The next section will look closely at how this context fits within the ongoing conversations in library work and identity literature, aiming to locate this project in the broader discussion. 


\subsection{The Study of Library Work and the Formation of Working Selves}

\subsubsection{Studies in Library Work}

Public libraries, which are in themselves public organizations, have not been immune to broader changes in political economy and public organizations, due to social spending cuts, the pervasiveness of information technology and the changing nature of library work (Stevenson, 2011). Much has been written about flexibility in library workplaces and how flexibility can be entertained in library workplaces (Walton, 2007; Goulding and Kerslake, 1996a). Kerslake and Goulding (1997), using quantitative and focus group approaches, examined the needs of "flexible information workers," who are not always seen as "real workers" as the discourse surrounding them "[...] constructs [them] as being less committed, less ambitious, as generally lesser workers, than their full-time colleagues" (p. 136). Flexible workers and fulltime workers also have differing reasons for working, and consequently, it is argued, managers should be aware of their needs and requirements in managing them (Goulding and Kerslake, 1996a) and moreover, management should update management techniques to appreciate the benefits and pitfalls to flexible work (Goulding and Kerslake, 1996b). Others have discussed the challenges that flexibility brings to service delivery (Hannabuss, 1998) and the impact flexible work practices in library and information service work has on the relationship to work-life balance (O'Brien and Hayden, 2007). Thus, there is a broad discussion about the implications of flexibility on library and information workers, yet, lacking here is a more in depth discussion in what these changes produce within individuals who work and what practices permit ongoing transformations. 
There has also been a discussion about library work and technology. The discussion has included topics related to technology inside and outside the workplace, yet further research looks to be required in demonstrating the influence of technology replacing routines and tasks in the workplace. Spacey, Goulding and Murray (2004) have explored characteristics such as gender, age, organizational variables, computer skills and experience as well as the influence of others to see how library staff's perception of the internet have been affected. Technology, thus, comes to play a critical role in the structure of the workplace, and ultimately work-related tasks. The accelerating rate of change has created pressures to flexibilize as "[n]ew technologies which might impact on services, such as blogs, wikis, Windows 2.0 , portable devices, wireless and e-books, are arriving regularly" (Walton, 2007, p. 167). Rapid technological change can come to play an important role in creating pressure in the library workplace for workers. O'Brien and Hayden (2007) note that increased user and workforce expectations have been reflected in the flexibilized library workplace because of "[...] increased user and technological requirements, gender factors and extended opening hours" (p. 222). Walton (2007) highlights that flexibility in library work has brought to the fore worker "[...] concerns about loss of professional identity and coping with increased change and stress" (p. 169). In discussing questions of identity, it is worth noting the use of the term "library workers." Stevenson (2011), for example, in one specific example, notes a discursive shift present in one particular Ontario library policy document, which discusses library labour and this is ideologically significant. Stevenson (2011) states that " $[\ldots]$ when labour is mentioned, generic labels such as 'library workers', 'staff', and 'volunteers' are used in place of the formal designation of "librarian"' (p. 784). This point is significant 
in two ways. Firstly, it suggests a broader ideological trend of deskilling and deprofessionalization associated with librarianship. Secondly, while the term "library workers" may obscure the role and position of a librarian, it at the same time acknowledges the reality that other workers are required in maintaining public libraries and that the labour of these individuals are important. For example, pages or book shelvers, clerks, clericals, librarians as well as cleaning staff all play a role in the operation of a public library. Consequently, this text implicitly glosses over the significant contribution of these other workers. Stevenson (2011) does discuss the role of librarian professional identities, but her study is limited in its scope partly because it does not directly engage with librarians or their experiences; her research is much more policy oriented in nature. It is, however, theoretically grounded in the French regulation school. Thus, there is theoretically grounded library work research in the literature. However, as has been demonstrated in the theoretical framework, I want to use an approach that is influenced by poststructuralism, in order to examine the processes and techniques that promote certain ways of being and capacities within individuals and further require them to engage in processes of self-transformation.

On a different note, the role of and the impact on the public is also acknowledged in the literature on library work. One study of two Norwegian cities has indicated that public response to change in the public library is not negative, but if institutional (public library) change deviates from core values associated with the public library such as noncommercialism, universalism, literacy promotion and democracy, “[...] it might affect the legitimacy of public libraries negatively" (Evjen and Aududson, 2009, p. 172). In reference to these core values, Kerslake and Kinnell (1998) have noted that public 
libraries have a critical function to play in promoting citizenship and democracy (p. 166). Furthermore, Leckie and Hopkins (2002) have argued that ideological shifts and not information technologies threaten the role of large central libraries as important public places (p. 360). Stevenson (2011) has also described discursive shifts in the identity of library users, from patrons, to customer to "information producer-consumer." This appears to suggest that the public's relationship with the public library and their perception and use of it have an important role to play. After all, users are catered to in service delivery. The result of these suggests that the relationship between the needs, uses and perceptions of the public or users of the public library is important to study in relation to identity. Moreover, the library as a public place for use by the public is also important to consider.

Other aspects of the literature on public libraries have looked at the gendered nature of library work and gender implications (Jones and Oppenheim, 2002) and the role that Black libarianship can have in combatting racism (Durrani, 1999). In these two cases, critical questions of identity are raised, whether in relation to gender, or to race/ethnicity/racialization or heritage. The impact of violence in library workplaces on workers by library users is also examined (McGrath and Goulding, 1996). A study from the United Kingdom in the late 1990s has also explored the qualities that the library and information services sector sought in workers. Unsurprisingly, their research revealed that the qualities most in demand of potential workers were " $[\ldots]$ the ability to accept pressure and flexibility" particularly in relation to economic, political, technical and social changes in the sector (Goulding, Bromham, Hannabus and Cramer, 1999, p. 220). These are linked to questions of identity as well, particularly in the relations workers may 
have with those whom they serve. The literature here is rather policy oriented, in that it defines problems and then suggests solutions that may be used to ameliorate said problems. Thus, while there is much in the literature in relation to study of identity, it does not appear to significantly delve into how library practices and discourses can actively shape, alter or impact the formation of working selves.

Furthermore, while the literature as surveyed in this section has highlighted the diverse nature of library research and while many of the themes I want to investigate have been explored to some degree, what I seek to accomplish localizes the study of labour within a specific public library system - Toronto Public Library. By examining Toronto Public Library as the site of study, and engaging with workers directly, the particular complexities of this one organization will percolate to the fore. This will allow a nuanced investigation of identities, generational prompts and a complex public organization.

\subsubsection{Forming Working Selves}

Sennett (1999) examines the structures which help to shape and discipline an individual in one's relation to work, and how this relationship with work comes to define one's own mental and personal wellbeing. To this end, Sennett (1999) reveals not only the type of worker that capital requires, but its effect on individual workers as well. Sennett (1999) notes two character traits that are required of the modern worker: "[...] the capacity of letting go of one's past, [and] the confidence to accept fragmentation [...]," but " $[\mathrm{t}]$ hese same traits of character begetting spontaneity become more self-destructive

for those who work lower down in the flexible regime" (p. 63). Moreover, Sennett (1999) notes that people's connection with work erodes as those on the lower strata of 
flexible work come to identify less with the work they do. One's place on the labour hierarchy ladder matters in this regard. Sennett (1999) also highlights the prevalence of risk in which contemporary capitalism creates " $[. .$.$] an anxiety about what might happen;$ apprehension is created in a climate emphasizing constant risk, and apprehension increases when past experience seems no guide to the present" (p. 97). Thus, Sennett (1999) discusses some of the personal consequences of work and the way in which workers come to engage with their work; it is the environment in which they work that comes to shape and demand these attributes. Accumulated experience of workers also appears undervalued (Sennett, 1999, p. 94). While Sennett's (1999) powerful and persuasive prose opens the door to exploring changing labour practices and the consequences they may have on the individual, his exploration is overly broad and is perhaps best viewed as a cursory exploration of the personal consequences of work in shaping the lives of individuals. It nonetheless provides a useful starting point in locating some techniques that should be further examined.

Sennett $(1999 ; 2006)$ and Lowe (2001) both note that older and younger workers have different expectations of their workplace and react differently to changes. For example, Sennett (1999) states:

Older experienced workers tend to be more judgemental of their superiors than workers just starting out. Their accumulated knowledge endows them with what the economist Albert Hirschmann calls the powers of 'voice,' which means older employees are more likely to speak up against what they see as bad decision-making. They will more often do so out of loyalty to the institution than to a particular manager. Many younger workers are more tolerant of taking bad orders. If they become unhappy, they are more likely to quit, rather than fight within, and for, the organization (Sennett 1999, p. 94). 
Here, the concept of accumulated knowledge is closely connected with the length of experience of workers. Similarly, in government work, workers of all ages look to have their needs met at work:

Generally, speaking, there is no unique set of 'youth' work values. However, young workers have always been more footloose and inclined to leave if their aspirations are not met. In contrast, older workers whose expectations are unmet are more likely to stay, but their morale and job satisfaction will suffer. But these differences aside, workers of all ages want similar personal rewards from their work, making it essential that government employers meet the career aspirations of all workers (Lowe, 2001, pp. 33-4).

The impact of age and generation as factors in shaping working identities is thus a critical point to underscore and is something which, I believe, needs to be developed further. In using these claims as hypotheses to test in this study, Sennett (1999) and Lowe (2001) provide a useful benchmark, to see if these claims necessarily hold true in Toronto Public Library, which I have pointed out throughout is a public organization that is layered with complexity in terms of technological implementation and organizational history.

From generation, one should look to organizational design for insight on how identity may develop. It is stated that " [...] even when young people do enter relatively fixed work pyramids, their points of reference is the fluid model, present-oriented, evoking possibility rather than progression" (Sennett, 2006, p. 79). ${ }^{6}$ Sennett (2006) underscores that an individual's sense of self can come to be shaped by one's place of work, its organization and its management. To a person's character, "[...] even while the value of working can remain strong, the moral prestige of work itself is transformed;

\footnotetext{
${ }^{6}$ Sennett (2006) evokes the work of Max Weber in describing the bureaucratic and militarized structures of work. He notes that "[a]s in an army, so in a big domestic bureaucracy, effective power is shaped like a pyramid. [...]As you move up the chain of command there should be ever fewer people in control; conversely as you move down, the less powerful people are, the more the organization can include. You are good at your job by doing that job and no other" (Sennett, 2006, p. 29).
} 
[labour] at the cutting edge disorients two key elements of the work ethic, deferred gratification and long-term strategic thinking" (Sennett, 2006, p. 81). Thus, the implications of contemporary capital have destabilized older notions of stability that were created by earlier modern forms of capital and bureaucratic structures and their effect on individuals. There has been a transformation to what one may have been accustomed in the operation of work.

Others have drawn from Sennett (1999) as well, and have applied his ideas to public service work and the effect New Public Management bureaucratic regimes demand (Balfour and Grubbs, 2000). Balfour and Grubbs (2000) examine the processes that are at play with regards to New Public Management organizational reform and the corresponding impact on individuals, offering some guidance in examining organizational reform in public organizations. The research here, however, is much more discursively and theoretically grounded and lacking a local examination of the impact of such reform on individuals. It should also be noted that Finnish welfare service workforce changes, gendered professional identities and impacts on trade unionism have had implications on the stability of work identities too (Henriksson, 2008) suggesting other factors that play a role in mediating identity in public organizations.

Other works have been influenced by the work of Foucault and poststructuralist theory in developing an understanding of questions of identity and the types of selves which come to be formed in workplaces. Du Gay (1996), for example, examines the role of consumption as being critical in forming an "enterprising self" at work in private firms. Sveningsson and Alvesson (2003) examine the inherent complexity of identity formation through examining managerial work identities. They note that " $[t]$ here are thus 
other, more personal sources of identity work than organizational discourses, social identities and roles" (Sveningsson and Alvesson, 2003, p. 1168). Research on call centres has also demonstrated how developing identities at work through workplace practices can also be means through which individuals can be governed (Winiecki, 2006; Winiecki, 2007; Winiecki and Wigman, 2007). The focus here has been in the private sector.

Context has also been shown to matter when conducting investigations about the formation of identity. Place, space and time filter and shape the production of working selves when workers receive and interpret managerial discourses, thus demonstrating how ubiquitously power operates within complex organizations such as the British National Health Service (Halford and Leonard, 2006). Moreover, Thornborrow and Brown (2009) have explored the role aspirational identities of British Parachute Regiment soldiers play in disciplining worker's identities and constituting them as "workers." This is a particularly interesting study because it effectively examines how identities are crafted through the self-disciplining of workers through an imagined notion of what it means to be the ideal British Parachuter. Through this ideal notion of a soldier, these Parachuters regulate and evoke change within themselves to encourage certain behaviours, aspirations and goals. The authors conclude their study by noting that "[a]n organization is a system of constraints that simultaneously discipline and enable the discursive identity strategies available to members" (Thornborrow and Brown, 2009, p. 372). Thus, through aspirational and ideal identities, this study reveals how within an organization one can work to develop oneself and become something which is needed or emphasized in the work environment. I similarly wish to translate some of these useful 
methods in relation to context and the role aspirational identities may play in the formation of working selves in public organizations.

Rouillard and Giroux (2005) use a different approach to study Canadian public administration reform. They explore the values and norms that guide public managers in decision-making, instead of through rules and regulations. To Rouillard and Giroux (2005) this indicates a broader shift from a disciplinary society to a control society, where rules and regulations are no longer the norm, but individual behaviours come to be guided by values and norms. Here it is suggested that such values and norms have the effect of opposing multiple work identities, and instead promote homogenous identities of civil servants that "[...] cannot be reduced merely to bureaucratic duties and responsibilities" (Rouillard and Giroux, 2005, p. 338). While this may be the case, I wonder what the impact of these norms and regulations are on individuals in practice. Thus, this study engages this notion of identity on a theoretical and textual level and does not proceed to investigate individual lived experiences of such managerialist norms. Nonetheless, the effect of organizational culture on worker behaviour comes to the fore, particularly in relation to public service work. My research then, helps to extend the scope of the study, by examining how organizational values may possibly be inculcated and used by workers in defining who they are and developing their capacities.

In discussing the development of individual capacities, Kelly, Allender and Colquhoun (2007) draw, in part, from Sennett (1999), Foucault and others to develop a certain workplace identity, the "corporate athlete" that appears through a health and fitness program within an information technology firm. Here, the role of identity comes to play an important role in understanding the "[...] ensemble of behaviours and 
dispositions which employees [...] [...] are encouraged, freely, to embrace" (Kelly,

Allender and Colquhoun, 2007, original emphasis, p. 281). Moreover:

[...] individualizing and normalizing processes in a globaliz[ed] risk society $[\ldots][\ldots]$ require those who wish to be positively identified as professional, entrepreneurial, resilient, effective, athletic (as descriptors of personhood) to do particular sorts of work on themselves-or suffer consequences such as retrenchment, insecurity, lack of career advancement" (Kelly, Allender and Colquhoun, 2007, original emphasis, pp. 281-2).

In this sense, certain identities and behaviours are encouraged within workers and if these are not freely cultivated within an individual, then potential negative repercussions may result. Ultimately, the pressures from external forces and capital come to demand certain types of workers. Here, what emerges is the notion of freedom and how individuals are given the opportunity to freely embrace certain behaviours or identities through workplace programs. In a similar way, I aim to combine approaches by Sennett and Foucault to examine not only the series of practices that emerge to shape identities in the public library, but the types of identities that emerge as well. Sennett also allows me to add depth to Foucault's approach by examining how identities may be further complicated through generational attributes and experiences.

Certainly research on the formation of working selves and work identities is quite diverse and developed. There has been much research on both public and private organizations and the techniques that are used to govern, manage and shape workers, and work identities. However, there seems to be a lack of research in attempting to bridge the gap between the study of library work and the techniques that are used to shape, guide and promote behaviour and work identities. It would further be worth asking: how would such an investigation on a personal level become more complicated through a 
generational study? Here, I am arguing that Toronto Public Library in particular is a complex organization where various practices that emanate from different sources, act to shape, alter and promote capacities within individuals. While the aforementioned studies use different approaches to study the formation of identities, this study aims to show how there is not a single source that shapes identity, but rather power relations operate diffusely allowing different selves to emerge in the workplace as different techniques promote different capacities and identities. Thus, the study of Toronto Public Library, will allow workers to describe what they see as shaping who they are, the techniques that emerge to promote certain capacities within them and if and to what degree their generational knowledge mediates these.

Therefore, it is the intention of this research project to narrow the gap between the study of work identities and the study of public library work, an institution and public organization that is identified with particular social and public goods, which is undergoing change through increased technologization within the workplace and technologization emerging as pressures from outside the organization. Moreover, the study of library workers, their generational experiences and attachment to their work, enables an investigation into how workers not only cope with change in their everyday work lives, but how they come to resist, interpret and enact discourses. It will also help to establish how worker's attachment to the social and public goods that their workplace provides interacts with changing organizational and labour practices in tasks and routines. Thus, the study of work identities of library workers will not only develop and enrich the literature on work identities and the study of libraries, but it will also seek to explore how workers come to interpret and enact discourses and practices that alter who they are and 
how these workers, who engage in different types of library work, interpret who they are when they do what they do. Moreover, engaging with workers and their experiences will allow one to understand how questions of identity are further embedded and intertwined in accumulated experience, organizational culture, workplace relations, organizational structure and change. It would examine directly and specifically with people who are at the heart of change, who actively resist it in their own ways, and who implement such change on their own within themselves and without.

The next chapter delves into the observation and analysis of this research. 


\section{Chapter: Techniques that Shape Identity}

Interviews yielded a wide range of information. Though, not all the data could be used in relation to this research project. Where I had once expected to find significant variation through generational differences, I soon found that there were more points of convergence than there were points of divergence.

Those from a first generation accessed a greater repository of accumulated work experience, particularly in terms of currently identifying with their work. Those from the second generation, may not access the same range or depth of organizational knowledge, but still use it in identifying with their work. Furthermore, it may be hypothesized that a critical event such as a strike may allow employees to develop greater solidarity and enable workers to reflect upon their work and their place at work much more dialogically with each other. This may have contributed to decreasing generational variation and may have had an impact on library staff recognizing or understanding shifting practices in similar ways. However, this is not a given.

In other ways, the generational division of workers seems artificial. While before amalgamation workers may have been part of a different library system with their own organizational cultures, after amalgamation residual elements of these cultures still appear to remain. Some aspects of these cultures may stay fixed geographically and in others, cultures may be inculcated or imprinted within individuals and as they move. Remnants of these past cultures move with them.

Beyond these generational differences, generational similarities that are worthy of examination in this research project also emerge. To examine how generation differentially affects identity and self in the workplace as well as how it may not be a 
significant factor in forming working selves, this chapter analyzes several common themes that emerged from the interviews. However, before delving into those themes, this chapter will discuss the role of the strike and its possible implications for this research project. It will then explore the specific importance of generation in this study. This will then be followed with an examination of themes associated with the workplace institution, organizational culture and its (dis)contents and the impact of technology in a bid to explore the implications of workplace discursive and material practices on identity.

\subsection{The Role of the Strike}

The role of the Toronto Public Library workers strike is consequential for the purposes of this study. While I sought to examine issues in interviews that did not include the recent strike, it became apparent that this was largely an important event in the experience of some of the workers I interviewed. This event occurred during the research process and in my attempts to solicit participants for my research project, it became clear that the strike played an important congealing role by establishing within the minds of some staff a sense of place, a sense of belonging, and a continued recognition of the ongoing changes in workplace practices at Toronto Public Library. Reasons for the strike have appeared in the press. As I have mentioned before, these at least in part, appear to be related to questions associated with job security and a shift to part-time work and one of the provisions of the contract that expired on December $31^{\text {st }}$ stipulated that " $[\ldots]$ no permanent library worker could be laid off in the event of outsourcing or technological changes" (Dale, 2012). Thus, on a superficial level at the very least, one could see how questions which this research project is exploring could be identified through issues related to the past labour dispute. 
The strike therefore is an issue that was largely unavoidable during the interviews. It revealed the extent to which questions of identity came to be filtered, cultivated and transformed because of this important event. Not all of the participants felt strongly about the strike in the same way, nor did all participants discuss the strike in the interview. However, most of those who discussed it strongly indicated that the strike was an important moment to reflect upon one's work-life narrative and one's position within the working organization. It is with this in mind, I want to open the analysis in this chapter. The strike became a tool of solidarity, unity, and helped workers reflect on the coherence of aspects of their own identity and attachment to work.

It [the interview] comes at a good time for me because it's after the work, the strike. [...] l've been thinking a lot about the library. [...][T] he strike really made me think a great deal. [...] And not only about what our organization, but about the bigger picture, it's made a big difference to me. Comes at a good time for me (Interview A, $1^{\text {st }}$ Generation).?

This is where the strike was really good for us. Like, that's a horrible thing to say, but it brought everybody together for one core reason [...] (Interview D, $2^{\text {nd }}$ Generation).

The strike's occurrence during and around the time of interviews then presents itself not only as a challenge to this research project, but it also adds another layer of complexity. It is ultimately difficult to disentangle this important event from the circumstances which I sought to explore in the interviews. The strike, whether directly or indirectly, still plays an important role in the research of this project. From the excerpts above, it shows how on the one hand there was a personal reflexive impact of the strike on issues of work and identity and on the other hand there was a larger perceived group identity impact.

\footnotetext{
${ }^{7}$ I have used a different font for interview excerpts to differentiate them from large block quotes derived from literature citations.
} 
In another manner, the strike has the potential to cut across views of the workplace and workplace change generationally. It might be something which allowed workers to converge their views on their workplace through a similar lens. Crucially, the strike may be something on workers' minds as a recent event, influencing their perspective and decreasing the differentiation one might expect from two generations of workers. To this, the variation I had expected between these two groups of workers that I had categorized were not as great as I had initially expected.

\subsection{The Importance of Generation}

A study of generation did reveal that the first generation of workers drew significantly from their vast past experiences in the library systems of the former Metropolitan Toronto area. While this was not the case for everyone, these workers have discussed at length a history of what their workplace was like in previous Metropolitan Toronto library systems - each former municipality had its own independent library system in Metropolitan Toronto and they had not yet been constituted as one city library organization until 1998. For example, one worker stated:

So the experience that I had in Scarborough is nothing like the experience of working for Toronto Public Library now (Interview B, $1^{\text {st }}$ Generation).

Another was able to express their feeling when amalgamation happened and the impact it had on their lives. They were able to recall how before amalgamation their ability to transfer from one area of the former Metropolitan Toronto to another to work in the library was unlikely. Amalgamation and the formation of Toronto the megacity, and a unified Toronto Public Library allowed them the freedom to move from one side of Toronto to the other. Here their description of Yonge Street is a reference point 
indicating the street running through the middle of Toronto, signifying how limited movement was pre-amalgamation.

So I was very excited when there was amalgamation. I was desperate, I was dying to get west of Yonge Street. [...]And [I] just did not want to stay east of Yonge Street anymore thank you very much (Interview A, $1^{\text {st }}$ Generation).

While there was a rich repository of knowledge and experience for these workers to access, not everyone from this group of workers was entirely attached to or nostalgic for the past. Instead, in one case, a participant was much more present-oriented. This suggests that not everyone is socialized in the same way through their experiences. Each of the workers from the first generation had come from different library systems before amalgamation, but not all of them had left the library system/region that they had initially worked in prior to amalgamation.

One of those interviewed delivered a strongly detailed experience from working in the Scarborough Public Library before transferring after amalgamation to another part of the newly merged Toronto Public Library; the old library systems had been reorganized into regions within the new Toronto Public Library. This staff member's story is important to consider because it begins to illuminate questions about how important the role of accumulated experience plays in day to day tasks. It also starts to suggest the importance of organizational culture which had developed in the workplace and how the worker comes to view that past work relationship with the organization. Here the worker stated:

So the concept that Scarborough Library formulated was you don't need a Master's degree to sing Skinamarink to children. You don't need a Master's degree to check books out, and you don't need a Master's degree to look stuff up in a medical dictionary, a Scott's Directory, like basic reference tools, right? So the smaller branches were designed to be standalone, they had good collections with a little bit of everything, so you never walked out empty handed. There was a huge emphasis on storefront. Very tidy shelves, 
everything shelved on time, good collection, well developed thoughtfully maintained, carefully weeded, and so the people that they brought into the library tended to have bookstore or retail backgrounds. And the clerks were hired to carry out that mandate (Interview B, $1^{\text {st }}$ Generation).

By highlighting this accumulated knowledge, the worker was able to describe how the organizational culture and practices in their past work organization at Scarborough Public Library were, and was then able to juxtapose this knowledge with their current situation. They indicated that not all tasks required professionalization of staff. In brief, the worker noted that the unified Toronto Public Library had changed job responsibilities of staff, where the variation in tasks conducted by Scarborough clericals had been reduced:

So what I've seen over the evolution of the new City is that all of that work, except for checking in and checking out, peeled away from the clericals... (Interview B, $1^{\text {st }}$ Generation).

Thus, with this past experience of working in a system that became part of larger whole, the library worker was able to juxtapose the range of duties that have shifted in the new organization. The ability to describe experiences that date and pre-date a specific event like amalgamation permit the lens of generation to be particularly useful. Here the role of generation is important because it highlights shifts in organizational practices. It also opens the door to discussing issues related to the roles and scripts associated with identity work and describes how techniques that produce identity regulation have changed over time. Finally, accumulated experience describes how the relationship with one's place of work has changed over time - how one identifies with one's place of work.

\subsection{The Workplace Institution}

One area of convergence between generations of workers was that of the value that staff placed on their place of work, the values it espoused, or the very essential characteristics which their place of workplace expressed through their own work. Of 
critical importance to a discussion on identity and the common threads that run through these generations of workers is the value placed on the site of work. The public library is seen as site of democracy, equality, social mobility, information sharing and the helping of others. This appears linked, at least to some degree, as a motivator in a decision to be employed in such an institution and public organization. It was not made evident that these notions of organizational culture were necessarily linked to Toronto Public Library's (2012b) mission and values. Instead, workers revealed this to be a purpose attached to the work they were doing and the broader implications of the work they do within the institution of the public library. This in itself is not an example of organizational culture, but of the imaginary associated with the public library which goes beyond the organizational culture or managerial discourses. At the same time, it also provides a critical reference point for workers in their understanding of who they are, and how they identify with their work and their organization broadly and in particular. Here are five excerpts from five interviews:

I think libraries are necessary. I think, it's just, it serves a need to have a repository of information and knowledge, [inaudible] preserves the need to have a venue where people can come to study and to learn from each... as well as to learn from each other. Not in a classroom setting as in with the entire school system which is an amazing thing. Not in, in a non-academic way. Because honestly, what is the library? It is the mode for lifelong learning. It's spectacular for that. [...]l can't imagine that [...] [...]the human being will ever not require the mode of lifelong [learning]. [...][P]ublic libraries are just, to me, they level the playing field. They don't even need anymore praise than that. We level the playing field. Do you understand what that means? (Interview A, $1^{\text {st }}$ Generation).

[...] [O]ne of the things that libraries do is provide a democratic, universal access to all and every kind of information. And if you're not doing that, then you're failing as a library (Interview B, $1^{\text {st }}$ Generation).

I was really pumped up at CLA [Canadian Library Association Conference] because they had some good speakers talking about, in particular, how important libraries are for people in the city who are not like rich, upper-middle 
class people like the role they [libraries] play in social mobility and education and non-regimented learning (Interview $\mathrm{C}, 2^{\text {nd }}$ Generation).

[...] [L]ibraries were set-up first, in the first thing [...] [to be] [...] an open free service open to the public to educate to bring in literacy (Interview $D, 2^{\text {nd }}$ Generation).

Information, helping, you know, helping people, [being an] information resource (Interview E, $1^{\text {st }}$ Generation).

These descriptions and visions of what library work entails and what the institution of the public library represents or nurtures help ascertain the values workers place in the work that they perform within the institution and the values associated with such work. This perception is important because it constructs an image of what the institution and the workplace are; it creates an idealized, platonic perception of what library work should be seeking to accomplish. However, it is not entirely clear from where this notion of what a library is develops, and what the values that are inscribed within this imagined notion of the public library are. For example, the notions of what a library is, and thus what one's work is fundamentally composed of may be derived from managerial discourses. One means to establish what composes these discourses is by examining the organizational vision and mission. Here the organizational vision of Toronto Public Library can be seen in the following light:

"Toronto Public Library inspires the spirit of exploration, the joy of reading, and the pursuit of knowledge for people of all ages and backgrounds, beginning with the very young.

"As cornerstones of their neighbourhoods, our libraries connect people to each other, to their community, and to their hopes and dreams.

"Our rich resources provide the opportunity for everyone to treasure the past and to create a future that is full of possibility.

"The Library promotes and enriches the democratic, cultural, educational and economic life of our diverse and evolving City" (Toronto Public Library, 2012b). 
Similarly, one can see the organizational mission:

"Toronto Public Library provides free and equitable access to public library services which meet the changing needs of the people of Toronto.

"Toronto Public Library preserves and promotes universal access to a broad range of human knowledge, experience, information and ideas in a welcoming and supportive environment. New technologies extend access to global information beyond library walls.

"The Toronto Public Library upholds the principle of Intellectual Freedom.

"Effective partnerships enhance library service throughout the city. Toronto Public Library is accountable for the effective management of library resources and for the quality of library service offered to the people of Toronto" (Toronto Public Library, 2012b).

Toronto Public Library also has organizational values. These values include:

accountability, creativity, equity, integrity, being "participatory", respect, vision, service orientation and intellectual freedom (Toronto Public Library, 2012b).

While such managerial discourses exist, it is also possible that such interpretations of what one's place of work is can be developed in other areas. For example, professional conferences might be one such place where such notions develop. How one experiences a library, how one's use is anchored in time, past or present, and the types of services one might access may lead to variations in a person's perception or image of what a library is (Evjen and Aududson, 2009, p. 164). Furthermore, as has been noted before, a Norwegian study noted the importance placed on "traditional public library values" such as non-commercialism, universal access, literacy promotion, and democracy by respondents, which if libraries shifted away from would attack their legitimacy as institutions (Evjen and Aududson, 2009, p. 172). Similarly, others have noted that libraries not only promote citizenship and democracy (Kerslake and Kinnell, 1998, p. 
166), but have historically played a role in allowing working and middle class persons find recreation and self-instruction (Kerslake and Kinnell, 1998, p. 161). Moreover, community librarianship has also been seen to play a role in allowing marginalized persons to participate more fully in society (Kerslake and Kinnell, 1998, p. 162).

Thus, the roles of the public library, and what they provide to others, are tempered through many things. They may be derived from how one experiences work, how they may understand its role through professional organizations, how users perceive of its role and how they have developed historically. In the case of Toronto, public discourse from the TPLWU strike and the City of Toronto budget deputations may have also contributed to developing, altering or enhancing one's perception of the institution of the public library and/or library work.

The images ascribed to organizations can play a significant role, particularly in the mediation of action, or the type of action, and the sentiments associated with one's place of work. How these organizational narratives which can be used for identity work and identity regulation is not easily deducible. It would, however, not be surprising to unearth that such an organizational culture narrative to be developed from a merger of different sources, a conflict between sources or developed through a syncretism of or negotiation between these various sources. Thus, as has been noted in the theoretical framework, it is never entirely clear how our understanding of things emerge; knowledge reproduces itself and creates itself in different ways.

Sennett's (2006) discussion about paid public service workers is particularly relevant in discussing why one would attach such value to a work environment such as the public library, one which is not privately held, but accessible to citizens as a public 
service. Sennett (2006) here notes that for a generation, British public service health workers had not only their institution derided as being inefficient but the workers were demeaned as well. Despite the attack on these workers, it was found that status played a key role in keeping immigrant bedpan changers working in the National Health Service and kept them from moving to the private sector for higher wages: "The purpose of the National Health Service- -health care for all-elicits the respect of most Britons; for these immigrants, the institution gave them a positive institutional place in British society" (Sennett, 2006, p. 190). Similarly, in asking members of the civil service why they continue to work in the public sector, it was noted that there was " $[\ldots]$ more recognition for one's work in the public than in the private realm" (Sennett, 2006, p. 191). Thus, what emerges from public sector work is that the purpose of an institution matters to the public at large, and this confers meaning to workers (Sennett, 2006, p. 191). Thus, one might infer that the purpose of one's work, which may be imagined, or which might be developed discursively, can be critical for why commitment to one's organization arises, particularly in knowing that there is a social good in serving the public in that work.

These discursive practices then, serve as an important frame of reference for workers by providing a foundation of what should guide the composition of their work and to them may serve as a vision for what they see should be done at work. It may play a strong role in how workers come to be attached to their organization and it certainly gives reason to how they identify with their place of work. It also suggests a role for identity work and identity regulation, as managerial scripts and discourses can come to be seen reflected within the expressions of workers in the value they place in the work they do. 


\subsection{Organizational Culture and its (Dis)contents}

Drawing from staff understandings of value placed on their work, it is worth examining organizational culture. In this section, there are examples of discursive and material practices ${ }^{8}$ that exist in and around the workplace, but may either be specific to particular regions or the larger Toronto Public Library as a whole. In a sense, regional cultures exist as remnants of previous organizational cultures. In a large organization such as Toronto Public Library, one would expect there to be a strong organizational culture, especially in light of the fact that it is a public organization. Though, keeping this in mind, with changes occurring in pubic organizations, a tension between the logic of efficiency and outcome-based performance is in tension with traditional public administration values and "[...] a respect for the democratic processes" (Rouillard and Giroux, 2008, p. 331). Organizational cultures can be a set of norms which can be used to alter individual behaviour (Rouillard and Giroux, 2005, p. 332). Organizational control, then, may be achieved through organizational culture, through managerial discourses, by providing scripts, discourses and roles, which individuals must be prepared to take on to be a member of an organization. As workers become more attached to organizational identities, identity regulation, one of means through which an organization may inculcate its own members, enables identity work and allows workers to engage in processes of self-transformation and the like (Alvesson and Willmott, 2002, p. 625). In the interviews, a participant from the first generation of workers noted the variation in organizational culture in the current Toronto Public Library. Here, the

\footnotetext{
${ }^{8}$ Though these are material practices, it should be noted that they are mediated through discourse in the interviews.
} 
participant describes the cultural traits that the different regions within Toronto have.

Each of the regions is largely composed of one of the former library systems from before amalgamation and in the case of the two smallest municipalities, York and East York, they were incorporated into other larger regions instead of standing on their own as independent regions within Toronto Public Library.

Toronto Public Library prefers to imagine that we're all $99-98$ branches now? Just all the same. We're not. We're nowhere the same. North has got a culture. South has got a culture. East and West are quite different. You know, really, really different. And old East York and old York, some of their branches were more kinda South-y, some of them were kind of more North-y. [...] North has got a much more corporate attitude they always have. South is much more "we the people" (Interview A, $1^{\text {st }}$ Generation).

In comparing this with another worker from the second generation of workers:

[...] / think any organizational culture is a number of different cultures. [...] [E]very branch I've worked at has had a different culture. It's had a lot to do with whose in... who, just who works at the branch. Not just the manager, not just the person who, you know... it's... it's a different personality, it's the branch... [...] and the different regions of the city, partly because this is an amalgamated system [....] [...] There's a lot of people who feel that there's just kind of been an organizational culture that was the organizational culture of one particular pre-amalgamation system that was then kind of imposed on everybody else and the last 15 years has kind of been changing things to get it more towards that one particular culture where a lot of the senior people who are still running the system came from (Interview $\mathrm{C}, 2^{\text {nd }}$ Generation).

With these two excerpts, the impact of generation seems to develop a clearer picture of the impact of organizational culture at Toronto Public Library. One worker notes how the organization has seen different regions develop, each with its own organizational culture. Yet, a worker who joined the organization after amalgamation, notes an intermixing of these cultures. As these separate library entities merged, workers who are acculturated with particular organizational roles and scripts transport aspects of these identities with them. Generational understandings of organizational cultures, then, may 
help develop a narrative as to why there might be such fragmented identities within the larger organization.

However, organizational cultures may clash, particularly as organizations are merged, new identities may not emerge or congeal in a new successor organization. Thus, it is worth noting Balfour and Grubbs (2000), who are concerned that: [...] fundamental transformations in public-sector agencies initiated as part of reform agendas may destroy important social attributes of public agencies, thereby weakening the sense of personal attachment held by individual workers. We expect that, as a result, public employees are experiencing a loss of identity, with their very notions of self and their organizational community lost in the noise of the change process (p. 580).

Even with such great changes taking place within public organizations, including public libraries, some may see work practices from the past preserved through the protection of past work practices which may preserve remnants of past organizational cultures. For workers from a previous generation, they may view the past with some sense of nostalgia. One worker compared the current Toronto Public Library organizational culture with the one with which they were most familiar from their past and it is here they noted how past organizational cultures fostered a different relationship with the worker. One worker strongly emphasized this point:

But a friend of mine described it this way: when we worked in Scarborough, if somebody [...] [...] came to us and said, we wanna implement e-books and here's how we wanna do it. The management would actually come to the staff, and say what do you think? And they would come to staff meetings, or they would ask the supervisors to take it to the staff, and the staff would say, well it means, this and this and this, and here's the good stuff, and here's the bad stuff. [...] And they would say, we hadn't thought of any of those things. That's true. And then they would come back with an amended proposal based on my response. And now, I'm just told... [...] Like there was a consultative culture and we were cranky. [...] You want a true opinion, you asked a bunch of crabby library workers. But... but we were all invested as a group in providing customer service (Interview B, $1^{\text {st }}$ Generation). 
This seems to reinforce Balfour and Grubbs' (2000) argument about a loss of organizational community at work in the process of predecessor library system merging into Toronto Public Library. For the worker discussing Scarborough above then, this denotes a drastic shift in organizational culture for them from a consultative one to one that is closed.

Another worker described the current state of work practice changes where new practices, tasks or procedures appear in the workplace.

A lot of things suddenly appear (Interview E, $1^{\text {st }}$ Generation).

Further, this worker noted that they attempt to have their say in changing workplace practices, but such an act is essentially meaningless:

So yeah, we will bring it up and say, "this doesn't make any sense," but there usually isn't any recourse after that. Like it doesn't go back up the chain because it's already been decided. It's come down to us and that's it (Interview $E, 1^{\text {st }}$ Generation).

The relationship between staff and workers, as portrayed by this worker, underscores the consultative nature of library organizational culture before amalgamation in Scarborough, however, in one key phrase, the worker notes "[a]nd now I'm just told..." revealing the new type of organizational culture where one is required to simply do what one is told. This relationship with the worker and its changing dynamic has an impact on workers, which will be explored later on, but from it emerges Billett's (2006) conceptualization of subjectivity that is associated with procedures, values and beliefs that are in part nonconscious but become conscious when their experiences do not fit with their expectations (p. 6). Here, the worker as subject highlights the discontinuity associated with the changing organizational norms and how drastic this turn has been in their experience. Further emerging from this is the relevance of organizational culture in having an 
educative purpose; the impact of workplace practices on individuals requires them to reflexively think about what they value and how they must be at work. At this point, a tension arises in what the library worker is looking for from the workplace, and what the impact of such workplace practices can have on the self. Thus, the worker views the change in organizational culture, or rather the emergence of a norm which does not require employee input, instead requiring a worker who does simply what they are told.

Attempts to fashion a coherent organizational culture through workplace practices appear to be taking place in the library workplace. As one participant has noted, they think that Toronto Public Library is attempting to standardize the way things are handled in the workplace by instituting common practices throughout the workplace.

The processing and the way that books [... and ...] materials are handled and processed. They've been trying to standardize that [...] [...] for the workers [...] (Interview E, $1^{\text {st }}$ Generation).

The greater organization attempts to standardize the work environment, which may be attempts to construct standard norms and foster an organizational culture. Within Toronto Public Library, it seems as though some staff resist from fully materially integrating with the broader organization and its standardized processes. One participant from the second generation noted the following:

How they process the paperbacks. You're only supposed to stick the barcode on and letter, right? So, this is the Danielle Steele's paperback. There's barcode "S". No "Romance", no "Mystery" [labels], no nothing. So we would do that in one branch that way, l'd go to the South for extra hours and they, and they'd be like no, you have to put a marker line here, we want this label... like it was to... I'm like what? We're not supposed to do it that way. We don't care that's the way we're doing it. There's a lot of we don't care[....] [...] So, yeah, it hasn't changed (Interview D, $2^{\text {nd }}$ Generation).

These inherited cultural practices within particular regions, or particular branches then, tend to remain, and for newer workers, who migrate from different regions, then, 
confusion as to how to go about working comes to the fore. On the one hand, the worker is required to do what they know is the "correct" way of following through with a task, but at the same time, the reinforcement of place and space within organizations create conflict in what one can do, and what the correct means of performing work is.

Workers have also noted-and this transgresses generations-that the library organization culture is such that there is little space for workers to be able to control what happens in the workplace. This indicates an organization with strong hierarchical tendencies where decisions are made at the top and they are made to be enacted by front line workers. Some of these have already been mentioned above describing a tightly controlled decision-making process where front-line staff have little ability to influence how things are implemented. Others have recognized this to be the case:

These centralized decision-making that's made without any account or consultation whatsoever with frontline staff about what the potential issues might be is that's one of the things that has been the most shocking to me about working for the library system because I know from other jobs that I've worked in that other types of organizations that do not espouse the values the libraries do, don't operate in that way. They actually genuinely do consultations with them. They consult with their staff because they know that it's effective. And they know that if you're talking about things... because, you know, the bulk of the, the bulk of the staff are people doing front-line service in different kinds of branches all over the system. But we have a very, for lack of a better word, kind of Soviet-style Politburo way of doing stuff where, you know, we have a central committee and maybe there's a representative from the public service but it's just kind of like well we'll do this and this and this and then... (Interview C, $2^{\text {nd }}$ Generation).

Consequently, the impact of different organizational cultures interacting with those who are heavily invested in prior organizational cultures may lose their sense of attachment to a workplace that feels alien and distant from what they have already known. 


\subsection{The Impact of Technology}

The impact of technology on staff is varied even within generations of workers. On the one hand, the capabilities of computer information and communications technologies have garnered interest because of their ability to process and store large amounts of information quickly and efficiently " $[\ldots]$ overcoming the barriers of time and space [...]" (Cheng, Son and Curtis, 2010, p. 445). Braverman (1998) on the other hand, as has been noted before, describes the broader implications of technology on labour stemming from a logic of productivity: "[a] necessary consequence of management and technology is a reduction in the demand for labor. The constant raising of the productivity of labor through the organizational and technical means that have been described herein must, in itself, produce this tendency" (p. 163). Thus, the impact of technology has a larger impact on questions of the self, particularly when displacing labour. The impact of technology has not been uniform throughout the library, nor within different generations of workers interviewed. Library workers also appeared to embrace some of the new technological benefits of the workplace and even praised them. However, library staff interviewed largely noted that the introduction of new technologies in the workplace which may bring with it greater productivity and efficiency brings with it a reduction in staff.

There are two key examples of new automated technology, an automated checkout machine, and an automated check-in machine, both of which emphasize the self-sufficiency of the user, displacing much of the need for staff to check-in and checkout materials for the public. I will largely focus my attention on the automated checkout machine however. In describing the technology, one worker stated: 
Oh yeah, express check-out. Yes, we cannot call it self-checkout, we must call it express checkout. [...]When it first came out it was called self-checkout and then I don't know, people got upset or, they got... I don't know whether it was the patrons, or who got mad and then it, it was immediately express checkout and we never refer to it as self-checkout again [...] (Interview D, $2^{\text {nd }}$ Generation).

The discursive construction of the checkout machine draws forth an immediate impact on the self. The way in which the technology is referred to evokes certain properties. By describing it as "express," the impact of technology is deflected onto the user and the relative rate at which they can proceed in checking out their material. The "self" in selfcheckout, however, conjures forth a transaction that requires no other assistance than the person who is using the device. "Express" does not necessarily suggest the removal of staff from the process of handling material in the transaction; it rather emphasizes the efficient nature of the transaction. ${ }^{9}$

The implementation of this technology has led to some interesting staff experiences with the public. At a branch where the broader RFID technology was implemented, one staff member described interactions with the public that reinforced the precarity of library work with the introduction of automated checkout:

Do you know when you install RFID in a branch you know what people say to you is really intriguing. [...] Customers came in one after the other, "Oh I hope you don't lose your job off of this." They say it right to your face. "Oh I don't know if I should be using this system that's gonna eventually cost you your job?" Again and again (Interview A, $1^{\text {st }}$ Generation).

Another has stated:

I've had more than one patron say well does this [automated check-in and/or checkout] replace people? Of course we can't say anything. We say, it's an efficiency. They don't like that there's no [social] interaction. They say well "I

\footnotetext{
${ }^{9}$ Interestingly, in visiting a Toronto Public Library branch profile website for Cedarbrae branch, under the "Features" tab, one may find that the branch possesses "Self Checkout" (cf. Toronto Public Library, 2012c).
} 
have to check my own books out, now you want me to return my own books? When do I get to talk to you?" (Interview D, $2^{\text {nd }}$ Generation). ${ }^{10}$

In both of these cases, workers draw one's attention to the change in the relationship between staff and the public and at the same time, staff are under public surveillance questioning the implementation of these new technological changes on staff. This creates an uneasy atmosphere, where workers must confront those whom they serve with the reality that they are slowly being made redundant. Workers, as has been noted, are aware of this reality, but when being confronted in the public space orally, it adds a new pressure. By referring to it as "an efficiency," the impacts of such change are constructed to be limited discursively.

While the nature of social interaction has been changing, the social interaction associated with library work is one which will continue:

Well, there's still a need for personal interaction. That remains constant. [...] [I]t's more likely in every hundred transactions in the old days, more of them, the highest percentage of people [would be] "hey hi, how are you, here are my books", perhaps it's overdue, ... [...] "I'm going to checkout now, thanks a lot" big smile. Nowadays, when do you see a person at the counter, if they have an overdue. [...] ]f there's a problem with their account. If the frigging computer doesn't work. [...]And you know, that's hard on people. Because in the old days, you get a lot of good stuff and then you have some problems. [...]And most of these folks got into the biz, uh, pre-tech.., you know, at least earlier than this technology, and they were looking forward to these pleasant transactions (Interview A, $1^{\text {st }}$ Generation).

Here emerges the impact of generation, where the worker uses their accumulated knowledge to describe the impact of the technology on social interaction at work. This is not solely something workers from an older generation have the ability to highlight as a worker from the second generation has noted something similar about the change in their

\footnotetext{
${ }^{10}$ From the transcription, it was not entirely clear if the participant was referring to either one of the automated technologies or both, but it is clear that the participant is talking about the impact of either one of or both of these technologies. As is noted in the excerpt, the participant goes on to discuss both automated technologies.
} 
interaction with the public; though the description of why workers may have opted to work in the public library is further established.

Also of note here is the impact that the technology has itself on the type of worker that is being promoted with the use of such technology. Whereas work before the implementation of this type of technology facilitated a much different type of social interaction with the public, the implementation of express checkout fosters a much more muted relationship with the public as interactions are much more limited to problem solving. Being promoted here then is a reduction in the types of interactions that appear to be extraneous to what the worker should be doing at work. Implicitly, there appears to be a construction of the type of staff-public relationship before the implementation of such technology as fostering an inefficient use of labour resources.

Another worker from the first generation of workers, however, notes that despite the fact that the work one does becomes more limited, it frees up one's time:

[...] [A]nd all the tasks that we do, like you can't self-register, you can't self-pay your fines... those are the things you come to the [front or circulation] desk for. It just sort of eliminates a very small aspect of handling things. You know, handling the book [...] ...[I]t [the automated checkout terminal] frees up a certain amount of time [for workers] [... and...] if you're doing your job properly, there's really not a spare moment in the day to like not do your work (Interview E, $1^{\text {st }}$ Generation).

Furthermore, it was stated that:

[T] hat's what I meant about the freeing up people's time, too. It's like, it would... we need to have some of our time freed up so that we could pass on the information [about services the library has to offer] to the custom... to the public... (Interview E, $1^{\text {st }}$ Generation).

In particular, the worker noted that by being made free by reducing some forms of work, allowed them to interact with new users, namely newcomers of the public library, 
introducing them to services that they would be unlikely to know the library provided otherwise.

An interesting point is raised by another participant on the uniformity of service that technology such as a self-checkout brings stands in contradistinction with the previous worker's claim to being made free. This worker, from a newer generation of workers highlights that because technology acts to standardize transactions, this can be detrimental to marginalized groups because of a lack of variation in the way difficult situations can then be addressed:

But I think that, I guess my, my big concern and this isn't based on... this isn't based on evidence, is that [inaudible], it's based on more my instincts which is that when you replace the techno... when you replace staff who can respond to a context with a machine that works in one particular way, the people who are most potentially harmed by that are people who are already marginalized, which are people like the elderly who might not be comfortable with computers; disabled people, who might have difficulty using the machines in the first place; children; newcomers; people who don't..., you know, non-English speakers; and I... like I... I feel that the, you know, as kind of a service that helps middle-class people save money on books I'm sure the library is popular. I mean, that's a major use of it for me and I'm... I'm a middle class person who saves a lot of money on books through the library but I don't think it's really something that justifies your existence. I think that what makes it, you know I think if you, if you ta... you make choices that diminish the ability of marginalized populations to access your services when you're a service like a library, I think that has really long term consequences. It has bad consequences for society, it has bad consequences for the institution. And it's really against what I got into it for (Interview C, $2^{\text {nd }}$ Generation).

In this light, the use of such technical innovations in the workplace stand at odds with what was constructed by workers as representing the value of the workplace. As one worker sees new technologies as making staff more useful in constructing quality relationships with individuals, this worker worries that such technology may work against the values which they associate with the public library. The direction which technology 
might lead the library, then has implications for how one sees oneself identifying with their place of work.

It is interesting to see that the same technology can be seen by two workers from two generations in two different lights. It is not clear if this is a generational distinction as these claims were not discussed or reinforced by others. In both cases, their arguments align with the vision established of how a public library is envisioned. This demonstrates how one innovation in itself is packed with contradictory perceptions. Both view the importance of being context sensitive as being important in the function of library work as a public service. Thus, in one sense, the technical innovation reinforces the meaning associated with one's work, and for another, the value, the meaning and the reason for getting involved in the work is eroded through it.

In understanding that the impact of technology has different impacts on different individuals, it is noted that:

I absolutely don't believe that technology is value neutral. I think that the way that technology is used in organizations is completely encoded with a particular set of values (Interview C, $2^{\text {nd }}$ Generation).

While it was not made entirely evident what those values were, notions of efficiency, productivity and staff reductions were acknowledged themes that resonated throughout the interviews. This also reinforces the notion that the implementation of technical innovations are part of broader attempts to foster certain capacities within individuals. It is worth discussing actor-network theory (ANT) here which suggests the interconnection of the human and physical worlds cannot be separated where the production of knowledge is seen "[...] to be a joint exercise within a network that is spread across space and time and includes inanimate-e.g. tools, pens, computers, mobile phones, charts, machinery -as well as animate objects" (Edwards and Nicoll, 2006, p. 187). 
Subjectivity, then, resides in not only our relationship with others, but also includes human and non-human actors (Edwards and Nicoll, 2006, p. 187). These aforementioned networks may also be in flux, be shaped and re-shaped; some networks call on combinations of flexible workers and docile bodies, while others emphasize them separately (Edwards and Nicoll, 2006, p. 188). The importance of ANT, in brief, lies in making visible the interconnectedness of subjects, objects and space, which combine to form materially grounded and congealed networks (Murdoch, 1998, p. 360). Thus, it is through these networks, that one's subjectivity can be shaped. The impact of technology then, is to promote certain types of capacities within individuals in emphasizing the type of work that is deemed important and efficient and aims to modify the focus of workers in delivering certain types of services more readily. Through induction of technology, one can see how identity regulation is facilitated in practices (Alvesson and Willmott, 2002) as technology such as "express checkout" fosters certain ways of acting in workers and displaces older notions of what it means to engage in library work, as responsibilities are transformed because of technical innovation.

Further logic for the continued technologization of organizations is described by Dunleavy et al. (2005) stating that as extensions of New Public Management (NPM), one particular theme of digital-era governance, that of "needs-based holism," explains the reasons for increasing digitization and the implementation of information technology in public organizations. The result of such "[...] reforms seek to simplify and change the entire relationship between agencies and their clients" and further "[...] stresses the development of more 'agile' government that can respond speedily and flexibly to changes in the social environment" (Dunleavy et al., 2005, p. 480) and at the same time 
shifts away from the stress NPM puts on "business process management" (p. 483). Moreover, another notable theme which this post-NPM, digital-era governance highlights is digitization and electronic processes that are realized for their productivity gains through their full integration including things such as electronic service delivery and new forms of automated processes (Dunleavy et al., 2005, pp. 480-481). Part of this notion of electronic service delivery can be seen in the concept of zero touch technology of which "[...] the ideal is that no human intervention is needed in a sale or administrative operation" (Dunleavy et al., 2005, p. 486). Ultimately a critical point which Dunleavy et al. (2005) underscore is that technological change has a transformative power in public organizations. While they may help transform an organization and how services are delivered to the public, they also have an impact in the way in which public servants perform tasks. The impact of technology then has a dual impact; on the one hand it delivers certain benefits in relation to service to users but it concurrently reduces the need for labour, which may create a sense of frustration within oneself. How workers make sense of this technology and the impact it has on them is somewhat varied, interactions with other factors that shape identity affect perceptions, even if they are built on similar grounds.

\subsection{Discussion}

What emerges from this discussion of the strike, the importance of place, organizational culture and the impact of technology are examples of narratives that guide and shape individuals. Generational differences emerged particularly in relation to one's ability to draw on accumulated knowledge to guide and reflect on changing material and discursive practices at work. However, there were more similarities and overlaps 
between the generations than there were differences between them and this I found surprising. I believe this provides some insight into the role that the strike played in bridging difference between generations and individuals.

Concurrently, a thread associated with identity work also emerged highlighting the ways in which individuals regulate and transform themselves (cf. Sveningsson and Alvesson, 2003). It does not necessarily mean, however, that techniques that promote transformation will be successful. However, what one also observes is that workers are quite clear that they have expectations of their place of work and that their place of work is nestled within certain values. Library work, then has a particular social and public value, which workers recognize in different yet similar ways. These techniques of understanding their place of work emerge not only through managerial discourses, but through other means, perhaps even through the labour dispute; it is not entirely clear from where one's sense of work and place emerge, but it nonetheless is important in defining what they do at work and how they experience it.

Another critical element must be acknowledged in this chapter - that of the role of place and space. Residual organizational cultures and/or regional organizational cultures exist in Toronto Public Library and their persistence, in a sense, creates friction and can espouse resistance to the dominant norms which the broader organizational culture seeks to promote. For one worker in particular, it brings a sense of conflict in conducting a task "correctly": is what the larger organization requires the correct way of doing things or should I do what I am told by my supervisor? What influences my supervisor to encourage a certain way of doing tasks? Another worker's insistence that different organizational cultures exist within different people and places in the organization, serves 
to highlight an awareness of a newer generation of workers of the movement of persons and their capacities in a diverse and uneven organization. Thus appears the political aspect of place, how different regions, and the inculcation of persons from those regions are in a state of tension when individuals resist attempts to foster a greater organizational culture. Experiencing different spaces and times then provide different complementary, competing and transformational resources that " $[\ldots]$ employees may draw, either to augment or resist the discursive constructions of their professional subjectivities" (Halford and Leonard, 2006, p. 670).

I was also surprised by the two statements from participants describing technologies such as the express checkout. One worker from the first generation praised it for freeing up time to perform other tasks in serving the public, while a worker from the second generation saw the standardized manner in which technology treats members of the public who have very specific needs as users as problematic. This, in my view, provides insight into variation arising from a participants' differential interaction with the technology in constructing a view of it, both appear concerned with their role in assisting the public. This might be worth interrogating in future research.

In sum, what I observed may have yielded more commonalities between the generations of workers, and this may be a product of the lack of total participants, but it also provided insight into how complex an organization Toronto Public Library was, even at a very small level. The impact of technology on staff showed to be varied in these cases, and so too did the impact of organizational cultures on individuals. While there were similarities in perception, not everyone experienced the aforementioned 
technology and culture in the same way. This, I believe, reinforces the notion that Toronto Public Library is a layered and complex organization for study.

The next chapter then will start to examine the impact organizational practices have on the shaping of the self. What techniques do we see emerge to shape individuals? What subjectivities are emphasized? What capacities are fostered and to what end? The next chapter will start explore these and other questions. 


\section{Chapter: Forming Working Selves}

Shifting material and discursive practices at work may be a foundation for shaping, altering and transforming workers. As workers do not always have input in doing their work, they may find that their work vigorously promotes certain identities or fosters particular ways of being as a result of the practices taking shape in their environment. Drawing from Foucault, Edwards and Nicoll (2004) note that different forms of power co-exist and have different focuses (p. 164). The result of this may hold that different forms of subjectivity, identity and working selves may appear differently in the same workplace concurrently and within the same worker.

Techniques for transforming individuals may be seen in one light as being educative, in that they foster or promote certain types of identities through discursive and material practices and consequently different types of identities may emerge. For this reason, workplace practices may promote particular types of selves such as a flexible self or at the same time we might see other types of workers developing because of what different workplace practices in different contexts encourage. Thus, this section describes several types of identities and selves that have emerged through the interview process. These include the following: the redundant and docile self, a self in stasis, a self adrift, a flexible self and an entrepreneurial self. While each of these identities appear separate and distinct, they may in fact may not be so distinct, and rather may manifest within the same individual depending on contexts or situations that promote them. After all, as noted before, context shapes the construction of identities, selves and subjectivities through the use of dynamic, complex and competing resources (Halford and Leonard, 
2006, p. 670). Moreover, a variety of subject positions can be formed through individuals' active use of competing resources (Halford and Leonard, 2006, p. 658).

While I was expecting to find generational differences in the types of selves that seemed to emerge from my interviews in the library workplace, I found more and more points of convergence as well as multiple forms of selves. Generation and accumulated experience may play some role in developing these selves, however it is not readily apparent that certain forms of selves are limited solely to certain generations of workers. Instead commonalities from the different generations of workers emerged.

\subsection{The Redundant and Docile Self}

In the case examined here, it does not appear as though generation played any sort of role in affecting staff differentially. Instead, cross-generationally, disciplinary technologies of power emerge in relation to staff's interaction with the public as new technologies are brought into the workplace, such as "express checkout" and the automated self-check-in:

[...] I feel like my relationship with patrons become an inconvenience to them[...] [...] and now, patrons are like, they're mad, they don't like checking out themselves; they don't like checking in themselves. So they're mad, and then they think you aren't doing any work [...] [...] because you know what "you don't check me out, you don't check me in [...] [...] what's your job anymore? What do you guys do?" You know, and... and l'm not saying that it's every patron. (Interview D, $2^{\text {nd }}$ Generation).

In a sense, one can see the impact of technical innovation on workers. On the one hand, before such technologies were implemented, workers had a much clearer sense of what they had to do in relation to their work with the public. However, with the advent of technologies that foster the self-sufficiency of the user and patron, the examination provided by the public on the worker individualizes and standardizes, by suggesting the 
redundancy of the worker. This may have further implications for workers if they then search for things to do in the face of visible scrutiny.

However, it has been noted how the public's perception of the library worker may be veiled by circumstance.

[...] [S]ome people know how much we're earning and when we're sitting behind a desk with a computer in front of us, it looks completely easy. It looks like we're not doing anything at all. A lot of it happens behind the scenes. The processing happens behind the scenes. You know it's, it... it's not supposed to... and it's not really not to inconvenience the public, but it's like your... your job is to me... to meet the public all the time. And that's, that's the priority. So you might be able to do a job alongside it, but make that a second priority, your first priority is the... is the customer. Yeah. No, I'm still surprised that people think it's an easy job because at some of the branches it's pretty rigorous (Interview $E$, $1^{\text {st }}$ Generation).

Thus, it is the expectation of the patron which comes to govern and normalize what is expected in the behaviour of the worker. In other words, the worker is disciplined by the public in how they visualize and construct what a library worker should do. One should recall Foucault (1995) who states that:

[i]n a sense, the power of normalization imposes homogeneity; but it individualizes by making it possible to measure gaps, to determine levels, to fix specialities and to render the differences useful by fitting them one to another. It is easy to understand how the power of the norm functions within a system of formal equality, since with a homogeneity that is the rule, the norm introduces as a usual and as a result of measurement, all the shading of individual differences (p. 184).

The normalizing judgement, here, produces a domain of truth (Foucault, 1995, p. 194) that "working" is associated with "doing something." Surveillance or a gaze appears through the watchful eye of the public. Townley (1993) importantly notes that "[d]isciplinary procedures most obviously define the parameters of acceptable and nonacceptable behavior, and as such, they contribute to the process of individuals' being able to identify the valid from the invalid" (p. 537) and this is something "public" 
regulation helps foster. The appearance of "not doing anything" may lead to a sense of precarity within the worker, and perhaps leads into the discussion of another emergent formation of self in the public library.

One may even go so far as to say that it is possible that normalizing judgement is heightened through the possibility of tactics that enforce "customer service feedback." 11 Feedback can work as a system of rewards or punishments for individuals. Thus, the potentiality and monitoring that is done by those around staff become motivation for staff to engage in self-transformation, which can be best understood through the framework of technologies of the self. When that which has been understood as "working" is no longer observed, the public unwittingly acts to regulate library workers' behaviour by making visible that their historic function no longer exists and that they are in fact redundant. These, however, are strong claims, and this project cannot conclusively suggest what the repercussions of public forms of surveillance might yield.

Nevertheless, what emerges from these situations may be an attempt to elicit a frontline library worker's docility in the workplace. The public acts as a disciplining force by making visible and measurable that the worker is "doing nothing" and so should be doing "something," at least something recognizable with how they perceive the worker's role. It broadly reinforces the notion that if one is not "working" in the front, then the purpose of that job is rendered redundant. This is most likely an unconscious technique which promotes and reinforces a reduction in service staff and plays into the narrative which facilitates discursive attacks on public service workers.

\footnotetext{
11 An example of such feedback provisions is present on the Toronto Public Library website (cf. Toronto Public Library, 2012d).
} 
This concept of docility is perhaps reinforced when considering the emotional toll of technical innovations on the worker. One member of staff stated that these changes makes them feel:

Angry. Like I, like I go home and feel frustrated and angry and the reason I can say that is because having just been at this branch that didn't have [these automated technologies], I went home, I had more energy, I was happy, I wasn't bitter, you know... (Interview D, $2^{\text {nd }}$ Generation).

While it is not entirely certain what the true impact of public monitoring may be because of technology, it can certainly be established that the technical innovation at work has meant changes to the work environment, tasks, procedures and roles all of which impact an individual worker. Docility, then, may emerge in a worker feeling "beat-up" and willing to simply get the job done despite the emotional and discursive toll it may have. As Foucault (1995) has stated: "[a] body is docile that may be subjected, used, transformed and improved" (p. 136). The emotional impact and the reinforcement of redundancy, then may elicit a sense of this docility to encourage a worker to be ready to be transformed and disciplined through disciplinary processes as noted above.

\subsection{A Flexible Self}

One participant described the implementation of new technologies associated with check-in and check-out as having some deleterious effects in work flow management. As they described it:

You've gotta go over and help those people [who are having difficulty with the express check-out], which is fine like don't get me wrong, but there's less people on the desk now because of this express check-out. So there's one person on the desk, you immediately have to run over and help them and then there's no one to help people who come up; can I put money on my card? Can I pay my fine? My address needs to be updated. So they're then waiting in line (Interview D, $2^{\text {nd }}$ Generation). 
The implementation of new technology which may not be ready to fully roll out or is not entirely flawless has changed the staffing requirements in the workplace. When express checkout does not function properly, the lack of staff requires the worker to be nimble and adapt to handling new problems and situations at once. The effect of this has meant that for those who work on the circulation or front desk, their relationship with the public in terms of social interaction has changed.

Yeah there's no interaction with people because you always feel like I can see out of the corner of my eye that that guy needs help. I can see out of the corner of my eye... and this poor old lady wants to talk about her, you know the new whatever, the Danielle Steele book, which I don't read, but I... I talk to her anyway. But now you feel like, you can't. You know. There's so much pressure to... I don't know, to get through to the next person (Interview $D, 2^{\text {nd }}$ Generation).

As the nature of the work has changed in the workplace, the worker must adapt as well. This adaptability has been fostered by the constant change in technology at work. The worker describes the new software they had to learn and adapt to:

I'm not afraid to learn new stuff. [...] [...] So when I first started, I learned on Dynix, 2008 we brought in Symphony, by 2010, 2011, I had to be familiar with RFID. So it's like, it doesn't scare me anymore. [...]And it [another new system] doesn't scare me. Like nothing, it doesn't worry me anymore. Like there's nothing that they can throw at me that I don't think I can't learn (Interview D, $2^{\text {nd }}$ Generation).

This ability to learn quickly, and be nimble, then, is an example of technologies of the self in practice. Shifting labour practices reinforce the educative capacity within individuals. As the workplace changes, so too must the worker and they must be as nimble as the world around themselves (Burkitt, 2002, p. 235). Similar to what Sennett (1999) has described about the worker under flexible capitalism, then "[w]orkers are asked to behave nimbly, to be open to change on short notice, to take risks continually, to 
become ever less dependent on regulations and formal procedures" (p. 9) and so too do we see the same in the library worker.

The result of constant change has meant that the worker is now prepared to embrace change in the workplace and the constant need to be nimble and be open to change on short notice. The same worker has noted again about new change in the workplace:

Like we got a new email system, Outlook. I hated it when it first came out. [...] I told my supervisor[...] [...] "fix it, before I hit the computer." And [the supervisor's] like, "oh all you have to do is put a dot here." And as soon as [the supervisor] did that, I'm like, "are you joking me? That's all I needed to do is another dot?" But now I don't care. I know how to use it, I embrace it... I... you know, like I don't know how to explain that, you know (Interview D, $2^{\text {nd }}$ Generation).

Technical innovations as tools have transformed the individual into one that must be willing to be flexible and adaptable to the constantly changing needs of worker in the workplace. The worker has learned to accept change and has embraced it. The worker has transformed themselves with a capacity to be willing, nimble and adaptable.

\subsection{A Self in Stasis}

In interviews, one pervasive theme drew on the notion that the public library was not a place where feedback from staff was promoted. Some workers felt as though this was reflective of a culture that did not foster worker participation or some saw this as part of an organizational environment that was dictatorial and bureaucratic. This cuts across generations.

One worker notes that attempts at soliciting staff feedback is limited and when it is sought, it is considered superficial:

[...] [There's] no interest in feedback from staff like[...] [...] there's kind of cursory feedback but there's so much $\{. .].[$ [...] well what I call innovation 
exhaustion, where every year and a half, it seems there's like a new initiative around something and there's a lot of meetings held and there's training and then nothing ever seems to come of it and people are like, well, whatever (Interview $C, 2^{\text {nd }}$ Generation).

To this worker, then, change appears to be superficial. It is not radical; it is not ground-

breaking, nor is it revolutionary.

$[\ldots][Y]$ ou know, classical stereotype is like you get ahead in government by not making decisions and not making waves and kind of not causing embarrassment and the systems have become more and more optimized every year towards doing exactly that, which is just keeping things in stasis [...] [...]And that's the... that's the... I think that is the great dream of maybe both library administrators and library workers in a lot of ways, which is, you know, very, very grudging change and kind of show change rather than actual change. [...T] his is why I think the solution [...] [...] is often well, you know we need to become more efficient let's install a bunch of machines; machines are efficient because what that let's you do is shuffle around operating budget and capital budget which is another one of the great statistical juggling tricks that organizations engage in but it... and it... it's almost, it's you know, you do that and then you don't really have to look at how your business model might have to change, you might not have to analyze, you know, your processes and how they might be efficient, like you can just like, you know, we'll cut two staff and spend three hundred thousand dollars of capital budget on machines, but we'll still continue to run the system in exactly the same way at kind of the macro-level... (Interview C, $2^{\text {nd }}$ Generation).

This seemingly superficial change then, does not do much for the organization, but rather removes workers' ability to be an active agents in the change process. As another participant noted, the attempts to standardize certain functions in the public library do not recognize particular subtleties and the uniqueness of certain branches in the organization:

[...A]nd that's the kind of change they make everything very generic, so that everyone's treated the same way. And as a result, nobody's treated any particular way. [...] [T]hey're coming down with every page [book shelver] and every location and every library has to shelve a cart exactly the same way. [...]And at the at North York Central Library, again, where you have bays and bays and bays of the same Dewey; that's [the context for shelving is] different again. And then at Toronto Reference Library uses a unique Dewey code. So every book has its own unique Dewey. That's different again. So it's gonna take you a lot longer to shelve something with a unique Dewey, right? 'Cause you have to find exactly [where to place the book], you can't sort of fake it and [inaudible] mix together, right? (Interview B, $1^{\text {st }}$ Generation). 
Attempts to standardize then appear as techniques of organizational control limiting the ability of workers to be innovative and find solutions to improve the place in which they work on their own.

Managing workers in this manner renders identity regulation operable by not only giving the appearance of employee participation in the decision making process, but by also fostering change that does not yield anything particular. As workers become exhausted by "new ideas" that constantly stream in, they appear to be pacified by change when they realize that they are not part of the decision making process; their concerns will only be superficially heeded.

\subsection{A Self Adrift}

Similar to what was developed in the narrative of $A$ Self in Stasis, another way to understand the form of self that has been nurtured in the library work environment is the idea of a self adrift. For one particular worker, decision-making is impacted by professional identities - that because the worker is not a professional librarian by trade, their voice in the workplace is particularly muted.

Well it's hard for me because I'm not a librarian. And I therefore, in this workplace, have no voice to speak to, what I need my library to do, to promote my skills, to promote... you know, l've... I've sort of fallen into a place in my head where I think, I'm, I'm holding up my end of the contract, I show up every day, I am ready to do work that I'm trained for, that I have the skills to do, that I have the background to do, and I'm never called upon to do it. And nobody asks me, why I'm not doing it. And because I'm not a librarian, I'm not considered qualified to tell anymore [inaudible] (Interview B, $1^{\text {st }}$ Generation).

The worker has internalized a sense of professional inferiority that their voice is not considered valuable at work. They have also noted that: 
[...] [T]hey have no value for clerical work, and I don't understand it (Interview B, $1^{\text {st }}$ Generation).

As was noted in the previous chapter, this worker drew on their past knowledge of work organizational culture. They realize the value that is placed on certain professional identities which past incarnations of a Toronto area library did not foster. Here the worker noted how in Scarborough, clerks and clericals were heavily relied upon, and did not need a Master's degree to perform their jobs. Moreover, the worker's personal experience and knowledge of Scarborough, demonstrated how feedback was appreciated in that environment. But in the new Toronto Public Library, such a practice has largely corroded with time. The result of these workplace practices promotes a capacity in the organization that is neither open to feedback, and thus appears to not value the accumulated knowledge and skills that staff have developed. Reflecting on workplace practices, then, has a critical purpose, of self-improvement and mediating the right balance of change, something which the worker feels is no longer valuable. This results in a worker who feels cut off from the organization, who may only come to work for a paycheque instead of feeling strongly connected with the organization.

[...] I think the only thing that's changed, is we've completely wandered away from, from the idea of perpetual training and perpetual thinking about what we do, and perpetual analysis of why we're doing it. And um, and you need your naysayers, and you need your grumpy old ladies to tell you why it won't work because, at least they're thinking about it, right? [...] At least they're thinking about why you're doing it. If you tell, tell people to stop thinking about why they're doing something, they will, right? [...]And it'll just drift, which is what's happening at least at the library to me. So, and, and I talk to the people who do other things and they say the same thing. It's just all adrift (Interview B, $1^{\text {st }}$ Generation).

This person also noted that the lack of organizational interest in staff feedback has detached them from the workplace. Critical analysis and reflection of organizational practices are not encouraged, nor are they sought out. 
The last time somebody actually sought out my opinion was probably 8 or 9 years ago[...]. [...] I have not been asked, I've been told, you know, and... but I've not ever, I've not been asked, and I'm the kind of person you should ask, and if not me, I can name 10 people you should ask, right? 10 smart, hardworking, people who are even better at their jobs than I am. Because I'm not the... I'm not a model employee all the time. And I can think of 10 people who are. You know, and they're not asked either (Interview B, $1^{\text {st }}$ Generation).

What comes to the fore in this form of identity is that without having an ability to be heard or be a part of the decision-making process, no matter how small, one feels cut off from the organization; they are constituted in a subject position that promotes docility and which dissuades a strong connection to the organization. Moreover, the impact is very particular to this person's generation because they are able to consider their professional status, particularly in relation to how they have understood their past relationship to their place of work. The worker thus feels as though they have been set adrift by an organization that encourages them to be merely an obedient subject.

\subsection{An Entrepreneurial Self}

While some have described their workplace as being restrictive, others have found ways to resist these tendencies, by engaging in seemingly subversive actions to create their own space at work from the dictates of management. This can be seen as an extension of power relations at work, where the relationship between workers and management is one where workers can negotiate space in their relations with others.

Resistance is thus found within power relationships and is not external to that relationship (Sakolsky, 1992, p. 243). Thus, while the workplace can be seen to be restrictive, it may also allow certain workers to cultivate aspects of themselves that attempt to resist organizational control.

"[...] is this [particular task or procedure workers have developed] gonna be okay?" I say, "Listen, if we ask, can we do this, and they say no; we can't do it. 
So, let's just do it and see what happens." That's my way of... of responding. (Interview A, $1^{\text {st }}$ Generation).

Resistance can then allow workers to carve out space in the workplace. This kind of resistance may then become useful for the larger organization as experts that work for an organization may then act upon these actions, whether to promote, problematize or revise practices that foster such action by workers (Knights and Vurdubakis, 1994, p. 180).

Another worker similarly engages in such action and does work that no one asks them to do, knowing full well that there is a limit to how far they may act within the bounds of the public library.

I love doing signage, labelling. I love... like identifying how things look. [...]You're not... and you can't... you're not allowed to go too far out of a [...] [...]standard, but you can play around in that. So I've [...] [done] [...]signage[...] [...]which nobody assigned me (Interview $E, 1^{\text {st }}$ Generation).

What this promotes is a work relationship, where workers are left to their own devices in filling the gaps of what should be done in the workplace. On the one hand, this has a functional purpose; it allows the employer to take advantage of the workers' "entrepreneurial spirit." Here the worker attempts to take risks in stirring innovation. Concurrently, this allows the staff to problematize and bring to the fore ways to shape, modify and change the workplace.

Similarly, one worker has noted that they have taken the initiative to work longer hours at the workplace than they are scheduled to. This in part is fostered by the worker's attachment to the importance they hold in organizational discourses associated with the public library, or at the very least the discourse they have helped construct surrounding their place of work. They stated:

[...] [P]ages [book shelvers] are like why are you here so early? And I'm like, "oh well this needs to get done before we open and this and this and this." And 
they're like, "so you're basically volunteering your time." I'm like "well you can't look at it that way." (Interview D, $2^{\text {nd }}$ Generation).

Risk-taking and participating in unassigned ventures appears to have a dual purpose. On the one hand, workers find ways to find "new" and other work to do, which they think will be beneficial to the workplace. On the other hand, such resistance allows the organization to benefit from such subversive acts. Thus, one can see how attempts at resistance do not alter a power relationship, but rather carve and negotiate space within it.

\subsection{Discussion}

What we see emerge from a closer look at the public library is a wide variety of identities, subjectivities and forms of selves that are promoted or elicited within workers. Identities should not be understood as being exclusive or determining, but rather should express the types of identities that are fostered in the workplace. Moreover, the role of generation in this analysis is seen to be one which does not necessarily play a strong role in determining how one's identity comes to be shaped. Although in one case, being part of the first generation allows them unique insight into how practices in the workplace manifested themselves, and served as a reference point for their concerns in how things are at present. The past allowed them to filter through and understand what troubled them.

I must caution, however, that the selves and subjectivities that have emerged in this section are limited in what they can express. After all, there was a limited pool from which to draw insights from participants, and unearth common themes. To this, I would suggest further research to develop each of these emergent selves. Nonetheless, discovering these aspects of self and identity then forces an important question: what are the implications of these findings? 
The next chapter will discuss in further depth the implications of this research project, and the implication the study of identity and generation have when considering the public library. 


\section{Chapter: Research Implications}

Investigating labour identities and subjectivities in Toronto Public Library has made visible the very complex nature of the organization, cultures, and shifting work practices. The result of these shifting practices has meant that workers have had to learn to adapt to new situations, some of which have promoted certain ways of functioning in the workplace. However, it is difficult to make any concretized conclusions regarding identity, self and work as this project was unable to meet its participant criteria and, as we will see in this chapter, the inherent complexity of Toronto Public Library makes it truly challenging to state clearly what was observed specifically. Moreover, the methods employed in this project present certain challenges in providing a thorough exploration of identity. Nonetheless, there are important implications of this study in what it makes visible to studies of library work, identity formation and subjectivity at work.

The way in which generation was operationalized in this research project also on the surface appears to reject aspects of Sennett's (1999) argument. Here it is not always clear that one's generation necessarily means that one will be impacted by organizational structures differently than others. All workers seemed to have been similarly judgemental of the organization in which they worked. Workers did not necessarily suggest that they actively spoke up against bad decision making because they were of an older generation (Sennett, 1999, p. 94), but through the interviews, it was shown that workers were quite invested in their workplace, the work that they did and were quite willing to be critical of their place of work. They explored what they saw as problematic in their workplace in trying to fulfil their work obligations; it appeared as though they were critical because of their loyalty to the institution of the public library (cf. Sennett 
1999, p. 94). This appeared cross-generational and was not solely limited to workers coming from an older generation nor was it necessarily a tendency of older workers over workers just entering the organization (cf. Sennett 1999, p. 94). It should be noted that workers who had entered the library system within two to three years of the study, however, were not interviewed in this project as a basis for comparison.

One might see a rationale for this embedded in the fact that the work is unionized and consequently the security provided for in work allowed them to feel freer in being critical of the organization in which they worked. Another rationale might lay in the strong attachment workers continue to have with their organization, or rather that workers know how crucial their work is in relation to the important work the public library does for the local community and society at large. Thirdly, it may simply be talking to me, the researcher, as someone who has been invested in the organization that gave the workers a chance to discuss their place at work. These three rationales are hypotheses, however, and it is not clear precisely what allows for open and honest constructive criticism. Importantly though, it was also not readily apparent if workers were always willing to be critical in other spaces or areas outside the interview such as at work, which is something that Sennett (1999) notes of in his example of older workers speaking out to their bosses at an advertising firm (p. 94). Nevertheless, we can still conclude that the organizational complexity of Toronto Public Library certainly makes clear cut generalizations about generation more difficult to state.

The presence of "speaking out" then, may be connected to one's aspirational vision of a place of work. Where for British Parachute soldiers this idealized notion of the parachute soldier acted as a means to regulate the behaviour of soldiers (Thornborrow 
and Brown, 2006), so too such an aspirational vision of the public library may guide library workers in not only identifying with their work, but regulating, shaping and guiding their own actions despite their own objections to changes at their place of work. This may act as a disciplinary tool. Moreover, a strong connection to the representation of one's work may also signify a continued attachment to the place of work; it does not necessarily signify that because a worker who has worked in the library system for a long time and has invested much time into it, that that is the sole reason they have continued to stay in a place of work in which they object to the myriad of practices.

Sennett (1999) had also noted that younger workers are more tolerant of taking bad orders and are more likely to quit rather than fight within and for the organization in which they work (p. 94), however, there has been no indication that this is necessarily the case and it would be difficult to prove this to be true as quitting would force workers to lose their seniority. ${ }^{12}$ Workers, however, may have the option to move to other branches as spaces free up and this may be a mitigating factor for workers to leave the library system entirely if they can avoid "bad orders". Finally, I should state that from the interviews, I developed the sense that workers, regardless of generation, were likely to fight for their organization. This requires one to re-examine the critical words given by workers in noting the value of the public library as an institution. Where Lowe (2001) has noted that older workers whose expectations were not met were more likely to stay but their morale and job satisfaction may suffer (pp. 33-4), it was observed that workers from an older generation were mixed in terms of morale and job satisfaction. This is

\footnotetext{
${ }^{12}$ Indeed, this is what happened to me when I left, however, I left the organization for academic or educationally-related reasons.
} 
likely because of different job positions and statuses among many other factors, contextually and differentially impact what those "expectations" of the job may be.

In considering the findings related to flexibility and generation, I believe it would also be worthwhile examining the impact of the hierarchical and bureaucratic nature of Toronto Public Library, as a participant had noted. Certainly, there are crucial elements of flexibility within the organization, but there are also elements which reinforce a bureaucratic or hierarchical design. One might also question if elements of a bureaucratic design also foster some uniformity between generations. Ultimately, while we see generation to play some role in showing difference between workers, it is not always clear if those differences are due to generation or some other reason. Furthermore the operationalization of generation in this project is somewhat weak and may thus have been a challenge to the study. As well, the lack of participants also creates another challenge. Finally, the lack of variation between generations may have developed as a result of the strike, which as one participant noted, acted as a unifying force for staff. Consequently, without a doubt, I must state that further research in this area is needed to test whether the conclusions on generation hold, or need to be developed further. Though, the inherent complexity of Toronto Public Library as a site for study is still observed.

Further discussing generation, it was observed that multiple subject positions emerge for persons working in the public library. The amalgamation of different library systems from the old Metropolitan Toronto area into a single unified Toronto Public Library provides one rationale for the emergence of multiple subject positions. The remnants of the old organizational cultures, which some workers have internalized, guide the vision of some library workers in determining what library work ought to be, or how 
it should be done. This has meant that the organizational culture of the current Toronto Public Library is not as strong, or that it operates alongside these old remnants with and for some workers. This has implications for identity because it highlights the role that culture and the degree to which one is inculcated within a culture matters in the manner in which one identifies with one's work. Thus, one may argue that if older organizational cultures still remain, they are diverse because of the different systems that have been incorporated into the larger Toronto Public Library.

Workers from an older generation that have been inculcated with certain organization values and practices may move between the regions or spaces where certain other cultures dominate. New workers who are part of a new generation of workers that have not been immersed in the library cultures of old join the newer Toronto Public Library and the organizational culture(s) emanating from it presently. Thus, the organization might find itself composed of much variation in the scripts, roles and norms through existing practices in guiding workers how to work. These older scripts, roles and norms will have interacted with newer scripts, roles and norms to create significant complexities and heterogeneity in subjectivities. Workers may come to gather from these different resources that are available to them, some of which have only been absorbed to a greater degree by workers from an older generation. This would appear to complicate the government of workers in shaping and guiding their actions. Attempts to foster capacities or identities may be thwarted, subverted or re-imagined in different ways by different workers.

In continuing a broader discussion about multiple subject positions and identities, it was found that multiple identities and subject positions may exist within a single 
person. This may be the case because different contexts demand different personas. Watson (2008) has noted that individuals must take on different corporate personas in organizations, and that these are likely to differ from personas that one must take on in other aspects of one's life (p.122). At the same time, I would argue that even within the same organization, one must also be willing to take on different personas, identities, "selves" or subjectivities. Job position, the type of generational experience, and the type of library within which one works, will all impact the way in which one experiences, perceives and translates the impact of practices within oneself and how one acts and comes to be. Thus, it is within certain contexts that certain identities emerge. Moreover, drawing in part from Hey, Fenwick and Somerville (2006) have indicated that at work, subjects perform multiple activities and are thus subject to multiple power relations, all of which shift "moment-to-moment" that cannot always be captured by theoretical abstractions (p. 253).

It has also been suggested that the adoption of dual or multiple identities are coping strategies and resistance techniques to processes of subjectivation (Fenwick and Somerville, 2006, p. 258). Thus, one may find the flexible self promoted in certain circumstances, while in others, selves that exhibit features that elicit an entrepreneurial spirit may be observed. Similarly, in Halford and Leonard's (2006) study on workplace subjectivities and context in the NHS, it was found that "[...] context shapes the construction of workplace subjectivities in complex, multiple and dynamic ways; and how the shifting contexts of individuals' everyday lives provide alternative and competing resources for the construction of self" (p. 670). Consequently, techniques that foster docility may on the one hand permit the greater pliability of subjects, to prepare 
them for different contexts. At the same time, knowing the aspirational image of the organization provides individuals with tools to engage in self-disciplining and selftransformations, being prepared to shape themselves as is necessary or required.

Through practices, images and calculations, as we have seen, individuals have been able to be governed through their own freedom to choose (Rose and Miller, 1992, p. 201); this is how governmental power operates through a distance without having to impose rules upon individuals and instead "incites" appropriate behaviour through an individual's freedom to choose (Wigman and Winiecki, 2007, p. 119); that which incites is guided by certain forms of expert knowledge (Wigman and Winiecki, 2007, p. 119). Thus, how one practices one's own freedom is necessarily conditioned by the discursive and material practices within one's own environment. Coupled with the contextual factors which affect subjectivities, one can see how one freely chooses to transform oneself within different environments, as is necessary. Here, one must recall the one participant who found that the emotional impact of working in a more technologized public library had a significant personal toll, than working in the library that was not as invested with such technology. It is likely that this worker was able to freely change themselves according to what was required of them working in branches that were different from each other.

Though, a better example likely lies with the same participant who underscored that they are now no longer afraid of change and consequently are much more open to new technologies and willing to learn them. The participant also felt as though they were now prepared to do, or learn anything. This may be a promotion of a flexible capacity in individuals and a technique to govern them from a distance without the need for 
observation or specific rules. Thus, it is the environment that fosters the individual to transform themselves at work. The expert knowledge here might lay in the need for greater flexibility.

Moreover, a conception of freedom is important to highlight in relation to acts of transformation within subjects. Foucault (1982) thus provides something further to understand about the nature of power relations in relations of ruling and government:

When one defines the exercise of power as a mode of action upon the actions of others, when one characterizes these actions by the government of men by other men - in the broadest sense of the term - one includes an important element: freedom. Power is exercised only over free subjects, and only insofar as they are free. By this we mean individual or collective subjects who are faced with a field of possibilities in which several ways of behaving, several reactions and diverse comportments may be realized. Where the determining factors saturate the whole there is no relationship of power $[\ldots]$. [...] In this game freedom may well appear as the condition for the exercise of power (at the same time its precondition, since freedom must exist for power to be exerted, and also its permanent support, since without the possibility of recalcitrance, power would be equivalent to a physical determination) (Foucault, 1982, p. 790).

Freedom can only be practised under power relationships where there is space for possibility. It is here that Dean's (2010) conception of subjectivity is so important in that government is engaged with promoting or eliciting a certain way of being and acting, and not determining outcome. It is in this relationship that an individual may be able to negotiate the terms of their subjugation, while still actively existing within a power relationship. One must refer back to the ways in which participants have noted how one may engage in resistance by knowing the limits of what is possible and what is not possible. The power relationship promotes a certain standard or way of acting at work none of which necessarily lead to the outcomes which, for example, management or the state may ideally desire - but it also allows for the creation of space that allows workers 
to opt to behave in certain ways. Government, thus "[...] presupposes the primary freedom of those who are governed entailed in the capacities of acting and thinking" (Dean, 2010, p. 24). Material and discursive practices, then, direct one in certain ways of behaving, but the end result is not determined, even if those who govern, such as management, value certain outcomes more than others. As we have also observed, the heterogeneity of the organization complicates the techniques that may be used to form certain identities.

It has thus been established that aspects of governmental power can be seen throughout the library organization, where certain capacities in individuals are promoted through the placing of tools and through material and discursive practices that promote individuals to effect by their own means changes on the self - to engage in selftransformation and be a productive member of an organization. It is not always clear who or what facilitates such change. Not only do managerial discourses and practices promote certain ways of being but even through workers' interaction with the public, certain forms of precarity and norms are established and reinforced.

Another interesting question appears here in this study as who "does" the governing; who conducts the conduct of individuals? While it may appear as this might be solely in the form of management this is not always the case. In fact, workers govern themselves, and are governed through each other, by management and even the public. In analyzing the interviews, it became apparent that one's manager is not simply the person who supervises and regulates one at work. This may be because of what Dean (2010) suggests that "[ $[\ldots]$ those who might be thought to exercise authority (over clients, investment decisions, workers, students) are subject to the exercise of other forms of 
authority" (Dean, 2010, p. 38). This might be conceptualized in the following way: a university may have authority over a student and a government over a university. Electors elect the government and taxpayers fund the schools. Yet a student can also be an elector and a taxpayer. Authority can thus be much more diffuse in its operation. This suggests that through problematizing the traditional manager and worker binary, one is able to see how workers are subject to different forms of authority as they come to act in the workplace.

For the study of identity, this broadens our scope of analysis, to examine the ways in which diffuse forms of power come to shape how we view our work, how we are attached to it and how we engage in it. In terms of library work, this notion of diffuse forms of authority perhaps appears best in the personal account of two participants and how they each were subject to members of the public reminding and promoting certain ways of acting and being in the workplace by suggesting or highlighting what was happening in the workplace. These sorts of seemingly diffuse forms of power, then, may impact the way in which one engages in identity work, in fashioning a coherent sense of self, particularly in a workplace that is undergoing transformation. These interactions may themselves foster self-transformation.

Participants have also discussed identity work and identity regulation. These provide further examples of how identities and subjectivities may be fashioned or elicited. While each of these may work together in strengthening the bond of individuals and their identity to their organization, they inculcate members through scripts and roles associated with an organization. Drawing from Giddens, Willmott and Alvesson (2002) have noted that self-identity refers to a coherent and secure sense of self that is 
reflexively organized and is developed from participating in competing discourses and experiences (pp. 625-626). Identity work involves maintaining, repairing or transforming this identity, revising one's sense of coherence which is developed through the myriad of daily interactions in life such as events encounters and transitions that permit one to become aware of this self-identity, compelling further identity work (Willmott and Alvesson, 2002, p. 626). Identity regulation, in particular, looks to the impact of social practices, such as induction, training and promotions, and their impact on identity formation (Willmott and Alvesson, 2002, p. 626). Together, these processes are engaged in techniques of organizational control through the self-positioning of employees within managerial discourses of work and organization (Willmott and Alvesson, 2002, p. 620).

What has been observed then, in the abstract or aspirational construction of the value workers have given to their place of work is the power of identity work and identity regulation in positioning workers within managerial discourses. It is not clear whether managerial discourses associated with the library's mission and values are necessarily the reason workers may develop an attachment to Toronto Public Library, or even if they are at least a source from where workers have constructed their abstract image of place. Nonetheless, this image of the library has played an important role in regulating workers at Toronto Public Library as it provides a certain degree or organizational control over staff. Workers seem to place themselves within such a discourse, at least to some degree. Moreover, the strike as a critical event has likely played an important role in unifying workers of the organization allowing for further identity work. Finally, technological transitions should be noted too, as the rollout of express checkout and self-check-in have 
provided existential worry for some, forcing them to confront and renegotiate a sense of self and identity (Alvesson and Willmott, 2002, p. 626).

One should also look to flexibility broadly, instead of simply in relation to generation, in impacting identity. Flexibility has come to impact public organizations, particularly in the form of New Public Management (NPM). This has necessarily put pressures on organizations to reinvent themselves (cf. Osborne and Gaebler, 1992) due to changing economic and political discourses that encourage reform and flexibility. Technological change, then, in public libraries, is no surprise, but the impact of such change is interesting because while they may pressure an organization to change itself, in Toronto Public Library, we still see, as workers have mentioned, a significant bureaucratic design. I am not critiquing the organizational design of Toronto Public Library here, I am merely drawing attention to it. Flexibility, in this organization, has manifested itself in the form of shifting tasks, which have been fostered by the implementation of new technologies in the workplace. The impact of this has meant that, for some, their working routines and tasks have had to change significantly, and the reasons why they may have joined library work in the first place, may have been compromised. It has been noted that " $[\ldots]$ the quest for innovation and efficiency inherent in NPM may instead be leading to feelings of indifference among public employees, due to a discrediting of individual knowledge and, consequently, a devaluation of our collective intelligence in public organizations" (original emphasis, Balfour and Grubbs, 2000, p. 577). This is something that has emerged in this research as some workers have found that innovation exhaustion and the lack of space for feedback have not resulted in anything tangible. 
Balfour and Grubbs (2000) have argued that " $[\ldots]$ an infatuation with the new, reinforced by a primacy of technical reason, may be diminishing our capacity to adequately learn from the past or reflect critically on the present" (original emphasis, Balfour and Grubbs, 2000, p. 578). One worker has noted something similar that new practices suddenly appear in the workplace. The desire for the new and a desire for new technologies does not necessarily allow workers to use their experience and knowledge to provide a source of information and knowledge. The result of this may foster sensations of feeling adrift or being in stasis. Here it is further worth noting the words of Balfour and Grubbs (2000) who state that: "[t]he recent move to reengineer public bureaucracies into flexible, streamlined organizations has effectively cast public employees adrift, leaving them searching for their organizational identities" (Balfour and Grubbs, 2000, p. 579).

While new technologies have arrived within public libraries, not all libraries have been treated equally in its implementation. Not all libraries have, for example, express checkout and self-check-in services. This has isolated the impact of space as an important complexity that impacts identity. The whole of Toronto Public Library has not been unified by one form of technology. This indicates that at some branches, one may see examples of staff that have been impacted by express checkout and self-check-in technologies, while others have only discursively understood its impact. In other words, not all workers have access to the same technology at their place of work, and some may have only experienced these sorts of technologies only through discussing it with their fellow co-workers. For example, as has been noted in the preceding two chapters one participant felt differently when working at a branch that did not have these electronic 
technologies. Then one might assume that depending on the branch in which one works, one's perception of such technology will necessarily be impacted. In their study of NHS hospitals, Halford and Leonard (2006) have noted how place and spatial contexts matter in the shaping of working selves. It is in being able to experience the impact of the technology first hand, and being able to compare it to moments when one did not have access to it that the impact of these technologies on identity may be more pronounced.

Thus, the public library has presented itself to be an important site of study because of the complex processes and techniques that regulate the development of individual identities and promote certain forms of selves in different contexts throughout the organization. It is equally important to recognize that the organization is not uniform in its design, its personnel and its culture. Context thus matters in the shaping of identity (Halford and Leonard, 2006). The literal place of the library, the composition of each library branch and the services that the library delivers as whole matter when exploring how identity is fashioned at work. The result of this means that attempting to fashion fixed and essentialist identities is rather foolhardy. Indeed, as Sveningsson and Alvesson (2003) have noted there has been a trend in literature that has shifted focus away from fixed or essentialized notion of identity towards detailing multiple identities (p. 1164).

My observations have also shown that interviews themselves are but one means through which to gauge how questions of identity and subjectivity are experienced through work. Here, discursive practices are emphasized in interviews as they focus observation and analysis on how a participant filters their experiences and perceptions of situations, environments and material practices. It provides a crucial connection to workers who experience not only change within the workplace, but change that is 
fostered around them from outside the workplace that necessarily impacts the way in which they go about their work. It does not necessarily allow a strong observation of material practices, however. Some of these changes might be due to broader economic pressures, some of which aim to increase budgetary constraints on the public library, and others that perhaps not directly, but indirectly impact the way in which a library functions.

Thus, the study of work in the public library has allowed an important and necessary understanding into the processes which guide, fashion, shape and/or promote certain identities and subjectivities at work. These identities are not necessarily uniform throughout the organization. While this project's original aim was to highlight the techniques that are generationally relevant, generation did not emerge too significantly throughout the entirety of this study. This highlights some methodological limitations of this project, which will be discussed more thoroughly in the final chapter. Nonetheless, some relevant aspects of accumulated and specialized knowledge did allow some to develop very specific forms of identity at work.

Before going into the final chapter, one that will discuss more in depth some of the methodological shortcomings of this project, some useful strategies for continuing studies on identity in library work, as well as implications this research has for library workers, I must note one important thing to emerge from this project. This is perhaps a contingent thought I feel should be stated. Toronto Public Library, from what I have observed, is blessed with a committed staff that is constantly engaged in processes of advocating for their organization and what their organization can provide. This is perhaps best noted through an analysis of the section of "the workplace institution." 
These workers are constantly reflecting on their work, and their place of work, and are an asset to the city of Toronto's public service. 


\section{Chapter: Conclusions}

While the previous chapter engaged with the research, examined its implications and began to highlight some of the limitations that were revealing, concealing and blurring, this final chapter will conclude that discussion on limitations. It will concurrently discuss the lessons learned from these limitations and how they have been rendered useful for future studies in the field of library work. This chapter will also discuss some implications this research has raised for library work broadly speaking and will finally end with some final conclusions.

\subsection{Limitations, Lessons Learned and Looking Forward}

The timing of this research project coincided with a labour dispute with members of TPLWU and Toronto Public Library. The alignment of this event with my research project, in my view, has played an important role in not only revealing many interesting processes and techniques that foster identity formation and promote certain ways of being in the public library, but also possibly blurring generational distinctions and how they mediate techniques that promote certain identities. The strike may have played a strong role in preventing me to connect with participants; it may have led potential participants to avoid the call for participants for my research project.

As I have noted in previous chapters, some of the issues with the labour dispute this past year are very much salient and within the scope of this research project. Workers/staff may have been exhausted from talking about these issues, or worried about the labour dispute to participate in the study. It is also likely that the techniques to solicit participants in the future would need to be more rigorous, and alternative techniques may 
need to be used. Though perhaps, engaging in this research at another time may allow for more interested participants.

Snowballing was one of the techniques employed to find participants in Winiecki's (2007) study of call centre workers. Winiecki (2007) contacted management to look to connect with a good participant, which in turn lead to interviews, an observation of that participant at work and a further recommendation of another potential participant from this original participant (p. 355). The more knowledgeable and familiar Winiecki (2007) became with the workplace, "[...][Winiecki] began selecting participants [himself] based on their participation in the processes in which [Winiecki] was interested" (p. 355). While there are some possible challenges with the use of such a technique, such as whether a snowballing method would permit anonymity, this technique is still useful. It appears to allow the researcher to understand the context of the work and workplace and be flexible to shift to situations that they find useful for the study of the organization and work.

Interviews as a technique are also seen to be limited in what they can offer. While they have provided rich, detailed descriptions of experiences and events, they are also limited in that they tell the perspective of an individual and how they experience and interpret them. It does not necessarily allow other contextual factors to emerge, and so may conceal other organizational, personal, social or political factors that play a significant role in affecting identity. With this in mind, while interviews are a necessary and important component of this research, future research should look to concurrently use ethnography in providing a stronger methodological backbone, enabling me to become active in experiencing organization change. 
Methodological rigour may be enhanced in a future project through the methods used by Sveningsson and Alvesson (2003) who, in their thorough and rich study of the managerial identity of one manager, state that there are "[...] more personal sources of identity work than organizational discourses, identities, social identities and roles" ( $p$. 1168). To access the rich context in which a person exists at work, Sveningsson and Alvesson (2003) employed multiple interviews with their participant, interviews with the individual's colleagues, informal discussions with the participant and their colleagues, and secured the trust and intimacy of the participant and colleagues by attending committee meetings for over a year (p. 1170). What is important to note here is the time and resources that were required in the study of one individual. Their approach also took into consideration "[...] life history, narrative identity, integrative capacities $[\ldots]$ " and included a rich organizational context and individual identity work to examine how individuals are active in constructing their identity (Sveningsson and Alvesson, 2003, p. 1169). More rigour in conducting the research project and employing various techniques in field research, then, may provide richer avenues for study. This should be noted for future research.

Future research also needs to be more sensitive to the various complexities that exist within a behemoth organization such as Toronto Public Library. I will discuss in brief these layers of complexity in terms of job position and labour relations and spatiality. Firstly, there is the issue of job position and labour relations. Pages (or book shelvers), clericals and professional librarians all work in the library, yet they are representative of the types of positions available at the library and they describe only three jobs available at the library. For example, the term "clerical" is a broad one 
encompassing those who are not librarians or pages. As such, I predict within this one group of persons alone there to be much variation in job positions, titles and hence tasks and responsibilities. Job position also adds another layer of complexity when we examine relations between people of different positions. Taking this into consideration, questions of identity and subjectivity are necessarily impacted by these internal labour relations.

Finally, one should also note more local phenomena such as spatiality, or the space in which branches exist for three reasons. Firstly, different branches are ordered and function differently. As one worker had highlighted, different branches at local levels have books shelved differently and in different places, even though they use the same system. The volume of material to be handled, techniques that permit responsibilities to be completed, and the manner in which books are presented and ordered in shelves for example, will impact how tasks are performed in the workplace. One should further note that other tasks might function differently in fulfilling responsibilities due to the very architecture and structure of the building and workplace. Edwards and Nicoll (2006) have observed that "[a]triums with coffee bars have very different affordances to enclosed offices" (p. 191) and similarly we should realize that branches within Toronto Public Library may not have wildly different affordances, but branches are also likely not to be all fashioned in the same way due to the simple design of a building.

Secondly, geography and spatiality should not solely be limited to the structure of branches but should also be examined in the degree to which the organization has permitted a branch to implement new technologies such as express checkout and self- 
check-in. This continues the discussion on how branches and workplaces in themselves are ordered and designed for use by the staff and the public, but focuses on the implementation of technology in relation to how those spaces are designed. One must be able to recognize branches that have greater technological development and the differing impact they have on identity and subjectivity. The organization of a workplace permits an observation into how boundaries and routines are maintained and how one's actions are then constrained in what one is capable of doing and what one is promoted to do in that space (Winiecki, 2006, p. 29).

This is also, perhaps, where a more rigorous use of actor-network theory would be appropriate as well. The importance of ANT, in brief, lays in making visible the interconnectedness of subjects, objects both animate and inanimate, and space, which combine to form materially grounded and congealed networks (Murdoch, 1998, p. 360). Murdoch (1998) states that ANT is also interested in describing the various means through which "[...] certain locales (centres) actively consolidate the position of others; the theory shows how spaces come to be connected in ways which permit certain actors (or centres) to determine the shape of others, from a distance" (p. 362). Thus, ANT permits an exploration of subjectivity within the self and in relationship with human and non-human others as "[s]ubjectivity is not simply a human attribute or characteristic, but co-emerges within a networks of actants that enable us to be who we are" (Edwards and Nicoll, 2006, p. 187). Thus, through these networks of humans and non-humans, one's subjectivity can be shaped or elicited.

Thirdly, one should note the implications of findings in relation to organizational cultures. It has been noted that niche, fragmented or perhaps residual organizational 
cultures exist within people, places and regions throughout the system. This has meant that certain practices may dominate in certain regions and individuals may carry with them certain practices from certain regions. This adds an important layer of complexity in terms of spatiality because it forces one to consider that depending on the region one might be in, and the cultural norms that dominate in those regions, one may be inculcated by those visions, norms or practices.

There are other limitations that should be discussed. One lies in the types of identities that were not brought to the fore and gender is one such identity. As has been noted, librarianship has been associated with certain gendered characteristics (Jones and Oppenheim, 2002) and library work has also been dominated by women (Hannabus, 1998, p. 108). Four of the five persons interviewed also identified as being woman or female. Yet because these identity questions were not the focus of this research, important findings in gender were likely overlooked. Because of the gendered nature of library work, examining gender dynamics in the public library is essential. For future studies then, the door remains open in extending an intersectional lens for the analysis of identity in the public library. How gender interacts with questions of generation would also provide an interesting avenue for investigation. One might ask for example, do differing conceptions of library work emerge within different genders across generations? What nurtures these conceptions and do these generate certain ways of being at work?

As a word of caution, it is worth describing McCall's (2005) hypothetical "[...] Arab-American, middle-class, heterosexual woman [who]is placed at the intersection of multiple categories (race-ethnicity, class, gender, and sexual) but only reflects a single 
dimension of each" (p. 1781). From this, it can be garnered that the inherent complexity of individuals and their relationships within certain contexts conjures unique and complex narratives surrounding identity. Thus, heterogeneity appears within the study of subjectivity within complex organizations and each narrative is representative of one aspect of the intersection of many social relations and not social relations on the whole (McCall, 2005, p. 1782). A project like this, and ones similar to it in the future, then, should not attempt to essentialize or generalize certain identities. Rather they should attempt to render visible and highlight how complexities within an organizations serve to elicit certain ways of being. From these, we may observe certain characteristics or common themes that give rise to certain subject positions. They may also reveal multiple subject positions between which individuals navigate in their working lives. It also does not mean to suggest that these positions are themselves fixed. These were some of the points which were highlighted in the analyses and implications chapters. The incomplete nature of this project only renders it possible to see certain aspects of identities, subjectivities and selves that emerge in the library workplace. More thorough methods may enable richer observations and develop different, competing, contradictory and/or complementary identities.

As well, I have found that this research should require a greater historical perspective. History and the use of a generational lens appear to be a natural fit. A stronger historical exploration of the subject matter would have permitted a deeper and richer analysis, particularly in recognizing and revealing the development of technological change and the change of roles and cultures within the organization. This would also allow one to look more specifically at if different forms of power existed 
within the organization through the tasks that were performed over time. Foucault

(1980b) notes the importance that a historic perspective allows:

One must rather conduct an ascending analysis of power, starting, that is, from infinitesimal mechanisms, which each have their own history, their own trajectory, their own techniques and tactics, and then see how these mechanisms of power have been - and continue to be - invested, colonised, utilised, involuted, transformed, displaced, extended, etc., by ever more general mechanisms and by forms of global domination (original emphasis, p. 99).

While this project did attempt to use an ascending analysis of power by asking participants about smaller workplace tasks and responsibilities, it did not interrogate too deeply into these. One means through which the impact of a historical perspective may be realized may be through the analysis of a single task and how it has evolved in the former Metropolitan Toronto. For example, one might look at the procedures that were associated with check-in and checkout throughout the organizational history of Toronto area libraries. How have these activities changed over time? What did they require of workers to do? Did they elicit or promote certain ways of being at work and did they promote different types of identities? These were certainly thematic questions which were involved in interviews, but the rigour to which they allowed a historical analysis were limited in the way in which the research was conducted, the participants interviewed, and ultimately the questions asked. Future research interrogating generation and changing workplaces practices, then, should adopt a far broader historical method than simply engaging in interviews to understand how everyday work procedures have changed over time.

Such a method should also allow a governmental approach to flourish much more fully in the research by permitting one to examine how practices at governing individuals 
in the public library have been constituted over time from various sources (Dean, 2010, p.

40). This would also help to understand:

[...] regimes of practices which partly comprise forms of knowledge and truth which define their field of operation and codify what can be known, and since these regimes of practices are penetrated by all types of programmes that seek their reform, one would need to add that this materialism must be concerned with thought. Practices are of interest, then, in that they exist in the medium of thought, given that thought is a non-subjective, technical and practical domain (Dean, 2010, p. 41).

While flexibility is one means through which we may understand this domain of thought, and a form of knowledge by which governing is accomplished (Dean, 2010, p. 40), this research is not conclusive enough to state clearly whether this holds to be the case. We have certainly seen the language of efficiency and productivity appear within that discourse as well, but again, we still cannot be conclusive about this. Instead, what we can state, in terms of governmentality, is that, at the very least, changes taking place in the workplace over time have developed and promoted certain types of identities and capacities within individuals in order to govern them in the public library (Dean, 2010, p. 40). The promotion of these types of identities may not, however, always be successful to the whims of different forms of authority. Thus, this project is not as strong in translating the impact of regimes of practices in the governmental aspect of this research and a historical approach here may be useful. Future studies should develop the application of governmentality studies further.

Finally, generation, as I have emphasized before, was difficult to structure. Using amalgamation as a critical event to divide groups of people appears appropriate for a study on generation, but it may not necessarily be too appropriate for a study on age. Even if one were to use age to define generation, it is challenging to clearly state what 
would necessarily justify boundaries for age groups. Studying generation, however forces the following questions: what permits one to be considered an older worker? A younger one? Certainly, Sennett (1999) has stated that age is associated with rigidity and firms have put pressure on executives in their late 50s to be pushed out of their positions (p. 96), but this does not suggest beginning with age as an indicator. Instead, this suggests opting for a more organic conception of age and generation, where these lenses are developed fully only after field research is conducted. This may prove more effective in defining what "younger" and "older" actually represent. This is something a future project might want to explore. Future research should also be clearer in defining if age is the criterion to be studied or generation, as both can be revealing and concealing in different ways, but may not yield similar results when put into a study. That being said, what this study has interestingly provided is an opportunity to explore the impact that an individual's entry into the Toronto-area library labour market may have in workers understanding themselves and processes that shape individuals.

\subsection{Implications for Library Work}

This research has raised an interest for me in one particular light in how individuals in public organizations come to regulate workers through one's relationship with the public. This is perhaps made most evident in learning more about "self-service" technologies at Toronto Public Library. In discussing self-service, du Gay (1996) underscores the implications such technologies have on consumers in the retail industry:

In other words, self-service functioned as a 'technique of individuation' for consumers, constituting them as self-regulating autonomous individual subjects exercising choice in a world of goods, and offering them more apparent involvement in, and control over, the act of purchase. Thus, retailers persuaded customers that self-service was in their own interests as 
individuals - offering them more involvement in and apparent control over the act of purchase - while simultaneously reaping the financial benefits of reduced labour costs and increased buying power over suppliers ( $p$. 105).

For public organizations then such technologies likely enable organization to reap the benefits of reduced labour costs. Moreover, as such technologies shift into public organizations and as users become "empowered," not always of their own choosing, they become a witness to seeing how redundant the service of some workers can be. This is reinforced by the public who become a regulative tool highlighting and reinforcing to workers the emerging reality of their workplace situation and their redundancy at work. This allows us to see how public workers come to be regulated by the everyday public through daily interaction.

This is an important area to explore further because it may allow us to examine how discourses associated with public work that emphasize its "luxurious" nature are reinforced and reproduced at a local level and how through technological and organizational changes, workers are forced to recognize through the public their positionality in how their work is valued. I am not highlighting the discursive technique of the "luxurious nature" of such work here, nor am I suggesting that some types of library work should be considered redundant. Rather I am referring to the discursive and material techniques that may be observed in rendering such conceptions to become a truth. Ultimately, this begs the following questions: how is it that discursive attacks on public sector workers develop and reproduce a norm and narrative of good, hard work in the labour market? What techniques permit the formation of a standard of the good work ethic in attacking public sector work? What conditions shape interactions between 
worker and the public and render operable standards of the good, and "reasonably" compensated public worker?

What this research also helps demonstrate is how diffuse power relations can be in shaping and promoting certain types of behaviour of library workers. For library workers then, I hope this research gives them an opportunity to recognize the diverse means through which everyday tasks come to shape who they are, but at the same time, I hope it highlights how much these workers value their place of work. Managerial discourses do not solely drive change in organization, and the changes within people. It appears as though our relations with others also play a role in shaping who we are, and how we come to find our place at work.

My hope is that this research makes visible the multiplicity of identities promoted within the workplace, through various means. Visibility, I hope will allow not only workers, but union and management to recognize the commitment, dedication and value workers place in their organization, particularly in the crucial broader social role the public library plays. These are dedicated workers, who may not always agree with the decisions that are being made in their workplace and the consequences they see with decisions being made. Thus, I believe this research brings to light changes in the library workplace from the perspective of 5 individuals, who describe their experiences with change, and how it impacts them personally, shapes them, and promotes certain ways of being. Not all aspects of changes do they see as being fruitful, or eliciting the type of situation that they think is appropriate, and at times, changes foster anxiety. This research then, provides a small sample into what workers see happening around them, and the impacts it has on the self. Thus, the implications of this research and perhaps the 
broader poststructural influence of this project enables experts, those who have a greater ability to foster change, an opportunity to address issues, challenges, and anxieties of workers and begin a process which takes these findings into account (cf. Knights and Vurdubakis, 1994, p. 180). Thus, the study of identity here has provided an opportunity to make visible the social and material relations as experienced by individuals within Toronto Public Library. The information garnered from this study, then, can be used by others to impel change for the better.

\subsection{Final Thoughts}

This research has made visible how investigations of identity and subjectivity allow an exploration of how bodies, individuals and persons can be rendered useful for the purposes of production and efficiency. Thus, within a society which exists under a flexible capitalism, understanding identity and subjectivity within public organizations reveals the impact that forms of rule enable within such a system. This allows for a more holistic understanding of how individuals become part of organizations which govern them.

I am drawn to Foucault (1995) once again, who states:

[...] the body is also directly involved in a political field; power relations have an immediate hold upon it; they invest it, mark it, train it, torture it, force it to carry out tasks, to perform ceremonies, to emit signs. This political investment of the body is bound up, in accordance with complex reciprocal relations, with its economic use; it is largely as a force of production that the body is invested with relations of power and domination; but on the other hand, its constitution as labour power is possible only if it is caught up in a system of subjection (in which need is also a political instrument meticulously prepared, calculated and used); the body becomes a useful force only if it is both a productive body and a subjected body (pp. 25-26). 
Here he highlights an important context as well as the poststructural influence this project has taken. It is in the study of individuals and how they are shaped, and how certain ways of being are promoted, that we can come to understand how individuals are prepared to fit within a broader economic regime. Lemke (2002) underscores this well by elaborating on Foucault's (1995) point as noted above: "Foucault showed that laborpower must first be constituted before it can be exploited: that is, that life time must be synthesized into labor time, individuals must be subjugated to the production circle, habits must be formed, and time and space must be organized according to a scheme" (p. 58). Thus, the poststructural and governmentality lens has enabled an exploration in how individuals are constituted and shaped as well as how certain ways of being are fostered before becoming an economic input necessary for production in public organizations in a highly mutable and flexible capitalist society. Though, this project does not always coherently describe a fixed scheme, nor does it suggest that all tactics will always be successful. However, this research has shown how organizational culture complicates the formation of identities. Moreover, it was also suggested that labour relations and spatiality may further contribute to such complications. This, of course, may have been because of the study's incomplete nature.

Certainly one may argue that which pervades the shifts and changes in the library workplace - and consequently the implications this has on the identity and subjectivity of library workers - is related to the implementation of flexibility within Toronto Public Library. This manifests itself as the organization attempts to become more efficient in the manner in which it provides services, through such things as technological change in the workplace. While this is certainly important to underscore, this central knowledge 
and its discourses do not pervade all aspects of the organization. For example, the public library, as has been highlighted by participants, is still very hierarchical and bureaucratic in its design. What this suggests then, is a closer examination is required to understand how certain logics that broadly reinforce norms within Toronto Public Library come to be established and reproduced and how these come to impact the way in which workers understand themselves in relation to the ongoing changes in the workplace. It is difficult to be conclusive on this as the research is not as rich to explore common observations made by staff in interviews, though the lessons I have mentioned above should help guide future research in developing a richer study.

I have also learned that the research process is one which is dynamic in that which we hope to originally achieve should not be cast in stone. Situations change, and contexts alter how we approach our work. In this case, the strike as an event, in my view, played a significant role in impacting the manner in which the research was conducted, in affecting responses from potential participants, and affecting the project's generational lens. This illustrates that one can never be fully cognizant of what will result in the research process and accordingly, one must be prepared that what one sets out to accomplish in a research project may not proceed or occur. Thus, the results of this research project reveal themselves to be preliminary in what they seek out to explore, yet renders it a crucial step in the study of library work and identity enacted within a complex public organization that is undergoing some very interesting changes.

Accordingly, like the research process itself, the findings here come to reveal the very dynamic nature of identity and subjectivity and the techniques that permit the shaping and promoting of certain types of identity and subjectivity. I cannot rigorously 
conclude to what degree the study fully, appropriately and effectively articulates the formation of identity and subjectivity promoted within the public library. Nonetheless, this research certainly-and crucially-opens the door to further thorough and richer studies of library work in public libraries. 


\section{Appendices}

\section{Appendix A Ethics Considerations}

I have found the Ethics Protocol at Carleton University to be a very important and helpful part of the research process. Not only does it require one to think about the procedures and processes required to ensure the anonymity of participants is appropriately considered, it also forces one to think about how to go about designing research. This section will, in brief, highlight what the ethics procedure entailed, and will highlight the steps taken to ensure its passage with the Carleton University Research Ethics Board.

The Ethics Protocol submission first required a description of the project, its methodology and how I aimed to select individuals for the purposes of this research. Here I noted how I aimed to divide up participants into two groups, with the intent of exploring generational differences. As well, at the time, I was awaiting word from library contacts if potential ads could be distributed on my behalf. To this end, I attached proposed sample ads, and proposed sample responses to those ads to the Protocol. I stated that I would get in touch with the Research Ethics Board to let them know of the results from those contacts. I also attached an Interview Guide to this Protocol and a consent form.

The Protocol also forced me to consider issues related to who I would consider to be an acceptable participant. By recognizing that I may come across potential participants with whom I have worked, or with those who have supervised me, the Protocol helped ensure that I was aware of issues related to power dynamics. I also noted 
in the Protocol that I aimed to avoid interviewing people who knew of me, but ultimately, stated I could not be sure to what end any potential participant knew of me and so I underscored that I would be diligent on a case by case basis to determine who I would deem appropriate for the study.

Issues with risks to participants were highlighted. The possibility exists that there may be social and/or economic harm for participants to be a part of this research project as a result of participants responding to questions in the way that they do and in giving explanations of certain details about their place of work. This was something I noted in the consent form that participants were required to sign, highlighting that participating in the project puts the participant in a vulnerable position. To ameliorate some of these concerns, in the Protocol, I had indicated that the identities of participants would not be revealed in the study. Moreover, on the consent form and in the interview, participants were given the option to opt out of answering any question and were not required to answer any question. They also had the ability to remove themselves from the entire interview at any time, and were also given a chance to opt out of the entire research project in writing within two weeks of the recorded interview. The consent form also highlighted that the information collected from the interview would not be personally attributed to them, nor would their name or other identifiers be used.

In the consent form, participants were also asked to be electronically recorded. These recordings are to be deleted at the completion of the project and participants were given the option to access an electronic copy of the final thesis. In the Protocol, I had also noted that my supervisor and/or committee members may have access to the recordings and that I would make a backup on an external hard drive of recordings and 
transcriptions. The consent form also highlighted that transcriptions from interviews were to be kept for future studies on the topic and if they are to be used for anything else, I would ask the participant's permission to use the data. Transcriptions will be difficult to attribute to anyone. This was echoed in the Protocol.

At a later date in May, I was required to renew my ethics application as I had not found enough participants for my project and was continuing working on it. Following this, I also sent in a procedure change highlighting a new technique for soliciting participants for the research project through Toronto Public Library Workers Union. This was approved allowing me to solicit participants through the help of the Union. 


\section{Appendix B Advertisements}

\section{B.1 Text of Advertisement sent in first @TPL}

Want to be part of a graduate student study on library workers?

Graduate student and former TPL staff member Kritee Ahmed is looking for 10 participants for a Carleton University graduate student study on changes in the library workplace and their impact on self-identity.

Face-to-face interviews for about 30-60 minutes are required. Interviews will be conducted on participants' own time.

Interested persons are requested to email Kritee Ahmed for more information: kahmed3@ connect.carleton.ca; or call:

The project has been approved by the Research Ethics Board at Carleton University.

\section{B.2 Text of Advertisement that was to be sent through Union}

Want to be part of a graduate student study on library workers?

Graduate student and former TPL staff member Kritee Ahmed is looking for 10 participants - both those who have started working at TPL and its predecessor library systems before amalgamation and those who have started after amalgamation in a unified TPL - for a Carleton University graduate student study on changes in the library workplace and their impact on self-identity.

Face-to-face interviews for about 30-60 minutes are required. Interviews will be conducted on participants' own time.

Interested persons are requested to email Kritee Ahmed for more information:

kahmed3@connect.carleton.ca; or call: . Please respond by June 8, 2012 at the latest.

The project has been approved by the Research Ethics Board at Carleton University. 


\section{Appendix C Interview Guide}

I have provided an example of an early Interview Guide. The Interview Guide developed throughout the course of the interview and was modified throughout the process. It should be noted that the Interview Guide, is just that, a guide. It guided me in conducting interviews and allowed me to have questions I could refer to and procedures I could look at in conducting the interviews. I did not ask all the questions noted in it, nor did I plan to do so, as after all, the interviews were semi-structured and open ended. Interviews, as I have noted, are not always predictable, and so one must be prepared to handle situations as they appear. For example, initially, the information to be relayed during the conclusion of the interview may not have been relayed during this time, however similar information was delivered at other times. In recognizing this, in an updated Interview Guide, I developed a paragraph script that would relay this information. It guided me to convey this information consistently and further guided me to note this at the end of the interview, as indicated in the Guide. Moreover, in subsequent Guides, I developed different questions as interviews progressed and I had included them in my research; this did not mean that I necessarily asked those questions, but having these questions in the Guide functioned as a reference from which I could easily refer.

\section{C.1 Interview Guide: Early Version}

\section{Interview Guide}

To begin the interview process, it is imperative to select an environment best suited for the participant to discuss issues pertinent to this project. After communicating 
with the participant, I will ask the participant, where they would like to meet, in order for the interview process to proceed. The most visible and important reason for allowing the participant to select the place for the interview, is to allow them to be in an environment where they will be comfortable to freely communicate with me. By giving them this flexibility, I hope that the participant will feel less restricted during the interview process.

\section{Beginning the Interview}

At the outset of the interview, I will introduce myself to the participant. Firstly, I will explain the purpose of the project, and describe its aims. I will also go on to describe my own background in Toronto Public Library to help establish an insider relationship with the participant.

Also, at this stage, I will require the participant to have a look at the consent form, then will allow the participant to ask questions about it and finally will have them sign it. I cannot proceed further from this point if the participant does not agree to sign it. I will also explain to the participant how I plan on maintaining their anonymity in this project by giving them an alias and altering some key facts about them to obscure their personal identity. After the form has been signed, I will transition into interview questions.

\section{Classifying Questions}

The following sample list of questions is meant to provide a semi-structured list of questions which would allow for effective feedback. This is not meant to be an exhaustive list of questions, but provides a guideline for the types of questions I will ask, and from here other questions might evolve out of the interview process in facilitating 
discussion on experiences and thoughts of participants. Before proceeding into more detailed questions, a few things about the participant must be established. These categorical markers might become useful later on. Questions pertaining to these categories must first be established:

- Age range

- Gender

- Identification with a cultural/racial/ethnic group

- Years of service

- Position and tasks related to and required of position

\section{Sample List of Questions}

More concrete questions associated with the key concepts will be asked. These questions aggregated along the following issues, in no particular order: mobility, responsibilities, technology and responsibilities, resistance and self-reflection. Here is a sample list of questions:

Mobility

- Have you worked different positions?

- Have you left a higher paying job for a lower paying one?

- Why did you do that? Did the workplace environment pressure you into moving?

○ Was it a good decision? 
- Have you found a relationship between your gender or a link to your cultural association ever come at odds with workplace practices?

- Did/Do these affect, impede or improve your ability to work?

- Have you worked at different branches?

- Has there been variation of technology at these different branches where you've worked?

Was it difficult to get used to the changes?

- How did you cope?

- How did the changes make you feel?

- Have they changed very much?

\section{Responsibilities}

- What tasks have changed over time? Has this affected your connection to the work you do? In what way?

- Have you felt these changes have impacted your expectations of yourself? How do you feel about these changes?

- What were your expectations of your work before certain changes? How have these changed?

- Do you find this tells you much or anything about the type of worker that is needed in today's society and economy?

- How demanding do you find these expectations? 


\section{Technology and Responsibilities}

- I asked you before about questions relating to changes and shifts taking place at work. Did any of these shifts happen in the work you do because of new technologies?

- Have these technological changes changed your duties at all?

o Have they made your work more or less difficult to perform? In what way? ${ }^{13}$

- Have you adjusted to the implementation of technology at work?

- Has technology shifted the work you're supposed to do?

- Has technology altered your relationship with other workers and patrons? If so, how has this occurred? Are there any concrete examples which you can provide?

o How has your interaction with this new technology made you feel? About the technology? About your performance with it? About yourself?

- How do you think others at work are coping with the technology? Newer staff? And staff who have been in the system for a longer period of time?

- How do you feel about new technologies being implemented at work?

- What types have you seen? Do you like these technologies?

- Have you enjoyed the way new technologies have already been implemented at work?

- What are your thoughts on new technologies that are slowly coming to replace books? I'm talking about technologies such as the Kindle, iPad, and other tablet

\footnotetext{
${ }^{13}$ I suspect I will receive responses from the two generations differently.
} 
devices? Do they come to create any anxieties about the future of the library for you? Do they create any anxieties about your job?

\section{Resistance}

- Is there a particular moment that you can recall and would like to share that speaks to your protest of a changing work practice? What was it?

- Why was it an issue for you to take a stand?

- What did this tell you about the people in your workplace and yourself?

- How did others respond to your protest?

- What was the result? How did that make you feel?

\section{$\underline{\text { Self-Reflection }}$}

- What have you learned about yourself at work or the work itself?

- Have there been any recent changes at work which have affected your ability to work?

- How did that make you feel?

- Did you feel you had less control over the work you were doing?

- Do changes in work practices excite/disappoint you?

- What do you think the future holds in terms of technological changes in the library?

- Does thinking about the future create any anxieties for you?

\section{Concluding the Interview}

Once the interview has reached its conclusion, I will end it by asking if the participant wishes to share anything else with me, based on the themes discussed in the 
interview. This open ended discussion period, is probably the most important part of the research process, as it gives the participant freedom to describe what they think is important to the topic of the project.

I will then thank the participant for their assistance in my project and let them know when I plan on finishing my completed thesis, and how I will allow them access to the final draft of my research. I will also let them know of how I plan to archive and eventually destroy the data from the interview. 


\section{Appendix D Interview Schedule}

In this section, I have noted some information regarding the participants interviewed. I have included their interview title, as used in the thesis, their generation and their gender/sex. One will note that I have included both female/woman and male/man. My intent here is not to promote a gender binary or to associate sex with gender. However, responses from participants varied in either referring to the sex or the gender when asked about their gender. Thus, in the interest of consistency, I have associated female/woman and male/man as appropriate.

Interview A - First Generation; Female/Woman

Interview B - First Generation; Female/Woman

Interview C - Second Generation; Male/Man

Interview D - Second Generation; Female/Woman

Interview E - First Generation; Female/Woman 


\section{Bibliography}

1. Adkins, L. and Lury, C. (1999). The labour of identity: performing identities, performing economies. Economy and Society 28 (3), pp. 598-614.

2. Alvesson, M. and Willmott, H. (2002). Identity Regulation as Organizational Control: Producing the Appropriate Individual. Journal of Management Studies 39 (5), pp. 619-644.

3. Archer, M. (2007). Making our Way through the World: Human Reflexivity and Social Mobility. New York: Cambridge University Press.

4. Aronowitz, S. and DiFazio, W. (2010). The Jobless Future $\left(2^{\text {nd }}\right.$ Ed.), Minneapolis: University of Minnesota Press.

5. Asdal, K. (2008). On Politics and the Little Tools of Democracy: A Down-toEarth Approach. Distinktion 16, pp. 11-26.

6. Balfour, D. and Grubbs, J. (2000). Character, Corrosion and the Civil Servant: The Human Consequences of Globalization and the New Public Management. Administrative Theory and Praxis 22 (3), pp. 570-584.

7. Ballamingie, P., and Johnson, S. (2011). The vulnerable researcher: Some unanticipated challenges of doctoral fieldwork. The Qualitative Report, 16 (3). [Accepted, in press].

8. Barry, A. (2002). The anti-political economy. Economy and Society, 31 (2), pp. 268-284.

9. Barry, A., Osborne, T. and Rose, N. (1996). "Introduction," in Andrew Barry, Thomas Osborne and Nikolas Rose (eds.), Foucault and Political Reason: Liberalism, neo-liberalism and rationalities of government. Chicago: The University of Chicago Press, pp. 1-17.

10. Berardi, F. (2009). The Soul at Work: From Alienation to Autonomy. Los Angeles: Semiotext(e).

11. Billett, S. (2006). "Work, Subjectivity and Learning," in Stephen Billett, Tara Fenwick and Margaret Somerville (eds.), Work, Subjectivity and Learning: Understanding Learning through Working Life. Dordrecht: Springer, pp. 1-20.

12. Boulton, S. and Houlihan, M. (2005). The (mis)representation of customer service. Work, employment and society, 19 (4), pp. 685-703.

13. Braverman, H. (1998). Labor and Monopoly Capital: The Degradation of Work in the Twentieth Century. New York: Monthly Review Press. 
14. Brooklyn Public Library (2012). "Only at BPL." Accessed on August 24, 2012, from http://www.brooklynpubliclibrary.org/only-bpl

15. Burchell, G. (1996). "Liberal government and techniques of the self," in Andrew Barry, Thomas Osborne and Nikolas Rose (eds.), Foucault and Political Reason: Liberalism, neo-liberalism and rationalities of government. Chicago: The University of Chicago Press, pp. 19-36.

16. Burkitt, I. (2002). "Technologies of the Self: Habitus and Capacities." Journal for the Theory of Social Behaviour 32 (2), pp. 219-237.

17. Cairns, L. and Malloch, M. (2010). "Theories of Work, Place and Learning: New Directions," in Margaret Malloch, Len Cairns, Karen Evans and Bridget O'Connor (eds.), The SAGE Handbook of Workplace Learning. London: Sage, pp. 3-16.

18. Cheng, J., Son, S.J. and Bonk, C. (2010). "Technology and Knowledge Management," in Margaret Malloch, Len Cairns, Karen Evans and Bridget O'Connor (eds.), The SAGE Handbook of Workplace Learning. London: Sage, pp. 443-455.

19. Collinson, D. (2003). Identities and Insecurities: Selves at Work. Organization $10(3)$, pp. 527-547.

20. de Certeau, M. (1984). The Practice of Everyday Life. Berkeley and Los Angeles: University of California Press.

21. du Gay, P. (1996). Consumption and Identity at Work. London: Sage.

22. Dale, D. (2012). "Toronto library strike: Job security the big issue again." Accessed on March 23, 2012, from http://www.thestar.com/news/cityhallpolitics/article/1148830--toronto-librarystrike-job-security-the-big-issue-again.

23. Dean, M. (1995). Governing the unemployed self in an active society. Economy and Society 24 (4), pp. 559-83.

24. Dean, M. (2010). Governmentality: Power and Rule in Modern Society Second Edition. London: Sage.

25. Durrani, S. (1999). Black communities and information workers in search of social justice. New Library World 100 (1151), pp. 265-278.

26. Edwards, R. and Nicoll, K. (2004). Mobilizing workplaces: actors, discipline and governmentality. Studies in Continuing Education 26 (2), pp. 159-173. 
27. Edwards, R. and Nicoll, K. (2006). "Action at a Distance: Governmentality, Subjectivity and Workplace Learning" in Stephen Billett, Tara Fenwick and Margaret Somerville (eds.), Work, Subjectivity and Learning: Understanding Learning through Working Life. Dordrecht: Springer, pp. 179-193.

28. Evjen, S. and Aududson, R. (2009). The complex library: Do the public's attitudes represent a barrier to institutional change in public libraries? New Library World 110 (3/4), pp. 161-174.

29. Fenwick, T. and Somerville, M. "Work, Subjectivity and Learning: Prospects and Issues," in Stephen Billett, Tara Fenwick and Margaret Somerville (eds.), Work, Subjectivity and Learning: Understanding Learning through Working Life. Dordrecht: Springer, pp. 247-265.

30. Foucault, M. (1980a). "Truth and Power," in Colin Gordon (ed.), Power/Knowledge: Selected Interviews and Other Writings 1972-1977. New York: Vintage Books, pp. 109-133.

31. Foucault, M. (1980b). "Two Lectures," in Colin Gordon (ed.), Power/Knowledge: Selected Interviews and Other Writings 1972-1977. New York: Vintage Books, pp. 78-108.

32. Foucault, M. (1980c). "Power and Strategies," in Colin Gordon (ed.), Power/Knowledge: Selected Interviews and Other Writings 1972-1977. New York: Vintage Books, pp.134-145.

33. Foucault, M. (1980d). "Questions on Geography," in Colin Gordon (ed.), Power/Knowledge: Selected Interviews and Other Writings 1972-1977. New York: Vintage Books, pp. 63-77.

34. Foucault, M. (1982). The Subject and Power. Critical Inquiry 8 (4), pp. 777 795.

35. Foucault, M. (1988). "Technologies of the Self," in Martin, L.H., Gutman, H. and Hutton, P.H. (eds.), Technologies of the Self: A Seminar With Michel Foucault. Cambridge, M.A.: MIT Press.

36. Foucault, M. (1993). About the Beginning of the Hermeneutics of the Self: Two Lectures at Dartmouth. Political Theory 21 (2), pp. 198-227.

37. Foucault, M. (1995). Discipline and Punish: The Birth of the Prison. New York: Vintage Books.

38. Frank, A. (2002). Why Study People's Stories? The Dialogical Ethics of Narartive Analysis. International Journal of Qualitative Methods 1(1), pp. 109117. 
39. Fridman, D. (2010). From Rats to Riches: Game Playing and the Production of the Capitalist Self. Qualitative Sociology 33 (4), pp. 423-446.

40. Gordon, C. (1991). "Governmental Rationality: An Introduction," in Graham Burchell, Colin Gordon and Peter Miller (eds.), The Foucault Effect: Studies in Governmentality. Chicago: The University of Chicago Press, pp. 1-51.

41. Goulding, A., Bromham, B., Hannabus, S. and Cramer, D. (1999). Supply and demand: the workforce needs of library and information services and personal qualities of new professionals. Journal of Librarianship and Information Science 31(4), pp. 212-223.

42. Goulding A., and Kerslake, E. (1996a). Flexible working in UK library and information services: current practice and concerns. Journal of Librarianship and Information Science 28 (4), pp. 203-216.

43. Goulding A., and Kerslake, E. (1996b). Flexible working in libraries: profit and potential pitfalls. Library Management 17 (2), pp. 8-16.

44. Guy, M., Newman, M. and Mastracci, S. (2010). "Are We There Yet? From Taylor's Triable to Follett's Web; From Knowledge Work to Emotion Work." In The Future of Public Administration Around the World: The Minnowbrook Perspective (eds. R. O'Leary, D. Van Slyke and Soonhee Kim). Washington: George Washington University Press, pp. 33-44.

45. Halford, S. and Leonard, P. (2006). Place, Space and Time: Contextualizing Workplace Subjectivities. Organization Studies 27 (5), pp. 657-676.

46. Hancock, A. (2007). When Multiplication Doesn't Equal Quick Addition: Examining Intersectionality as a Research Paradigm. Perspectives on Politics 5 (1), pp. 63-79.

47. Haney, L. (2010). Offending Women: Power, Punishment, and the Regulation of Desire. Berkeley: University of California Press.

48. Hannabuss, S. (1998). Flexible jobs: changing patterns in information and library work. New Library World 99 (1141), pp. 104-111.

49. Henriksson, L. (2008). Reconfiguring Finnish welfare service workforce: Inequalities and Identity. Equal Opportunities International 27 (1), pp. 49-63.

50. Inda, J. (2005). "Analytics of the Modern: An Introduction." In Jonathan Xavier Inda (ed.), Anthropologies of Modernity: Foucault, Governmentality, and Life Politics. Malden, MA: Blackwell, pp. 1-20. 
51. Jermier, J., Knights, D. and Nord, W. (1994). "Introduction." In John M. Jermier, David Knights and Walter R. Nord (eds.), Resistance and Power in Organizations. London and New York: Routledge, pp. 1-24.

52. Jones, E., and Oppenheim, C. (2002). Glass ceiling issues in the UK library profession. Journal of Librarianship and Information Science 34 (2), pp. 103115.

53. Kalleberg, A. (2009). Precarious Work, Insecure Workers: Employment Relations in Transition. American Sociological Review 74 (1), pp. 1-22.

54. Kerslake, E., and Goulding, A. (1997). Current practice in training flexible information workers. Library Management 18 (3), pp. 135-147.

55. Kerslake, E., and Kinnell, M. (1998). Public libraries, public interest and the information society: theoretical issues in the social impact of public libraries. Journal of Librarianship and Information Science 30 (3), pp.159-167.

56. Kelly, P., Allender, S. and Colquhoun, D. (2007). New Work Ethics?: The Corporate Athlete's Back End Index and Organizational Performance. Organization 14 (2), pp. 267-285.

57. Kitay, J. and Callus, R. (1998). "The Role and Challenge of Case Study Design in Industrial Relations Research." In Keith Whitfield and George Strauss (eds.), Researching the World of Work: Strategies and Methods in Studying Industrial Relations. Ithaca: Cornell University Press, pp. 101-112.

58. Knights, D. and Vurdubakis, T. (1994). "Foucault, Power, Resistance and All That." In John M. Jermier, David Knights and Walter R. Nord (eds.), Resistance and Power in Organizations. London and New York: Routledge, pp. 167-198.

59. Kuhn, T. (2006). A 'Demented Work Ethic' and a 'Lifestyle Firm': Discourse, Identity, and Workplace Time Commitments. Organization Studies 27 (9), pp. 1339-1358.

60. Leckie, G. and Hopkins, J. (2002). The Public Place of Central Libraries: Findings from Toronto and Vancouver. Library Quarterly 72 (3), pp. 326-372.

61. Lemke, T. (2001). The birth of biopolitics: Michel Foucault's lecture at the College de France. Economy and Society 30 (2), pp. 190-207.

62. Lemke, T. (2002). Foucault, Governmentality and Critique. Rethinking Marxism 14 (3), pp. 49-64.

63. Lemke, T. (2011). Foucault, Governmentality, and Critique. Boulder, Colorado: Paradigm Publishers. 
64. Lewis, T. (2007). Braverman, Foucault and the labor process: framing the current high-skills debate. Journal of Education and Work 20 (5), pp. 397-415.

65. Lowe, G. (2001). Employer of Choice? Workplace Innovation in Government. Ottawa: Canadian Policy Research Networks.

66. Martin, E. (1994). Flexible Bodies: Tracking Immunity in American CultureFrom the Days of Polio to the Age of AIDS. Boston: Beacon Press.

67. McCall, L. (2005). The Complexity of Intersectionality. Signs: Journal of Women in Culture and Society 30 (3), pp. 1771-1800.

68. McGrath, H. and Goulding, A. (1996). Part of the job: violence in public libraries. New Library World 97 (1127), pp. 4-13.

69. Michie, J. and Sheehan-Quinn, M. (2001). Labour Market Flexibility, Human Resource Management and Corporate Performance. British Journal of Management 12 (4), pp. 287-306.

70. Mills, C. W. (2002). White Collar: The American Middle Classes, Fiftieth Anniversary Edition. New York: Oxford University Press.

71. Moen, T. (2006). Reflections on the Narrative Research Approach. International Journal of Qualitaitve Methods 5 (4), pp. 56-69.

72. Murdoch, J. (1998). The Spaces of Actor-Network Theory. Critical Review 29 (4), pp. 357-374.

73. Neysmith, S., Bezanson, K., and O'Connell, A. (2005). Telling Tales: Living the Effects of Public Policy. Halifax: Fernwood Publishing.

74. O'Brien, T. and Hayden, H. (2007). Flexible work practices and the LIS sector: balancing the needs of work and life? Library Management 29 (3), pp. 199-228.

75. O'Doherty, D. and Willmott, H. (2001). Debating Labour Process Theory: The Issue of Subjectivity and the Relevance of Poststructuralism. Sociology 35 (2), pp. 457-476.

76. Osborne, D. and Gaebler, T. (1992). Reinventing Government: How the Entrepreneurial Spirit is Transforming the Public Sector. Reading, MA: Addison -Wesley.

77. Poulantzas, N. (1978). State, Power, Socialism. London: NLB. 
78. Regini, M. (2000). "The Dilemmas of Labour Market Regulation." In Gøsta Esping-Andersen and Marino Regini (eds.), Why Deregulate Labour Markets? Oxford: Oxford University Press, pp. 11-29.

79. Rose, N. (1996). "Governing 'advanced' liberal democracies," in Andrew Barry, Thomas Osborne and Nikolas Rose (eds.), Foucault and Political Reason: Liberalism, neo-liberalism and rationalities of government. Chicago: The University of Chicago Press, pp. 37-64.

80. Rose, N. (1999). Governing the Soul: The Shaping of the Private Self. London and New York: Free Association Books.

81. Rose, N. and Miller, P. (1992). Political Power beyond the State: Problematics of Government. The British Journal of Sociology 43 (2), pp. 173-205.

82. Rosen, M. and Baroudi, J. (1992). "Computer-Based Technology and the Emergence of New Forms of Managerial Control." In Andrew Sturdy, David Knights and Hugh Willmott (eds.), Skill and Consent: Contemporary Studies in the Labour Process. London: Routledge, pp. 213-234.

83. Rouillard, C. and Giroux, D. (2005). Public Administration and the Managerialist Fervour for Values and Ethics: Of Collective Confusion in Control Societies. Administrative Theory and Praxis 27 (2), pp. 330-357.

84. Sakolsky, R. (1992). "'Disciplinary Power' and the Labour Process," in Andrew Sturdy, David Knights and Hugh Willmott (eds.), Skill and Consent:

Contemporary Studies in the Labour Process. London: Routledge, pp. 235-254.

85. Sennett, R. (1999). The Corrosion of Character: The Personal Consequences of Work in the New Capitalism. New York: W.W. Norton and Company.

86. Sennett, R. (2006). The Culture of the New Capitalism. New Haven: Yale University Press.

87. Sennett, R. (2008). The Craftsman. New Haven: Yale University Press.

88. Sennett, R. and Cobb, J. (1973). The Hidden Injuries of Class. New York: Vintage Books.

89. Skeggs, B. (2004). "Exchange, value and affect: Bourdieu and 'the self'." In Lisa Adkins and Beverly Skeggs (eds.), Feminism After Bourdieu. Oxford and Malden, MA: Blackwell Publishing/The Sociological Review, pp. 75-95.

90. Somers, M. (1994). The Narrative Constitution of Identity: A Relational and Network Approach. Theory and Society 23 (5), pp. 605-649. 
91. Spacey, R., Goulding, A. and Murray, I. (2004). The power of influence: what affects public library staff's attitudes to the Internet? Library Management 25 (6-7), pp. 270-276.

92. Stevenson, S. (2011). New-labour in libraries: the post-Fordist public library. Journal of Documentation 67 (5), pp. 773-790.

93. Sturdy, A. (1992). "Clerical Consent: 'Shifting' Work in the Insurance Office." In Andrew Sturdy, David Knights and Hugh Willmott (eds.), Skill and Consent: Contemporary Studies in the Labour Process. London: Routledge, pp.115-148.

94. Sveningsson, S. and Alvesson, M. (2003). Managing managerial identities: Organizational fragmentation, discourse and identity struggle. Human Relations $56(10)$, pp. 1163-1193.

95. Swan, E. and Fox, S. (2009). Becoming Flexible: Self-Flexibility and its Pedagogies. British Journal of Management 20, pp. S149-S159.

96. Terkel, S. (2007). The Studs Terkel Reader: My American Century. New York: The New Press.

97. Thornborrow, T. and Brown, A. (2009). 'Being Regimented': Aspiration, Discipline and Identity Work in the British Parachute Regiment. Organization Studies 30 (4), pp. 355-376.

98. Toronto Public Library, (2012a). "Programs, Classes \& Exhibits." Accessed on August 24, 2012, from http://www.torontopubliclibrary.ca/programs-andclasses/.

99. Toronto Public Library, (2012b). "Mission, Vision \& Values." Accessed on July 28, 2012, from http://www.torontopubliclibrary.ca/about-the-library/missionvision-values/.

100.Toronto Public Library, (2012c) "Cedarbrae." Accessed on August 4" 2012 from http://www.torontopubliclibrary.ca/detail.jsp?Entt=RDMLIB08\&R=LIB08.

101.Toronto Public Library (2012d). "Customer Feedback Standards \& Practices." Accessed on August 21, 2012 from http://www.torontopubliclibrary.ca/aboutthe-library/customer-care/

102.Townley, B. (1993). Foucault, Power/Knowledge, and its Relevance for Human Resource Management. Academy of Management Review 18 (3), pp. 518-545.

103. Veyne, P. (2010). Foucault: His Thought, His Character. Malden, M.A.: Polity Press. 
104. Walton, G. (2007). Theory, research and practice in library management 1 : Flexibility. Library Management 28 (3), pp. 165-171.

105.Watson, T. (2008). Managing Identity: Identity Work, Personal Predicaments and Structural Circumstances. Organization 15 (1), pp. 121-143.

106. Weiss, R. (1994). Learning from Strangers. New York: The Free Press.

107. Whittle, A. and Spicer, A. (2008). Is Actor Network Theory Critique?

Organization Studies 29 (4), pp. 611-629.

108. Winiecki, D. (2006). Discipline and Governmentality at Work: Making the Subject and Subjectivity in Modern Tertiary Labour. London: Free Association Books.

109. Winiecki, D. (2007). Subjects, Subjectivity, and Subjectification in Call Center Work: The Doings of Doings. Journal of Contemporary Ethnography 36 (4), pp. 351-377.

110.Winiecki, D. and Wigman, B. (2007). Making and maintaining the subject in call centre work. New Technology, Work and Employment 22 (2), pp. 118-131. 